\title{
NON-DESTRUCTIVE INVESTIGATION \& FEA CORRELATION ON AN AIRCRAFT SANDWICH COMPOSITE STRUCTURE
}

\author{
A Thesis \\ Presented to \\ The Graduate Faculty of the University of Akron
}

\author{
In Partial Fulfillment \\ of the Requirements for the Degree \\ Master of Civil Engineering
}

Justin L. Bail

December, 2007 


\section{NON-DESTRUCTIVE INVESTIGATION \& FEA CORRELATION ON AN AIRCRAFT SANDWICH COMPOSITE STRUCTURE}

Justin L. Bail

Thesis

Approved:

Accepted:

Academic Advisor

Dean of the College

Dr. Wieslaw Binienda

Dr. George Haritos

Faculty Reader

Dr. Craig Menzemer

Dean of the Graduate School

Dr. George R. Newkome

Faculty Reader

Date

Dr. Robert Goldberg

Civil Engineering Department $C h a i r$

Dr. Wieslaw Binienda 


\begin{abstract}
Composites are being used at a very high increasing rate where the weight to strength ratios is critical. As a result of the increase of the composites use, such as the Boeing 787 which is comprised of nearly $50 \%$ composite structures, a better knowledge and behavioral prediction is desired. This can be done through computational models and/or physical testing. Numerous FEA programs are used to aid in the design process and to predict the performance and behavior of composite structures. There are also many non destructive methods of investigation (NDI) which are used in both quality control and behavioral observations.
\end{abstract}

A composite flight structure common to many airplanes is a radome, which can be defined as a structural enclosure used to protect an antenna from the environment which includes the aerodynamic loading and weather. The specific radome being tested is a SAT-COM radome used on aircraft such as Boeing 767-777 \& Airbus A320, A330 and A340. It is desired to perform vibration testing as well as internal pressure testing to correlate the FEA models used in the design of the radome. This is completed by performing 2 different types of NDI (Shearography \& Vibrometry) and 1 vacuum pressure test. The results are compared and used to validate the current FEA model. Shearography allows us to measure the surface deformation of an object when under a stress. Shearography was completed to determine any possible defects caused in manufacturing (or transporting) the radome. De-lamination will possibly cause 
unpredicted response in the vibration or pressure tests. Areas of different construction as well as defects will deflect non-uniformly. There were no flaws detected in the composite radome tested.

Laser Doppler Vibrometry (LDV) is a non-contact vibration measurement that is used to determine the natural frequencies and mode shapes of the Composite Radome Structure. The vibration testing was completed using a few different boundary conditions which include approximately free-free BC's and fixed BC's. The testing has corresponded accurately in comparison to the FEA model however; it is suspected that there is some slight error caused by the fixed fixture for vibration testing. 


\title{
ACKNOWLEDGEMENTS
}

\author{
David Stresing \\ Saint-Gobain Flight Structures \\ Dr. Wieslaw Binienda \\ Academic Advisor \\ Dr. Robert Goldberg \\ University of Akron Professor \\ William Stankavich \\ Saint-Gobain Flight Structures \\ Vikrant Palant \\ Polytec Engineer
}




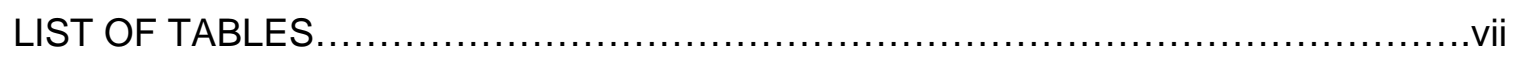

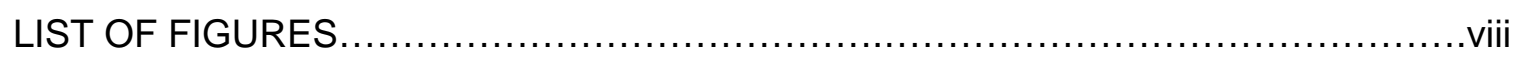
CHAPTER

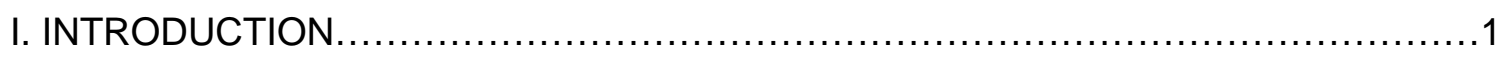

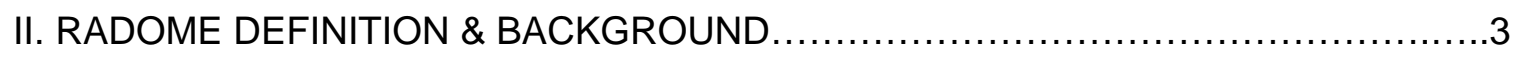

III. RADOME GEOMETRY CONSTRUCTION.........................................

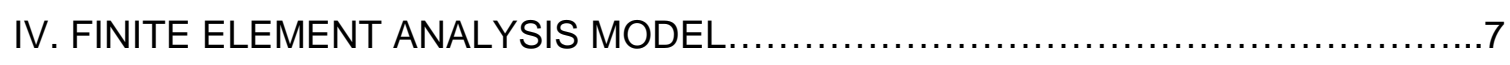

V. HAND CALCULATIONS FOR MATERIAL PROPERTIES

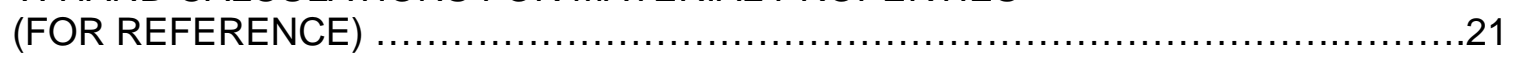

VI. RADOME TESTING \& CORRELATION TO FEA .....................................24

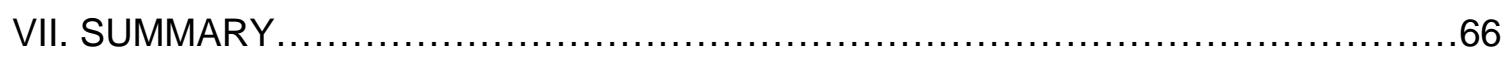

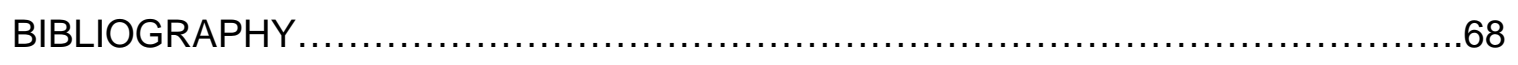




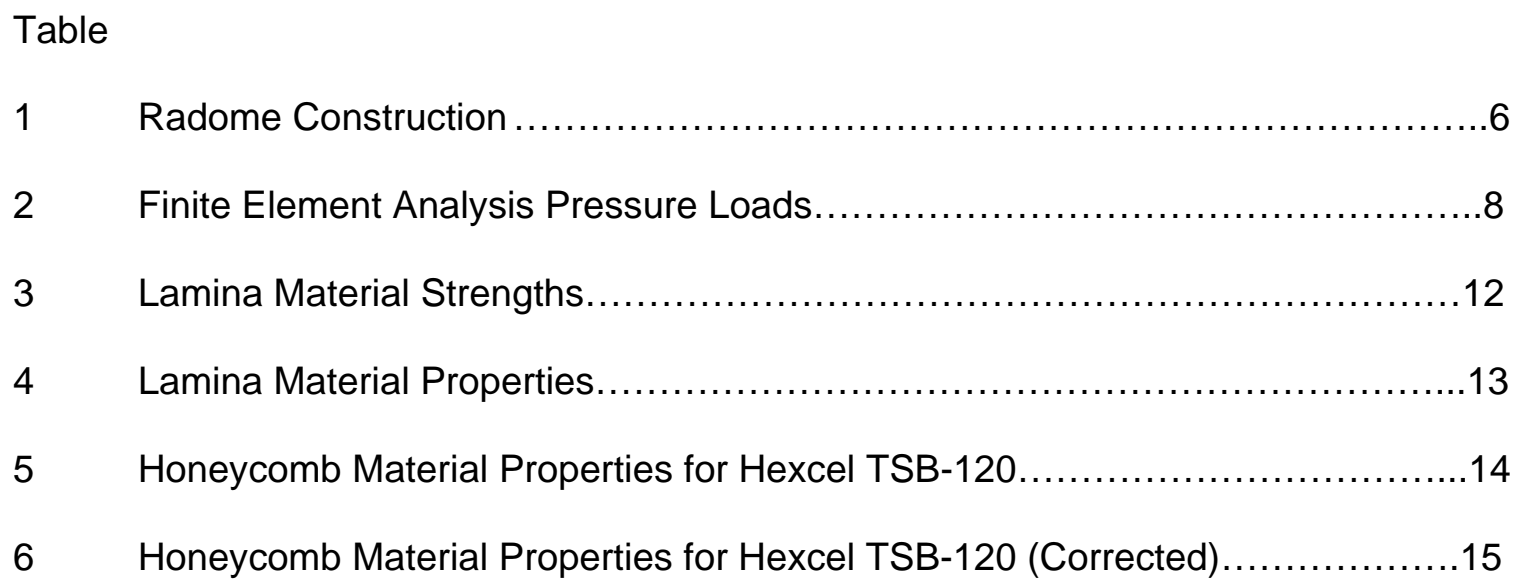


Figure

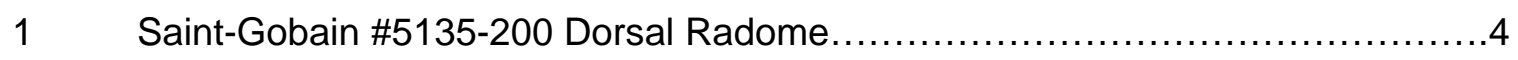

2 Saint-Gobain \#5135-200 Dorsal Radome on AirBus A-320 .....................4

3 CATIA Model - Radome Construction, Isometric View.......................

4 CATIA Model - Radome Construction, Side View..........................

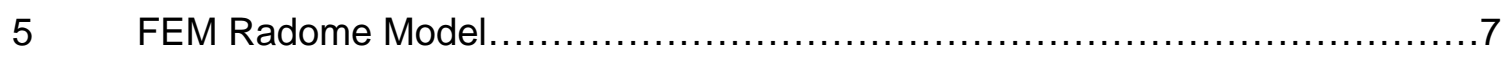

6 Finite Element Model and Boundary Conditions for the Pressure Loading.........9

$7 \quad$ Finite Element Model and Boundary Conditions for Vibration Setup \#1 $\ldots \ldots \ldots . . .10$

8 Finite Element Model and Boundary Conditions for Vibration Setup \#2..........11

9 Honeycomb Thickness Correction from Hexcel TSB-120 ....................15

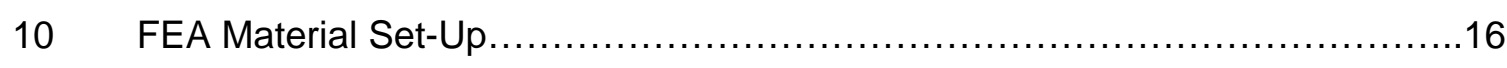

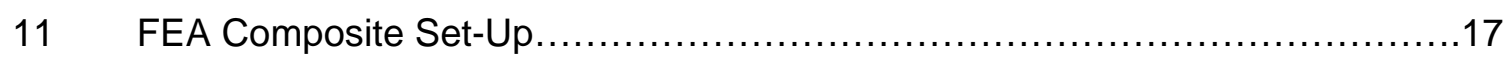

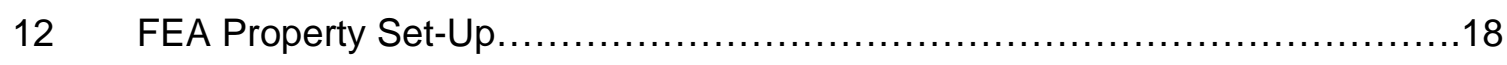

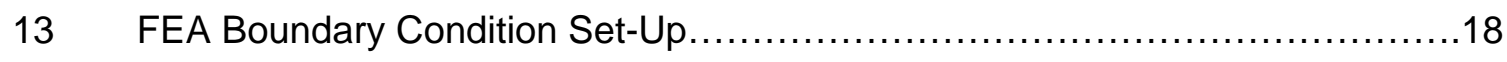

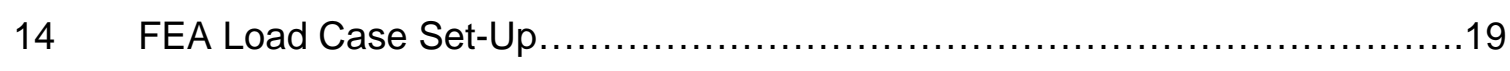

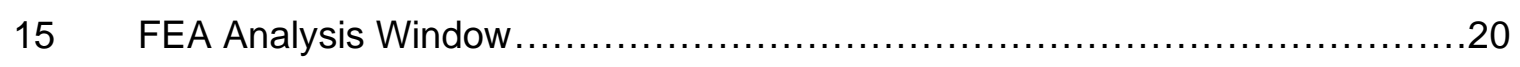

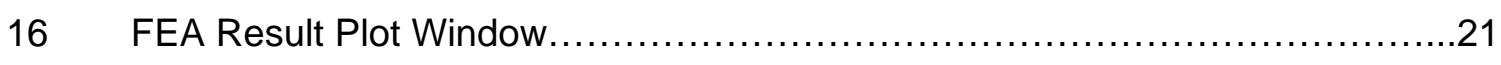

17 Example of Manufacturing Defect in Composite Structure......................26

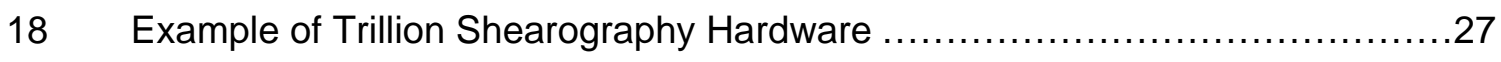




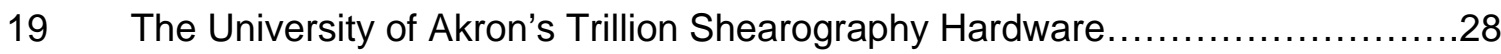

$20 \quad 5135-200$ Radome - Shearography Investigation Grid.......................29

$21 \quad$ University of Akron's Vacuum Chamber........................................

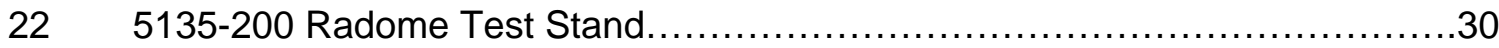

$23 \quad 5135-200$ Radome Shearography Test Set-Up..............................30

24 Simply Supported Beam Mode Shapes.....................................

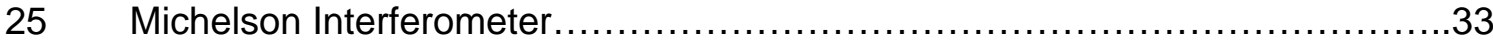

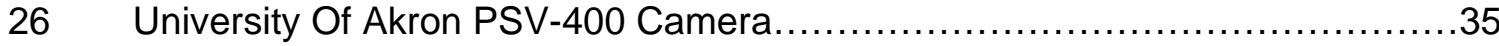

27 University Of Akron PSV-400 Laser Vibrometer System .......................35

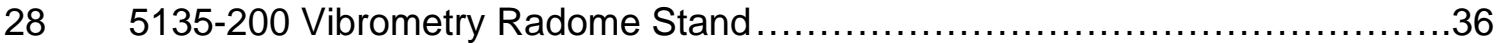

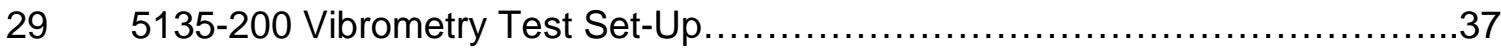

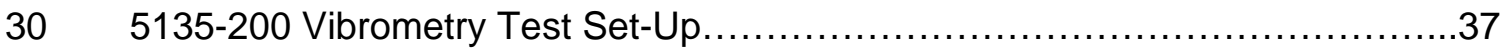

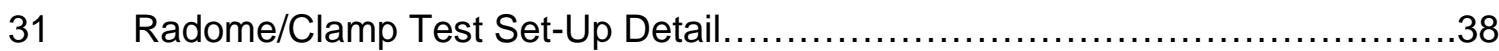

32 Grid Outline for Laser Scanning Points .....................................39

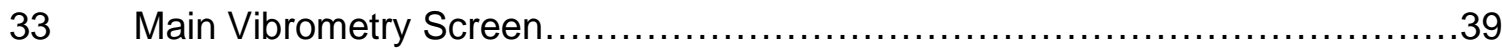

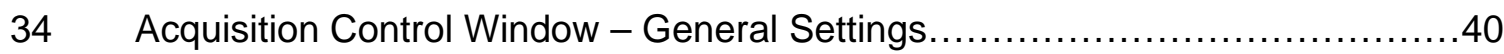

35 Acquisition Control Window - Acquisition Settings..........................40

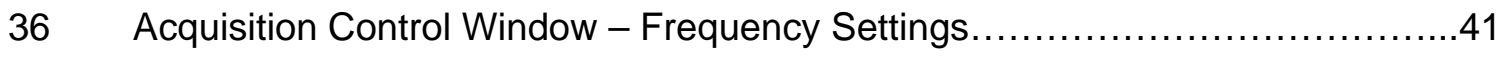

37 Acquisition Control Window - Generator Settings $\ldots \ldots \ldots \ldots \ldots \ldots \ldots \ldots \ldots \ldots . \ldots 2$

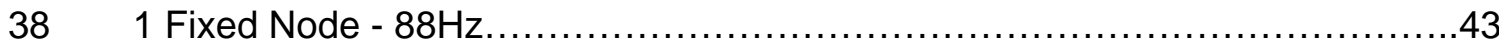

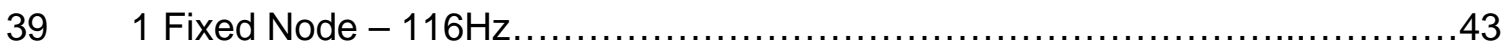

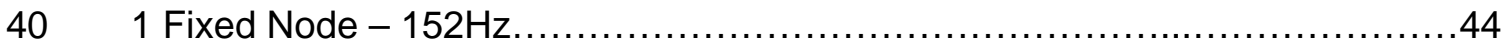

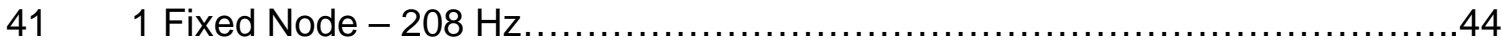

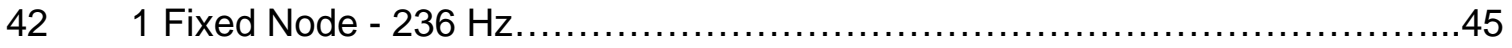




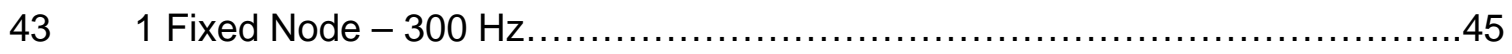

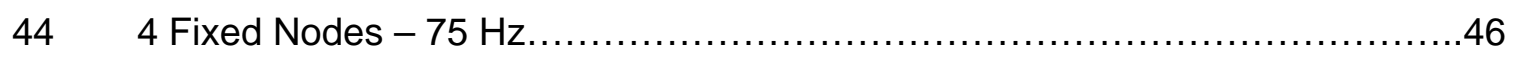

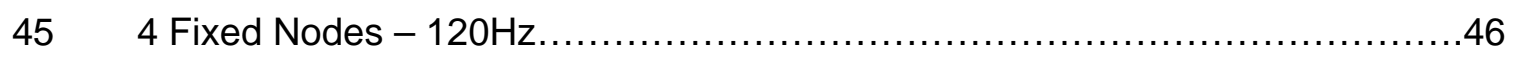

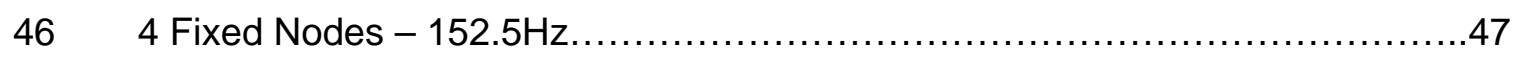

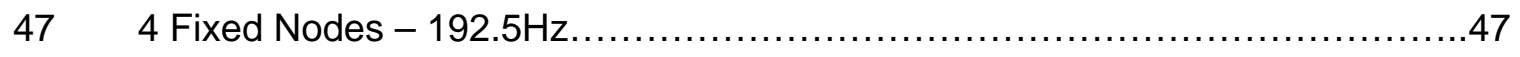

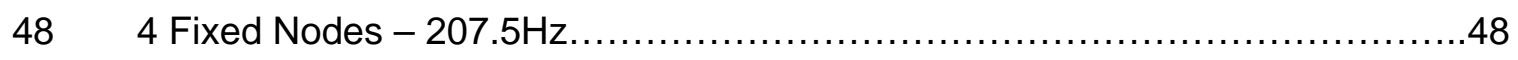

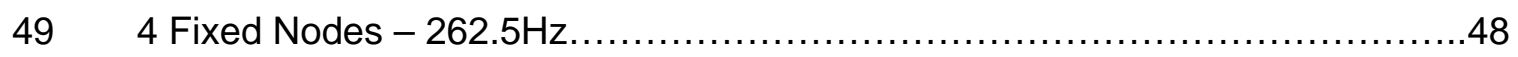

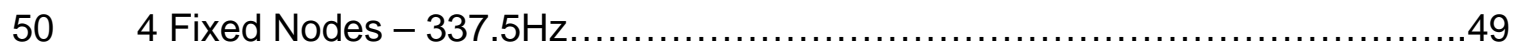

$51 \quad$ Frequency Response for 1 fixed point..................................... 49

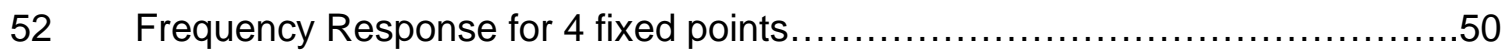

53 Frequency Response - Boundary Condition Comparison (Normalized) ..........50

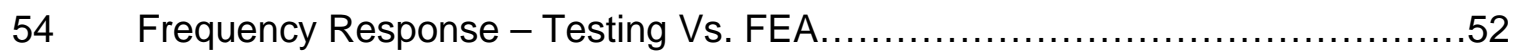

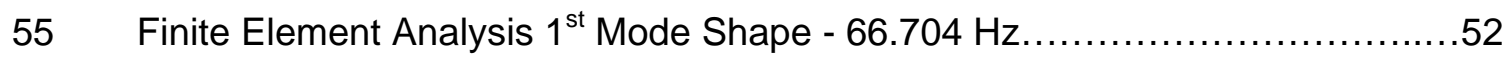

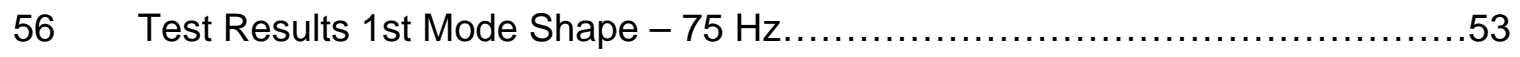

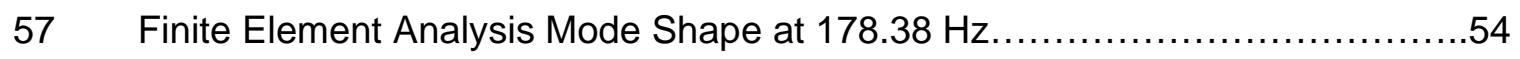

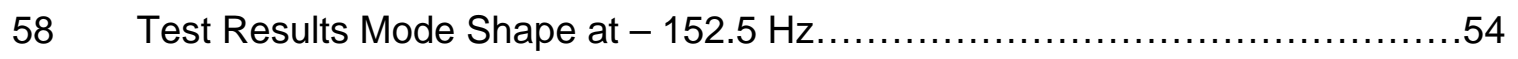

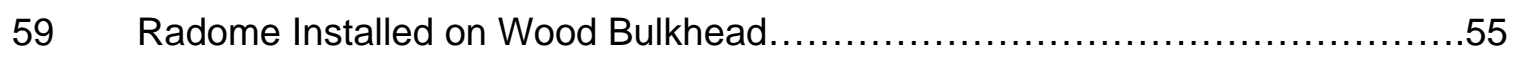

60 Standard Screw Installed on Wood Bulkhead................................. 56

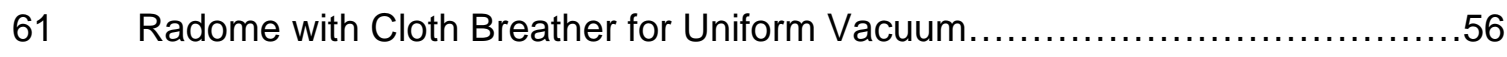

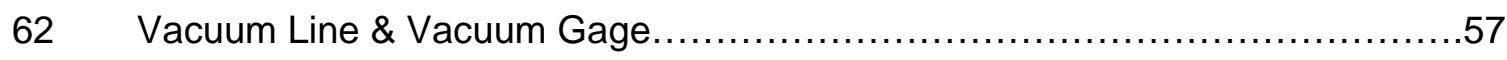

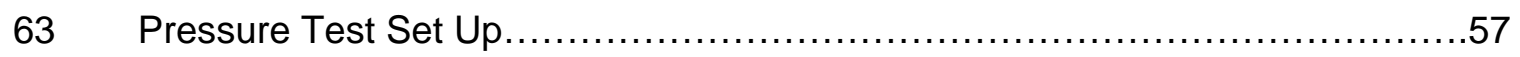

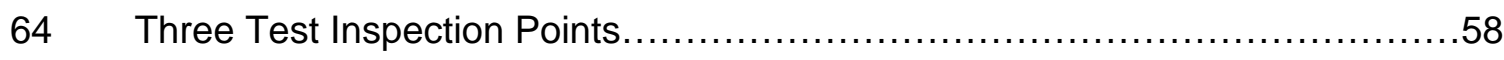

65 Three Test Inspection Points in CATIA File for FEA .......................59

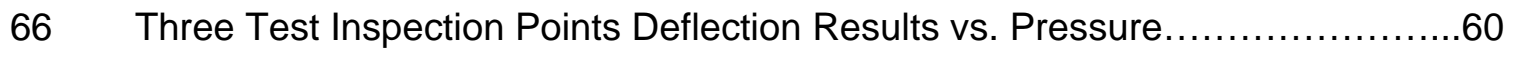


67 Three FEA Points Deflection Results vs. Pressure..........................61

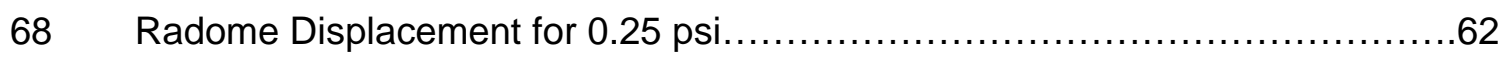

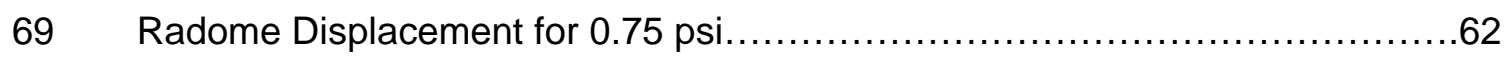

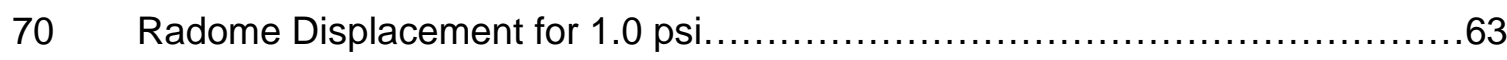

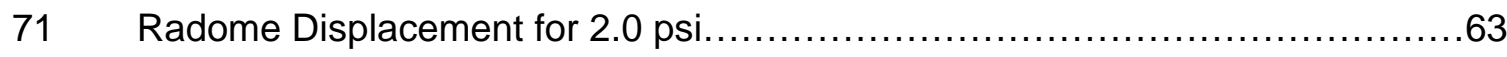

72 Radome Displacement for 3.0 psi.......................................... 64

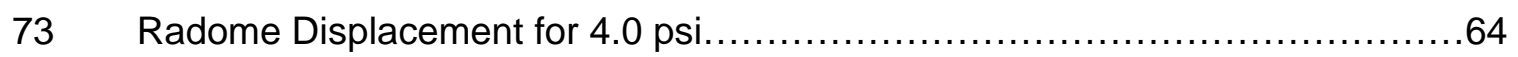

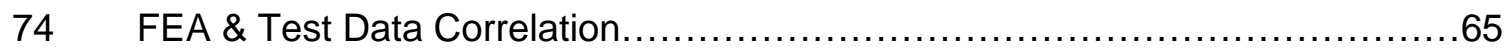




\section{CHAPTER I}

\section{INTRODUCTION}

\section{$1.1 \quad$ Research Goals}

It was desired to validate several finite element analyses for the \#5135-200 Dorsal Radome by completing physical testing and comparing to predicted results. This will be accomplished by completing Laser Vibrometry to compare to a Nastran FEA modal analysis and by completing a pressure test on the radome to compare the deflections to a Nastran FEA model. The Nastran model will also be checked by comparing the computer calculated laminate constituent values to the theoretical calculated values. The background and information presented in this report was learned from the composite expertise at Saint-Gobain, from the professors/classes at the University of Akron and from Polytec Engineers/Training Course.

\subsection{Existing Technology Review}

There are many methods for Non-Destructive investigation for finding manufacturing defects and for characterizing the response of an object to vibration. The Ultrasonic method of non-destructive testing uses beams of short wavelength and high frequency and transmitted from a probe and detected by the same or other probes. This process is completed by a hand held device that is placed on the test article. A display on the device shows the time it takes for an ultrasonic pulse to travel to a reflector. The flaw can be the back surface or a defect in manufacturing. Water is used to provide a medium for the ultrasonic waves for the inspection. This is not desirable for composites. 
There are several methods currently used for measuring vibration the most popular being the measurement of acceleration. By measuring the acceleration the velocity and amplitude at a specific vibration, frequency can me calculated and recorded. The hardware used in this sort of testing includes accelerometers which are small devices attached to the test article that measure the acceleration of the surface at that specific point. Using a Scanning Vibrometer, similar to the Polytec Vibrometer at the University of Akron, a field of points can be measured during one very repeatable scan. The system is also easily moved to perform on-site testing.

Literature produced by Purdue University titled "Nonlinear analysis of composite laminates," written by Chen, J., uses a nine-node isoparametric quadrilateral element according to the Mindlin plate theory and von Karman large deflection assumptions. The finite element analysis used in the report incorporates a four nodded quadrilateral element. Using a more complicated element may produce more accurate results for what is believed to be a geometrically non-linear model. 


\section{CHAPTER II}

\section{RADOME DEFINITION \& BACKGROUND}

Composites are being used at a very high increasing rate where the weight to strength ratios is critical. As a result of the increase of the composites used in structures such as the Boeing 787 which is comprised of nearly $50 \%$ composite structures, a better knowledge and behavioral prediction is desired. This can be done through computational models and/or physical testing. A composite flight structure common to many airplanes is a radome, which can be defined as a structural enclosure used to protect an antenna from the environment which includes the aerodynamic loading and weather. The specific radome being tested is a satellite communications radome is installed to a number of different aircraft including the Airbus $A 320$ (A319, A320, \& A321) series aircraft, Boeing 737 and 777.

A Radome is a protective covering used to enclose electronics such as radar and other antenna from the environment. Radomes are used in ground applications, marine applications and in aerospace. Finite element models are frequently used in the aerospace industry to aid in the design of the composite radomes. Because Nastran and other FEA packages are being relied upon more and more, validation of the computer models is greatly desired. 


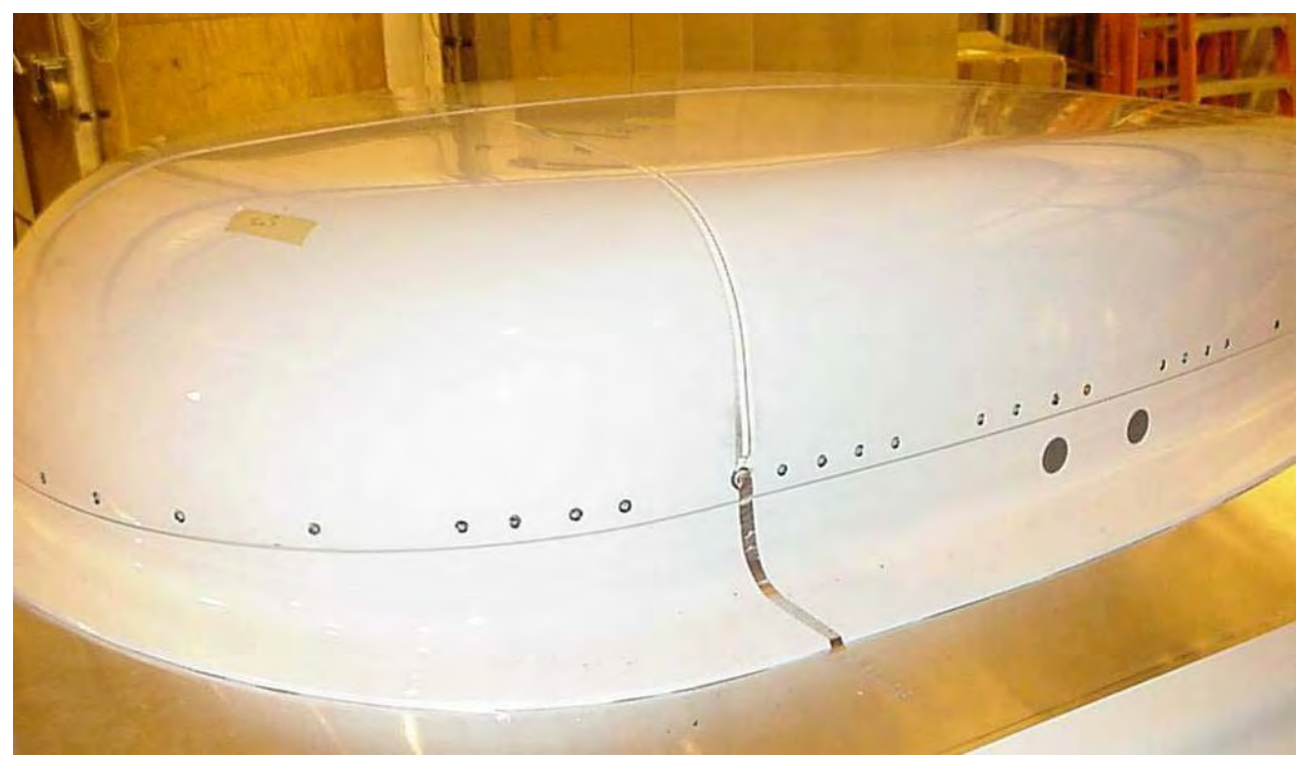

Figure 1) Saint-Gobain \#5135-200 Dorsal Radome

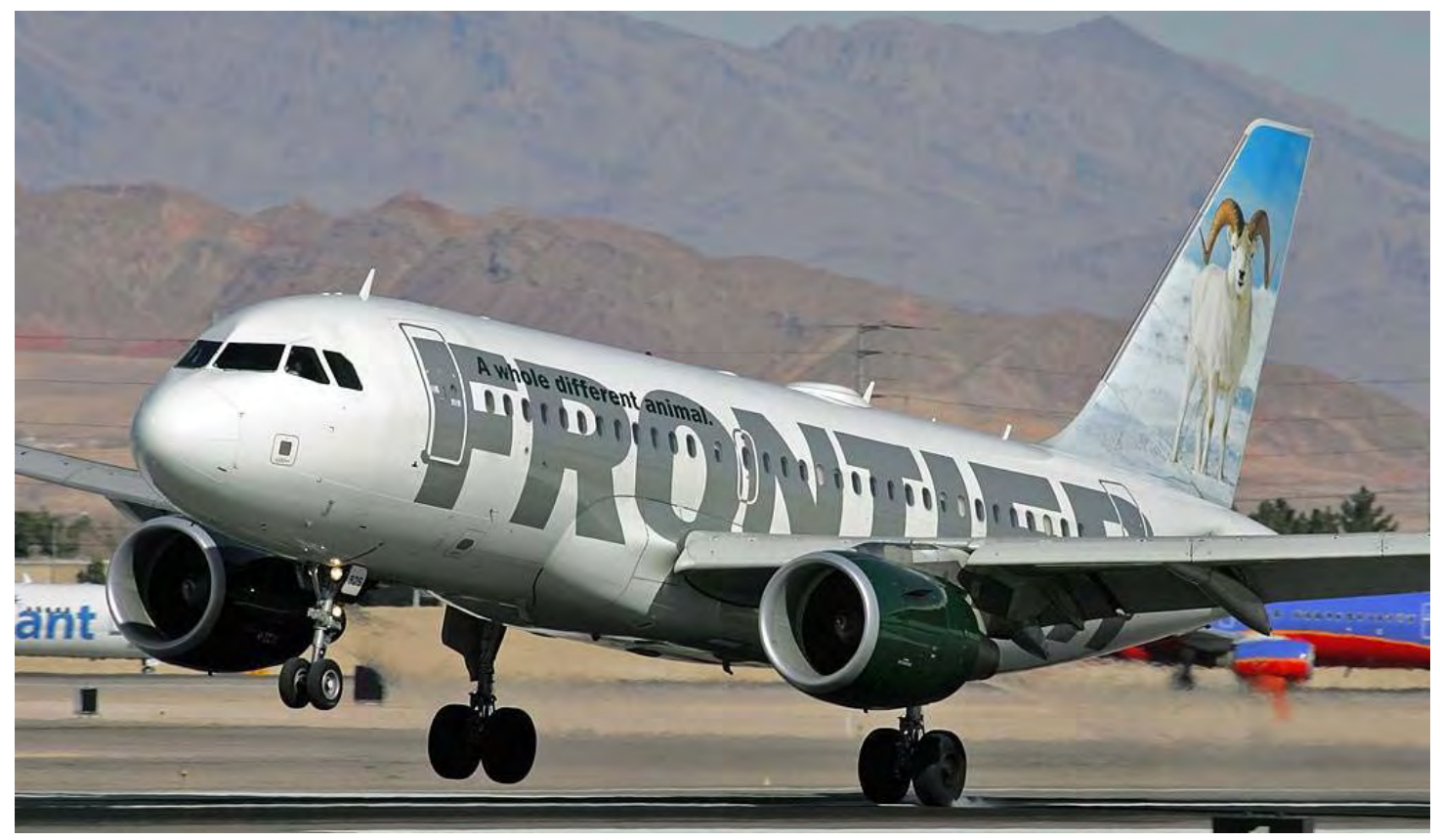

Figure 2) Saint-Gobain \#5135-200 Dorsal Radome on Airbus A-320

(Reference 2. www.frontier.com) 
CHAPTER III

\section{RADOME GEOMETRY CONSTRUCTION}

The radome assembly is a relatively flat streamline shaped honeycomb sandwich composite structure. The radome is composed of three (3) different material regions: an Upper C-Sandwich structure, a Sidewall C-Sandwich structure, and a Solid Laminate Edgeband that runs completely around the radome perimeter. Each color in the following figures represents a different construction and is defined by the corresponding table.

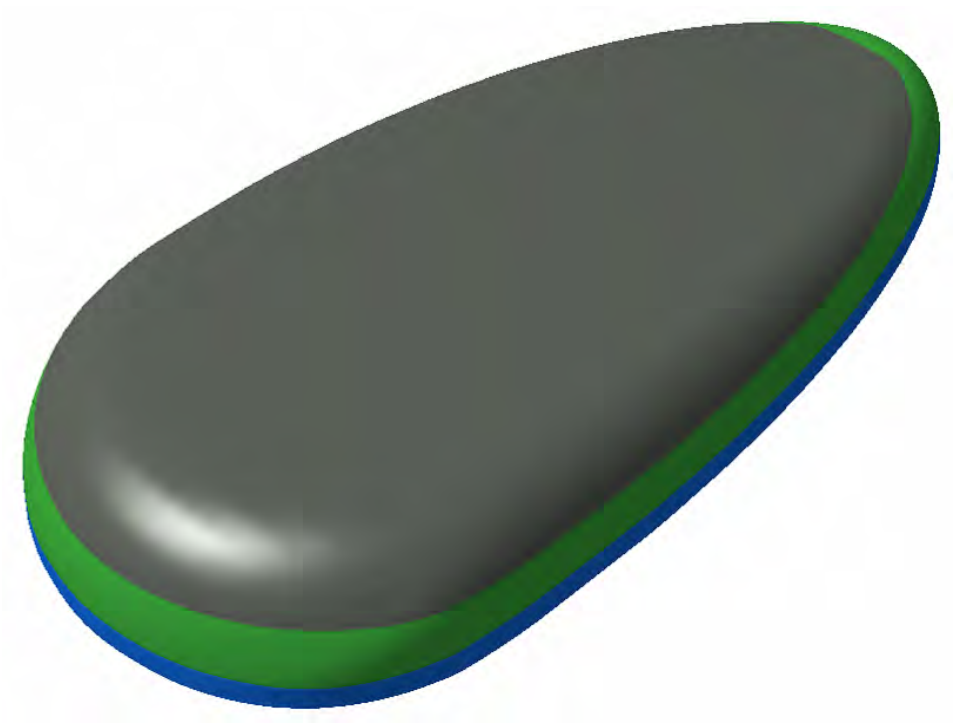

Figure 3) CATIA Model - Radome Construction, Isometric View 


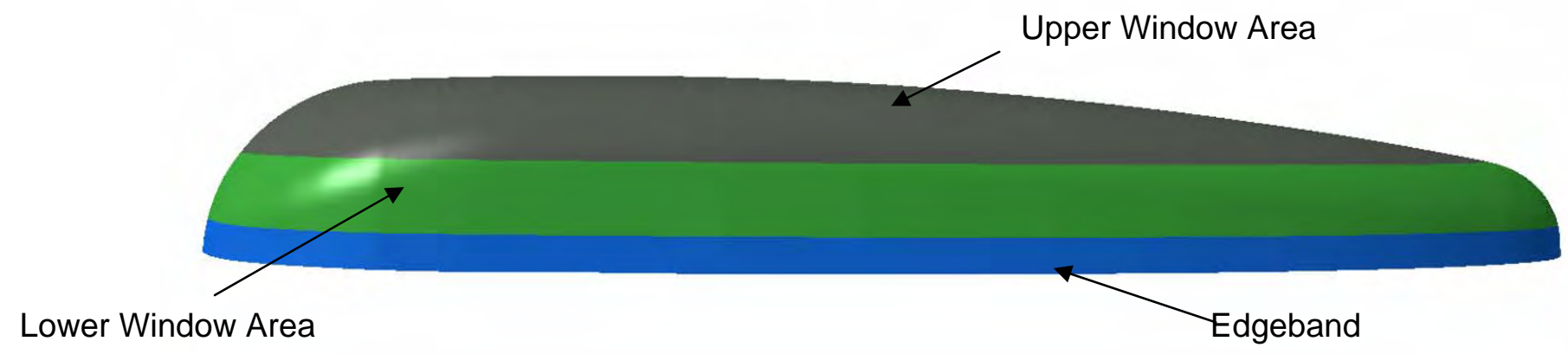

Figure 4) CATIA Model - Radome Construction, Side View

Table 1) Radome Construction

\begin{tabular}{|c|c|c|c|}
\hline Area $A$ & Thickness & Area $B$ & Thickness \\
\hline Radome Edge band & (in) & Lower Window Area & (in) \\
\hline 3 plies Quartz Epoxy [0/-45/90] & 0.0315 & 3 plies Quartz Epoxy [0/-45/90] & 0.0315 \\
\hline 4 plies Glass Epoxy [+45/0/0/+45] & 0.0400 & $0.180 " 5.0 \mathrm{lb}$ Honeycomb & 0.1800 \\
\hline 3 plies Quartz Epoxy [90/-45/0] & 0.0315 & 4 plies Glass Epoxy [+45/0/0/+45] & 0.0400 \\
\hline \multirow[t]{2}{*}{2 plies Glass Epoxy [0/0] } & 0.0200 & $0.180 " 5.0 \mathrm{lb}$ Honeycomb & 0.1800 \\
\hline & & 3 plies Quartz Epoxy [90/-45/0] & 0.0315 \\
\hline Area $C$ & Thickness & & \\
\hline Upper Window Area & (in) & & \\
\hline 3 plies Quartz Epoxy [0/-45/90] & 0.0315 & & \\
\hline $0.180 " 5.5 \mathrm{lb}$ Honeycomb & 0.1800 & & \\
\hline 4 plies Glass Epoxy [+45/0/0/+45] & 0.0400 & & \\
\hline $0.180 " 5.5$ lb Honeycomb & 0.1800 & & \\
\hline 3 plies Quartz Epoxy [90/-45/0] & 0.0315 & & \\
\hline
\end{tabular}




\section{CHAPTER IV}

\section{FINITE ELEMENT ANALYSIS MODEL}

The outer mold line $(\mathrm{OML})$, boundary curves separating the various material regions, and the fastener locations for this radome assembly were electronically imported into the finite element analysis program through an IGES translation file. The finite element mesh was constructed so as to capture the appropriate material transitions, geometric detail, and boundary condition locations. Small construction details such as ply overlaps, and honeycomb thickness transition bevels are not modeled. The node numbers shown in the figure below depict the radome to the ring (which is attached to the fuselage) attachments. This is modeled in Nastran as fixed the $X, Y \& Z$ directions.

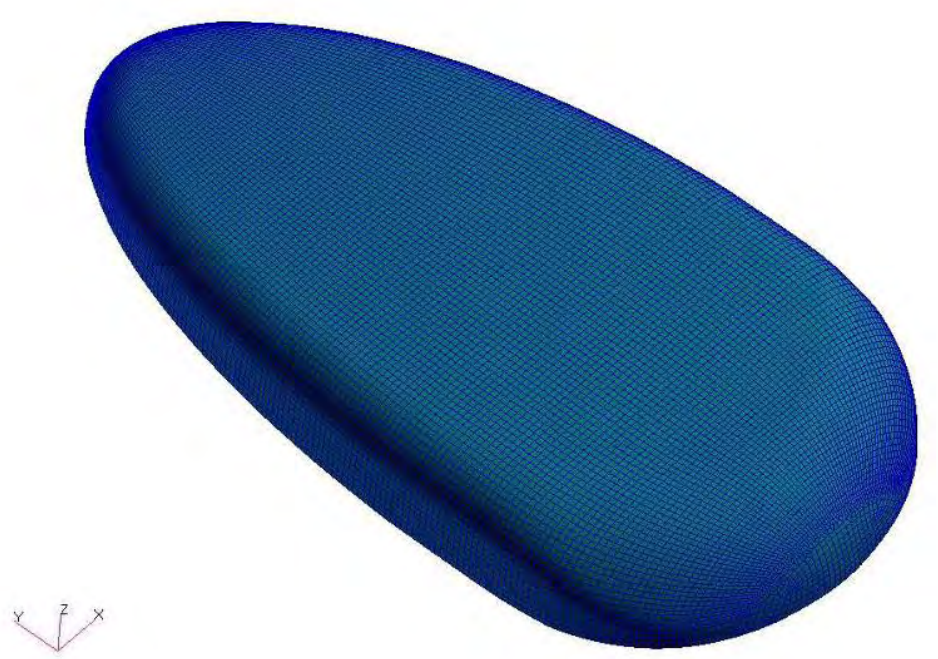

Figure 5) FEM Radome Model 


\subsection{Loading}

A series of pressures were applied to the model with the end goal to predict failure. The pressures modeled were determined by what could be tested in the lab. The modeled pressures are acting inward and are shown in the table below. Note these pressures were not included in the finite element modal analysis or frequency response.

Table 2) Finite Element Analysis Pressure Loads

\begin{tabular}{cc} 
Load Case \# & $\begin{array}{c}\text { Pressure } \\
\left(\mathrm{lb} / \mathrm{in}^{2}\right)\end{array}$ \\
\hline 1 & 0.25 \\
2 & 0.5 \\
3 & 1.0 \\
4 & 2.0 \\
5 & 3.0 \\
6 & 4.0 \\
7 & 5.0 \\
8 & 6.0
\end{tabular}

\subsection{Boundary Conditions}

To accurately model the wood bulk head used in the pressure testing, the boundary conditions for the finite element model were relatively complicated.

\subsubsection{BC's for Pressure Loading}

Four points were fixed in the $\mathrm{X}, \mathrm{Y}$ and $\mathrm{Z}$ directions to represent the four fasteners screwed through the radome edgeband into the bulkhead. The nodes on the sides of the radome, approximately 1.5 inches up from the edge of the radome, were constricted from moving inward representing the restriction cased by the wood. As mentioned earlier the pressures are acting inward representing the vacuum pressure applied by the vacuum bag and vacuum line during the pressure test. The following figure depicts the boundary conditions applied to the finite element model to represent the pressure test assembly. 


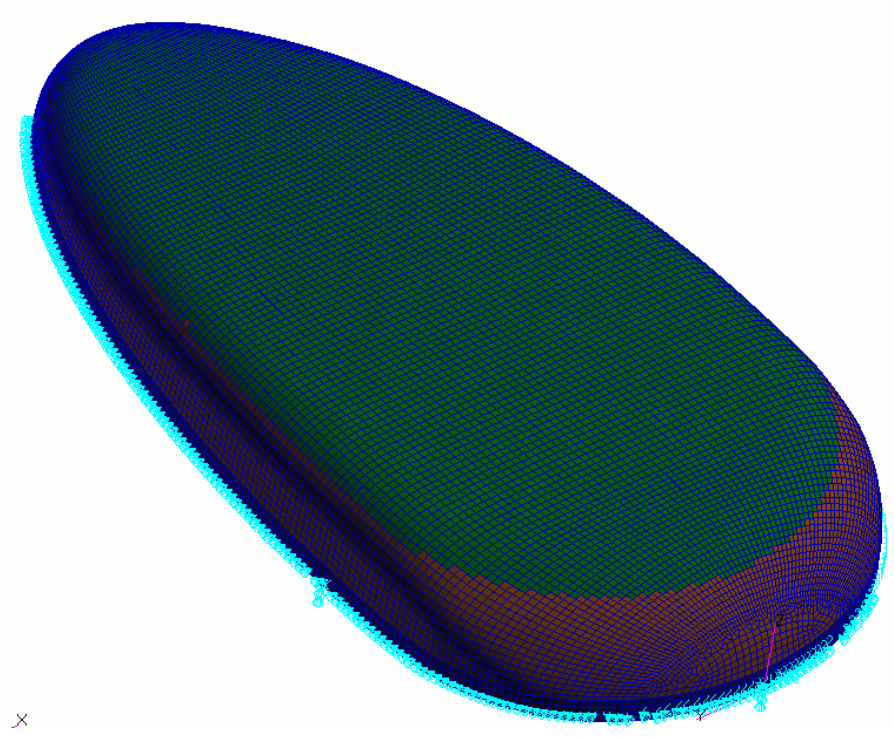

Figure 6) Finite Element Model and Boundary Conditions for the Pressure Loading

\subsubsection{BC's for Vibration Analysis}

Two separate cases were completed for the Vibration analysis with respect to the boundary conditions. The first case that was tested attempted to model free-free boundary conditions. But since we are on the planet earth and gravity is always present, free-free boundary conditions were not actually achieved. The radome was constrained at one point at the very bottom of the radome. The figure below depicts the boundary condition applied to one node on the bottom portion of the edgeband of the radome. 


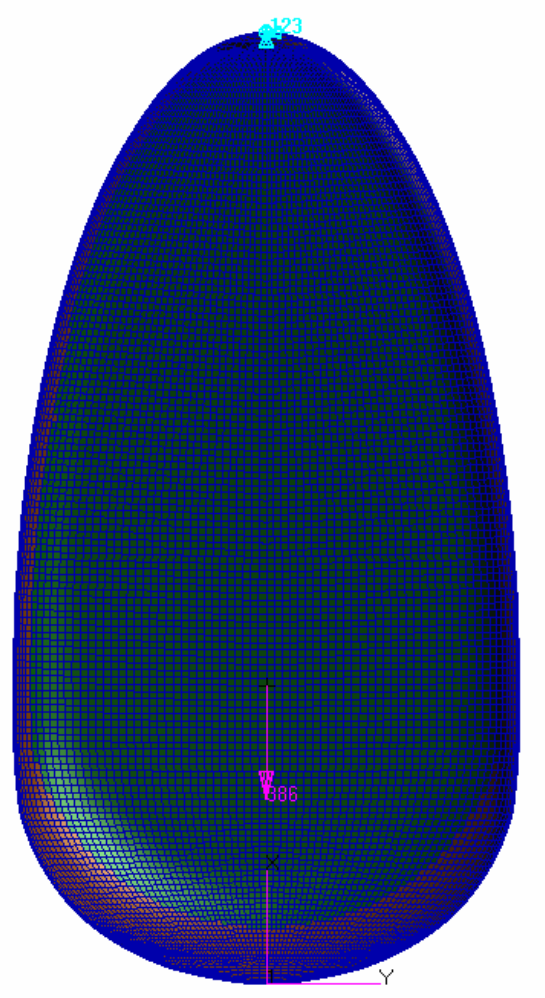

Figure 7) Finite Element Model and Boundary Conditions for Vibration Setup \#1 The second boundary conditions applied for the Vibration analysis was four small footprints fixed in the $X, Y$ and $Z$ directions to represent the four clamps and stand that held the radome in the fixed Vibration testing. The figure below depicts the boundary condition applied to the four footprints on the the edgeband of the radome. 


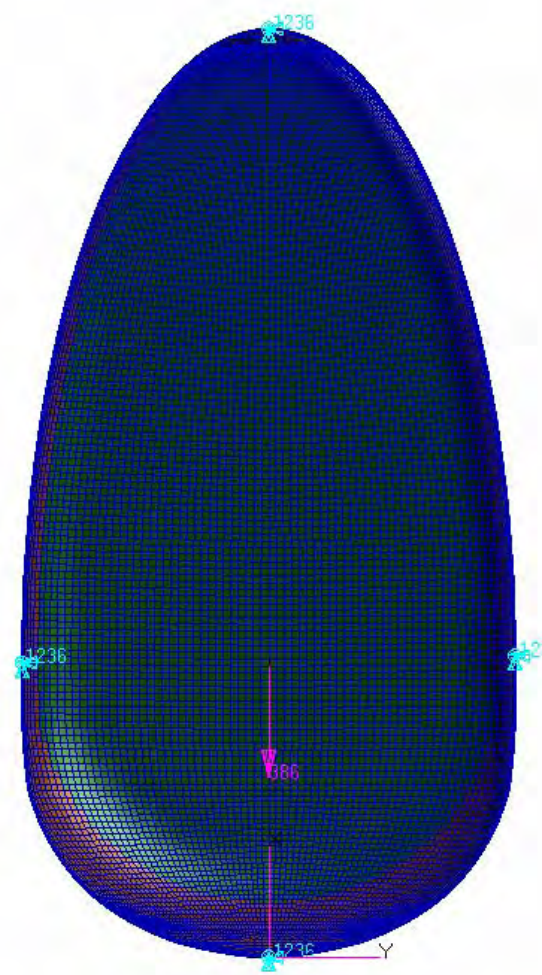

Figure 8) Finite Element Model and Boundary Conditions for Vibration Setup \#2 4.3 Material Properties:

\subsubsection{Laminate Properties}

The following laminate mechanical strength values used in this analysis have been developed at Saint-Gobain through an on going composites testing program and approved by the FAA (test plan, conformed specimens, test witnessing \& results). Reduced (humidity saturated, $+160^{\circ} \mathrm{F}, \mathrm{EWT}$ ) values are developed in accordance with Mil-HDBK-17 recommendations. All mechanical properties are representative of vacuum bag cured laminates.

The materials used in this radome have material strength values tested at temperatures including Cold Dry Temperatures (CDT) of $-65^{\circ} \mathrm{F}\left(-55^{\circ} \mathrm{C}\right)$, Dry Room Temperature (DRT) of $68^{\circ} \mathrm{F}\left(+20^{\circ} \mathrm{C}\right)$ to Elevated Temperatures (HWT) of $+160^{\circ} \mathrm{F}$ 
$\left(+70^{\circ} \mathrm{C}\right)$. Since the completed testing was done at room temperature, the Average DRT allowables and properties are used.

Table 3) Lamina Material Strengths (Reference 12. Saint-Gobain)

Design Allowable 15155 Quartz/Epoxy Composite Laminate Material Strengths

\begin{tabular}{|c|c|c|c|}
\hline Condition & $\begin{array}{l}\text { Tensile, } 0^{\circ} / 90^{\circ} \\
\text { Strength KSI }\end{array}$ & $\begin{array}{c}\text { Compressive, } 0^{\circ} / 90^{\circ} \\
\text { Strength } \mathrm{KSI}\end{array}$ & $\begin{array}{l}\text { In-Plane Shear } \\
\text { Strength, KSI }\end{array}$ \\
\hline $\begin{array}{c}\text { Average } \\
\text { CDT }\end{array}$ & 110.2 / 75.0 & 83.2 / 72.2 & 14.1 \\
\hline Average & & & \\
\hline DRT & $80.0 / 60.0$ & $65.0 / 60.0$ & 10.0 \\
\hline $\begin{array}{l}\text { Hot/Wet } \\
\text { B-Basis }\end{array}$ & $22.0 / 20.0$ & $30.0 / 28.0$ & 4.2 \\
\hline
\end{tabular}

Design Allowable 7781 E-Glass/Epoxy Composite Laminate Material Strength

\begin{tabular}{c|c|c|c}
\hline \hline Condition & $\begin{array}{c}\text { Tensile, } 0^{\circ} / 90^{\circ} \\
\text { Strength KSI }\end{array}$ & $\begin{array}{c}\text { Compressive, } 0^{\circ} / 90^{\circ} \\
\text { Strength KSI }\end{array}$ & $\begin{array}{c}\text { In-Plane Shear } \\
\text { Strength, KSI }\end{array}$ \\
\hline Average & $64.0 / 56.0$ & $67.0 / 55.0$ & 8.8 \\
DRT & $32.0 / 30.0$ & $25.0 / 24.0$ & 2.5 \\
Hot/Wet & & & \\
B-Basis & & &
\end{tabular}


Table 4) Lamina Properties (Reference 12. Saint-Gobain)

\begin{tabular}{|c|c|c|}
\hline & $\begin{array}{c}15155 \\
\text { Quartz/Epoxy }\end{array}$ & $\begin{array}{c}7781 \mathrm{E}- \\
\text { Glass/Epoxy }\end{array}$ \\
\hline Tensile Modulus $0^{\circ} / 90^{\circ}$ & $3.0 / 2.7 \mathrm{MSI}$ & $2.9 / 2.7 \mathrm{MSI}$ \\
\hline Compressive Modulus $0^{\circ} / 90^{\circ}$ & $3.0 / 2.7 \mathrm{MSI}$ & $2.9 / 2.7 \mathrm{MSI}$ \\
\hline In-Plane Shear Modulus & $0.35 \mathrm{MSI}$ & $0.27 \mathrm{MSI}$ \\
\hline $\begin{array}{l}\text { Transverse Shear Modulus } \\
1-3 \text { and } 2-3 \text { direction }\end{array}$ & $0.15 \mathrm{MSI}$ & $0.15 \mathrm{MSI}$ \\
\hline $\begin{array}{l}\text { Poisson's Ratio } \\
1-2 \text { and 2-1 direction }\end{array}$ & 0.13 & 0.14 \\
\hline $\begin{array}{l}\text { Poisson's Ratio } \\
1-3 \text { and 2-3 direction }\end{array}$ & 0.20 & 0.20 \\
\hline Ply Thickness & $0.0105 "$ & $0.010 "$ \\
\hline
\end{tabular}

Tensile, compressive \& in-plane shear modulus are average hot, wet mechanical properties. Dry, room temperature properties are about $10 \%$ higher. Transverse shear modulus is derived from neat epoxy resin modulus of elasticity $(0.3 \mathrm{msi})$ and Poisson's ratio $(0.20)$ using the bulk modulus equation $\mathrm{G}=\mathrm{E} /(2(1+\mathrm{v}))$.

Honeycomb is widely used in composite aircraft structures to provide thickness, increasing the composite strength while adding minimal weight. An industry leader for the honeycomb which is used in the part being analyzed is Hexcel. The honeycomb properties are defined in Hexcel TSB-120, which is a public Hexcel document that provides companies with material properties and design information. 
Table 5) Honeycomb Material Properties for Hexcel TSB-120

(Reference 11. Hexcel)

\begin{tabular}{||c|c||}
\hline $\begin{array}{c}\text { Shear L / W } \\
\text { Minimum Strength, psi } \\
\text { Modulus, psi }\end{array}$ & $\begin{array}{c}\text { Compressive } \\
\text { Minimum Strength psi } \\
\text { Modulus, psi }\end{array}$ \\
\hline 5.5 LB. Density, 3/16 Cell, Glass Honeycomb Core - TSB-120 Values - 0.50" Thick \\
\hline 390 / 200 & 750 \\
$19,000 / 11,000$ & 95,000 \\
\hline 5.0 LB. Density, F50 Aramid Flex-core - TSB-120 Values - 0.50" Thick \\
\hline 300 / 170 \\
10,000 / 5,200 \\
\hline
\end{tabular}

Since the provided material data is for a thickness of 0.50 " the honeycomb core strengths are modified to account for the thickness used. The following graph, also taken from Hexcel TSB-120, shows that thinner core has a higher than specified shear strength. This is due to the shear strength test method placing the core in shear and tension, and not "pure" tension. For thin cores, sandwich facing resin fillets will also improve strength. To account for the 0.180 " core actually used in the actual part, a thickness correction factor of 1.16 is calculated. 
Hexcel TSB-120 Non-Metallic Honeycomb - Strength Correction Factor

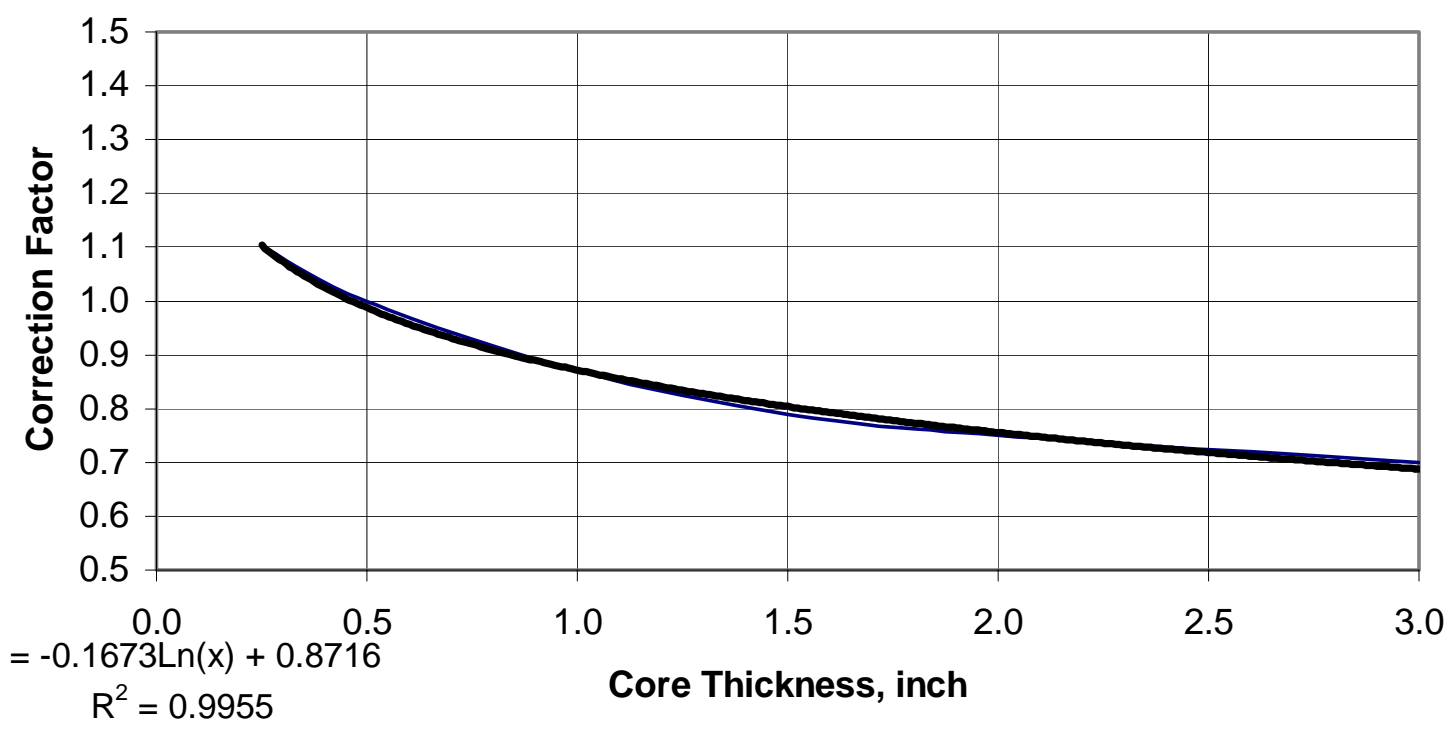

Figure 9) Honeycomb Thickness Correction from Hexcel TSB-120 (Reference 11. Hexcel)

The summary minimum honeycomb core properties used in the analysis, taking thickness into account, are shown in the table below.

Table 6) Honeycomb Material Properties from Hexcel TSB-120 Corrected (Reference 11. Hexcel)

\begin{tabular}{|c|c|}
\hline Shear L/W & Compressive \\
\hline Minimum Strength, psi & Minimum Strength psi \\
\hline Modulus, psi & Modulus, psi \\
\hline \multicolumn{2}{|c|}{ Adjusted 5.5 LB. Density, 3/16 Cell, Glass Honeycomb Core } \\
\hline $407 / 209$ & 675 \\
\hline $19,000 / 11,000$ & 95,000 \\
\hline \multicolumn{2}{|c|}{ Adjusted 5.0 LB. Density, F50 Aramid Flex-Core } \\
\hline $313 / 177$ & 486 \\
\hline $10,000 / 5,200$ & 37,000 \\
\hline
\end{tabular}




\subsection{Finite Element Analysis Program Interface}

To set up the finite element model of the radome the shape was imported as an IGS file translation. The surface was imported with the edgeband already separated from the other portion of the radome. Using Quad4 shell elements, the surfaces were meshed allowing a minimum of 3 elements to represent the width of the edgeband. After the surfaces were meshed, material properties were set up for the lamina and the honeycomb core as two-dimensional orthotropic materials. This is depicted in the following figure for the 15155 Quartz.

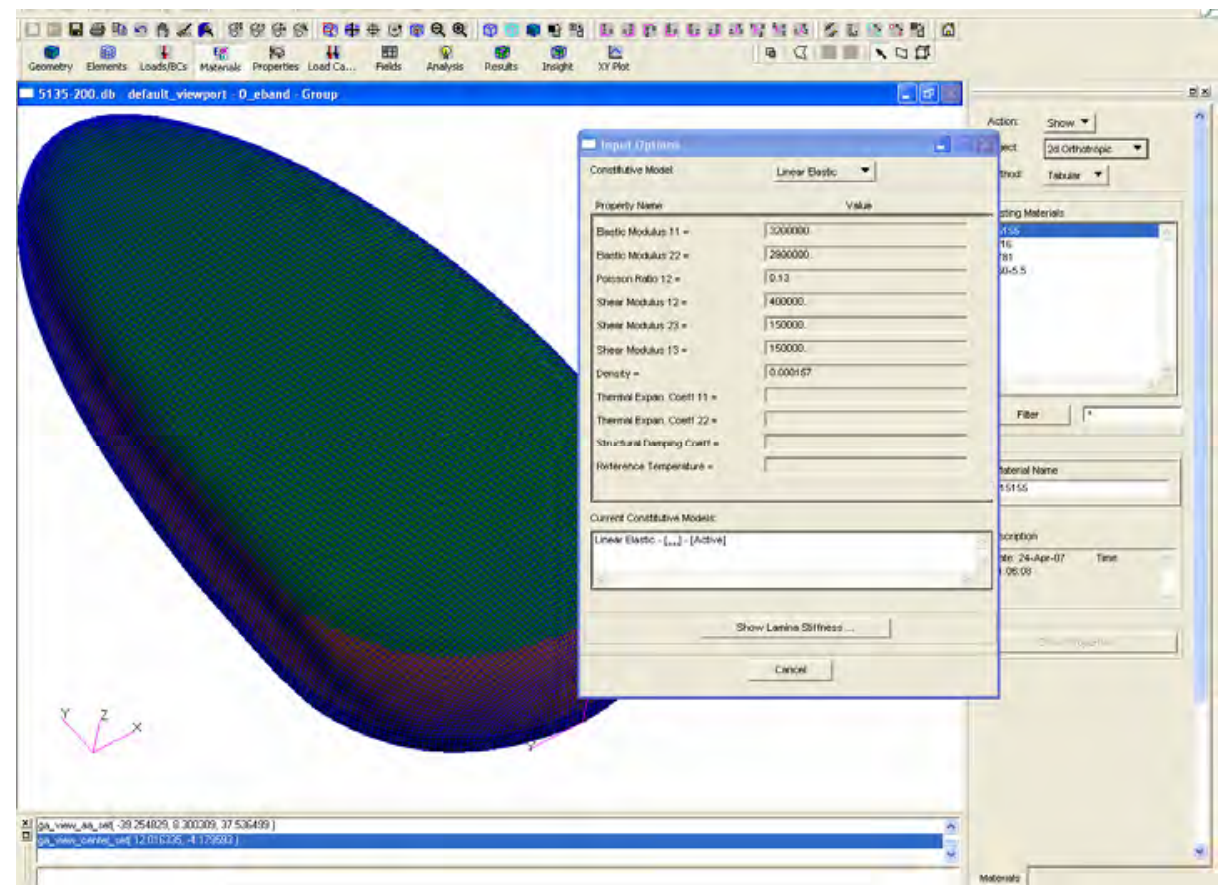

Figure 10) FEA Material Set-Up 


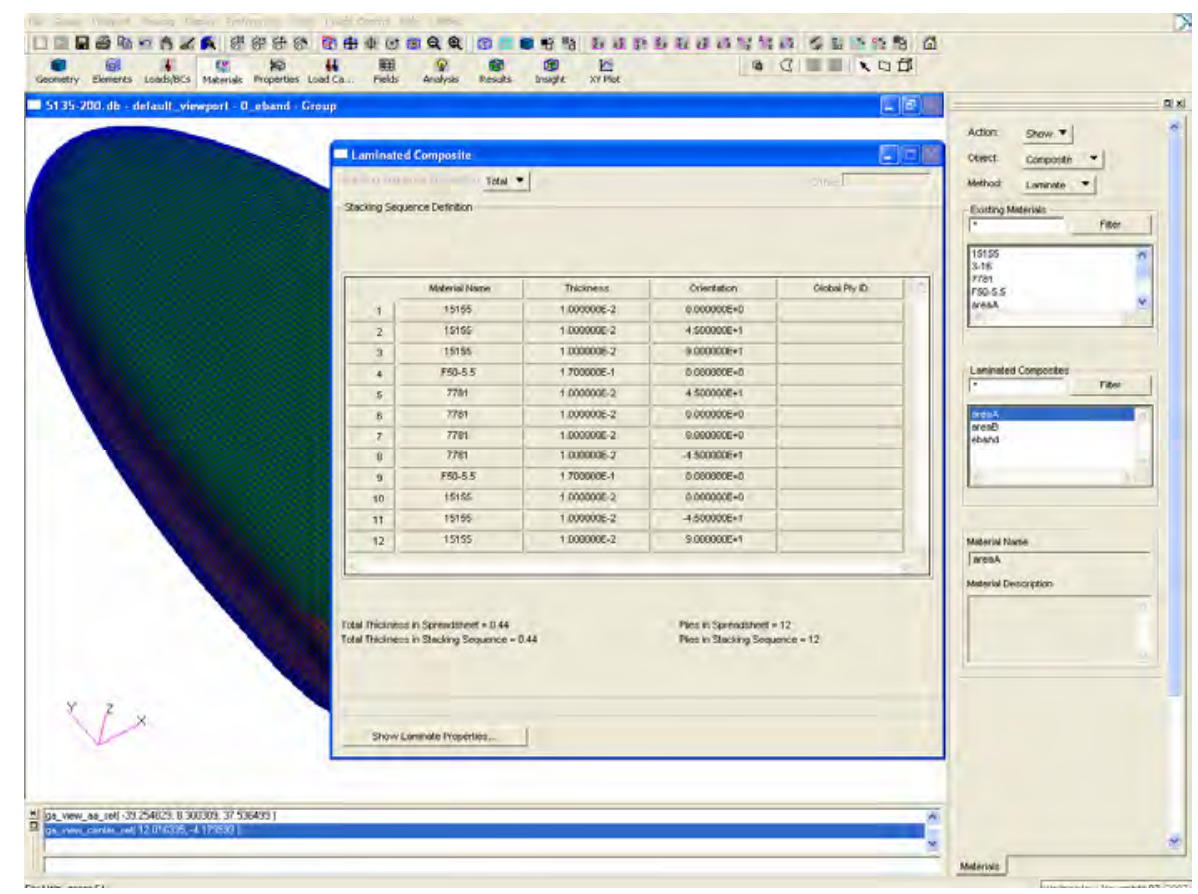

Figure 11) FEA Composite Set-Up

After the two-dimensional orthotropic materials are set up, the actual construction is modeled as a composite property. In this window, the material stack-up, thickness and orientation are specified for the three construction sections of the radome. These include the two composite sandwich constructions and the solid laminate construction. The previous figure depicts finite element program input for the composite creation. Note the specified ply orientations can be entered and modified in the following window.

The appropriate construction regions then have a two-dimensional shell property assigned to them which specifies the material, the material axis coordinate system and plate offset. Negative One half of the thickness is used as a plate offset. 


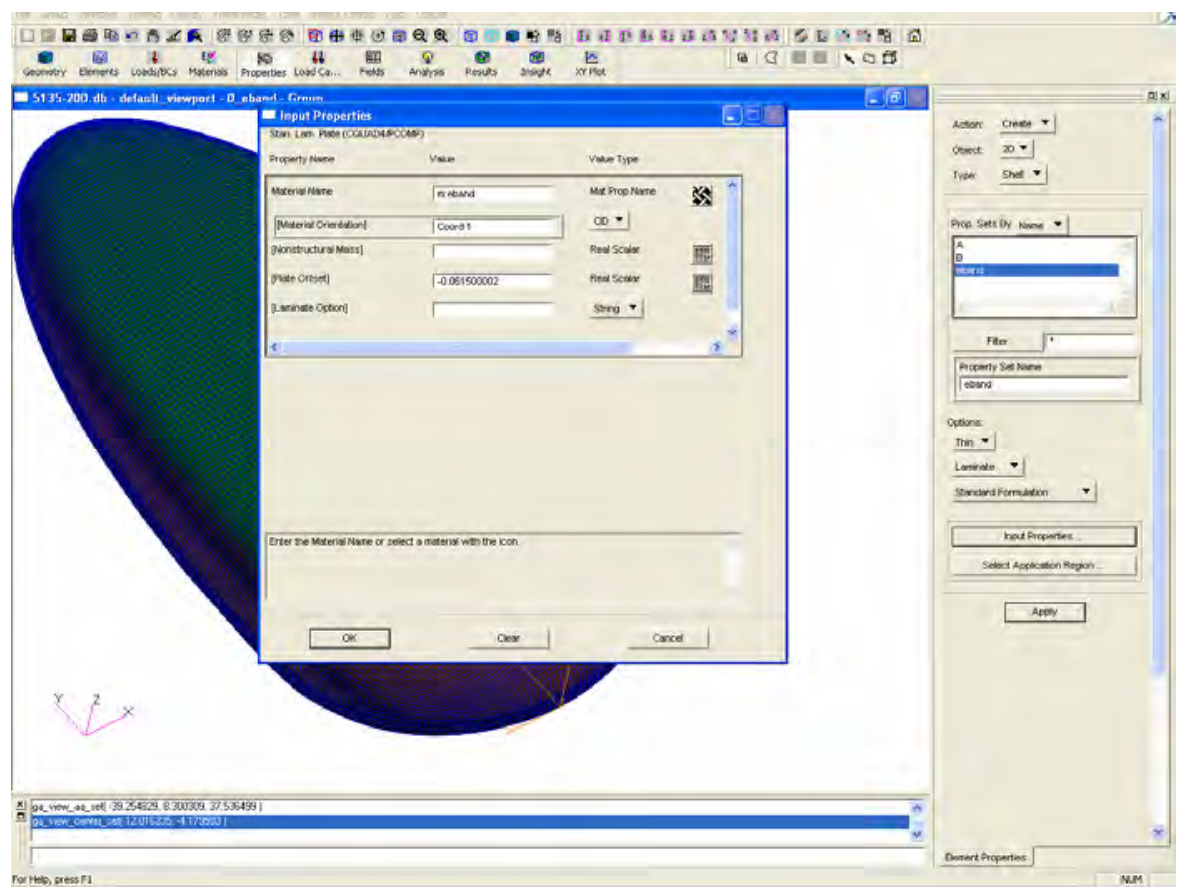

Figure 12) FEA Property Set-Up

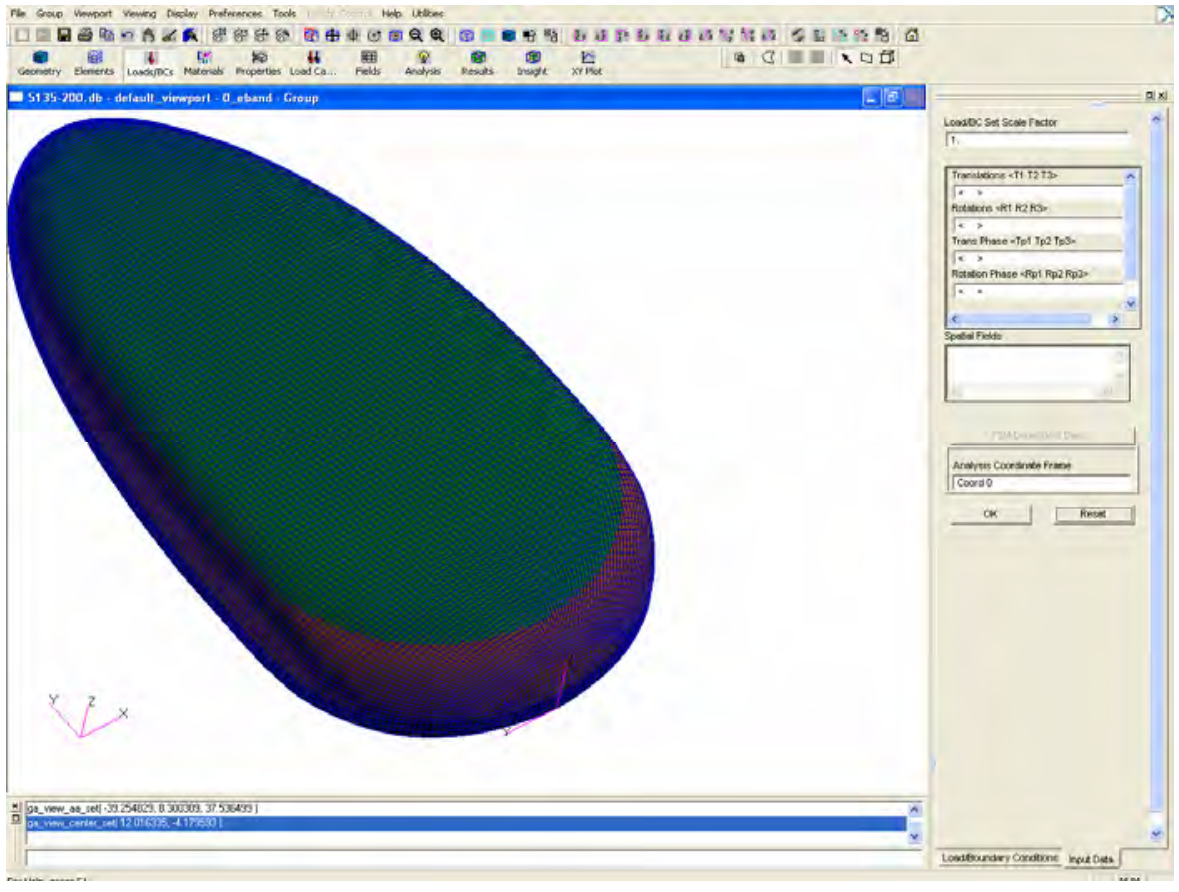

Figure 13) FEA Boundary Condition Set-Up

Following the set-up of the materials and properties boundary conditions were applied as discussed earlier. As depicted in the figure above, for a displacement 
boundary condition, the translation, rotation and phase can be specified. If any of the settings are not specified they are calculated. For example if the translations are set to $<0,0,0>$ and no other values are specified, then rotations will be calculated at the specified point. The following figure shows a load case which specifies which boundary conditions, forces, inertial loads or other loading will be analyzed. Several different load cases can be run during one analysis which was convenient when running several vacuum loading conditions.

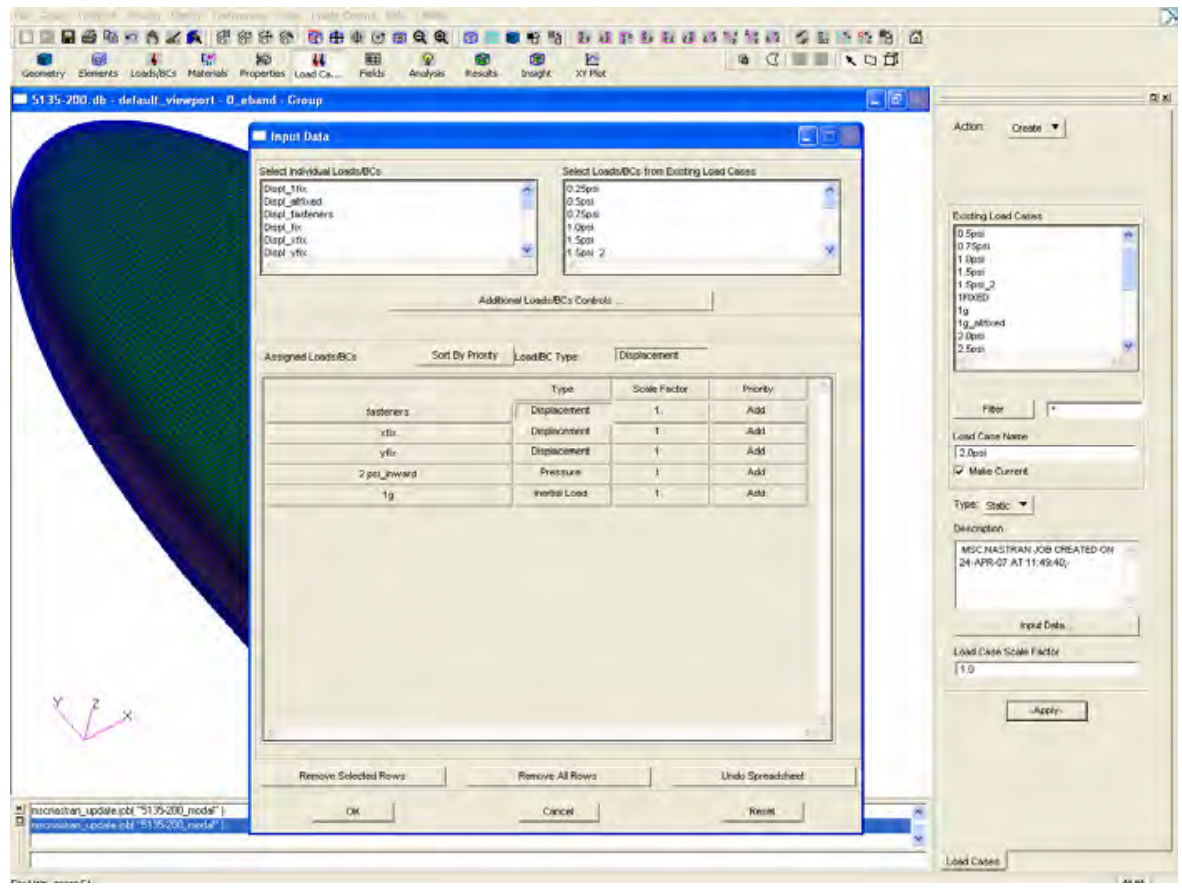

Figure 14) FEA Load Case Set-Up 


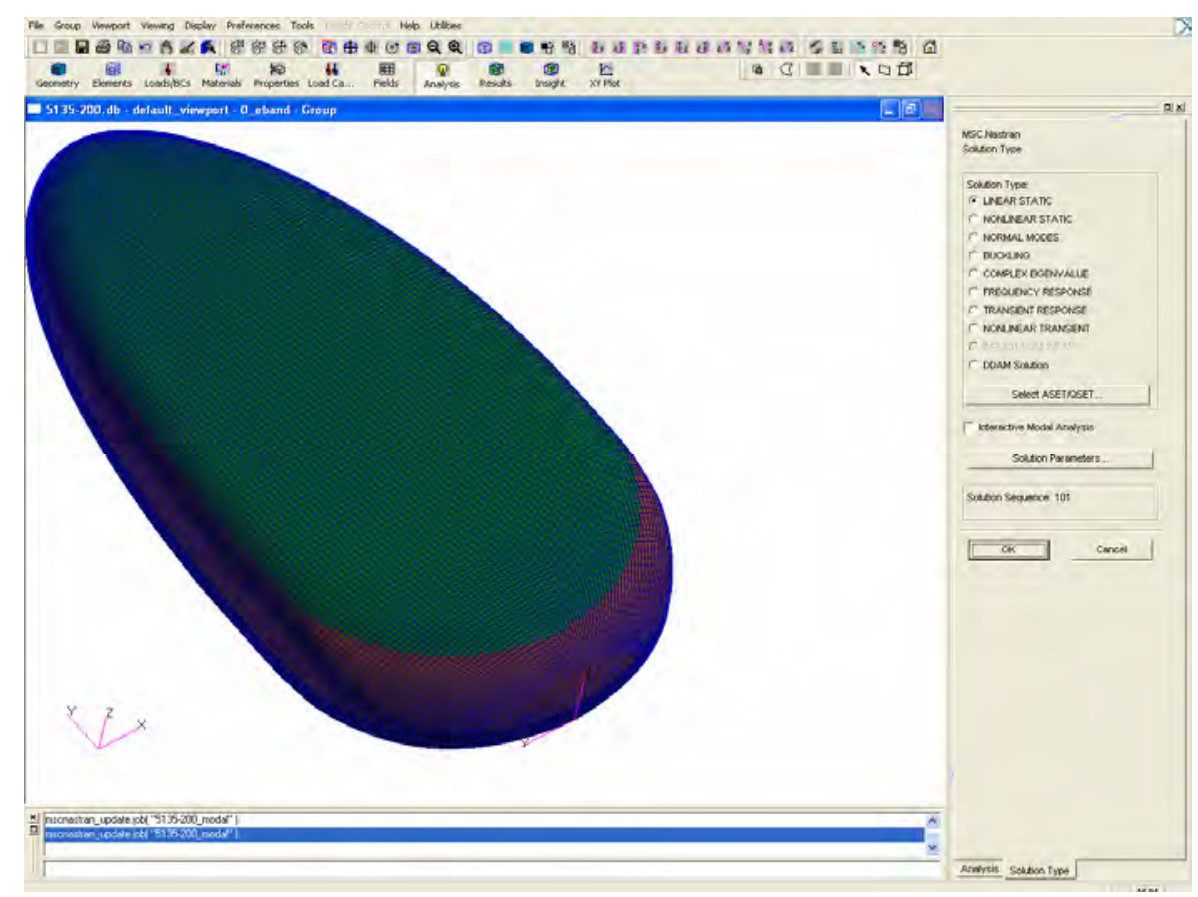

Figure 15) FEA Analysis Window

The previous figure showed an example of the analysis window in which a linear static model was selected. For the other analyses run, normal modes and frequency response was selected. After the analysis is complete the analysis output file containing all of the results is imported back into the program. Stresses, strains, displacements and other results can be plotted onto the geometry for each individual load case that was analyzed as shown below. 


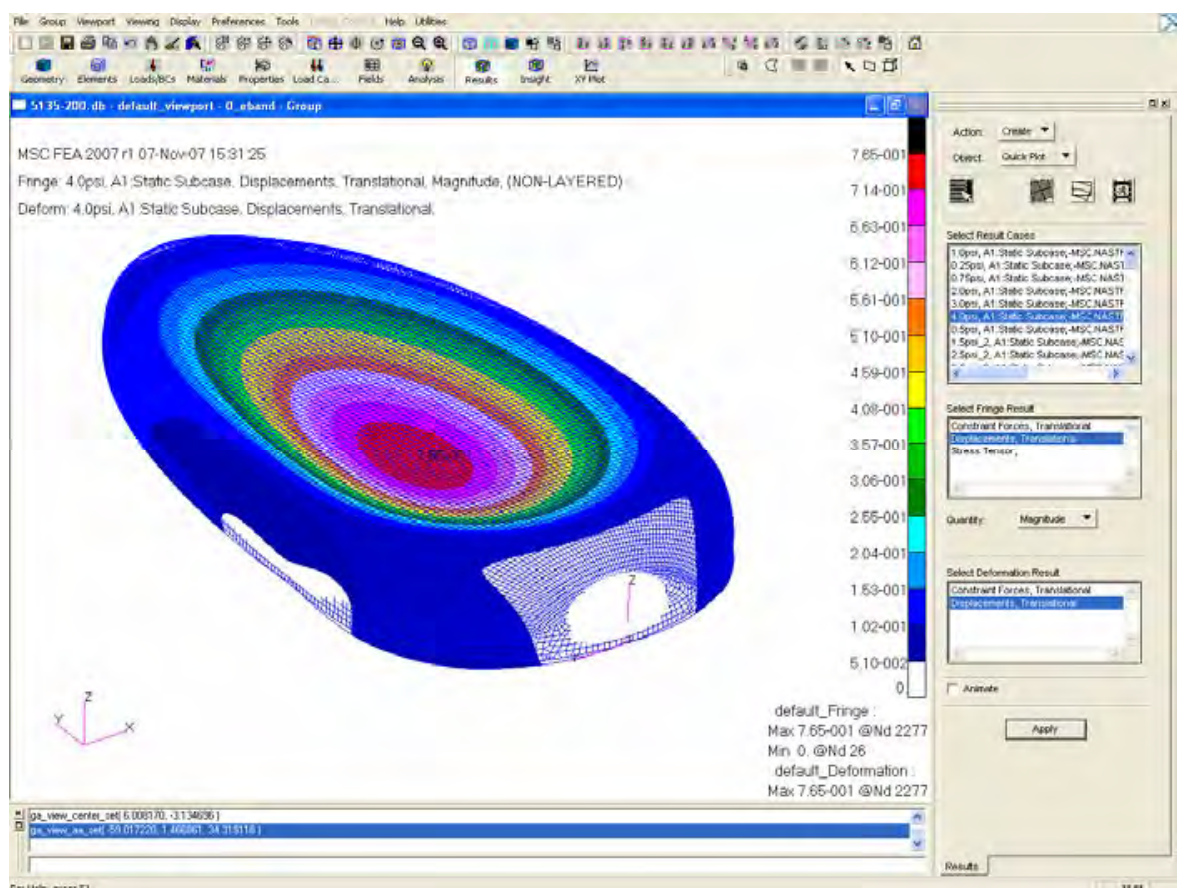

Figure 16) FEA Result Plot Window 


\section{CHAPTER V}

\section{HAND CALCULATIONS FOR MATERIAL PROPERTIES (FOR REFERENCE)}

For the many design engineers, specifically in composite design, it is useful to show the composite laminate constitutive values, which include the stiffness matrix, compliance matrix and the A, B \& D matrices. Each individual ply has its own material properties as well as the honeycomb core. The quantity, order and orientation of the laminate stack-up all effect the overall laminate properties. Shown in the following equations are the standard formulations for calculating the laminate properties. These values were not used since Nastran completes these calculations internally; they are shown for reference only. As expected the B and D matricies are nearly zero because excluding the last two plies this radome has a symmetric construction.

$$
\begin{aligned}
& \text { LAMINA COMPLIANCE MATRIX } \\
& {\left[\mathrm{S}_{\mathrm{ij}}\right]=\left\{\begin{array}{ccc}
1 / \mathrm{E}_{11} & \left(-v_{21}\right) / \mathrm{E}_{22} & 0 \\
\left(-v_{12}\right) / \mathrm{E}_{11} & 1 / \mathrm{E}_{22} & 0 \\
0 & 0 & 1 / \mathrm{E}_{66}
\end{array}\right\}} \\
& \text { LAMINA STIFFNESS MATRIX } \\
& {\left[\mathrm{C}_{\mathrm{ij}}\right]=\left[\mathrm{S}_{\mathrm{ij}}\right]^{-1}}
\end{aligned}
$$

TRANSFORMATION MATRIX FOR LAMINA AT ANGLE $\theta$ $\mathrm{m}=\cos (\theta)$$$
\mathrm{n}=\sin (\theta)
$$

$$
[T]=\left\{\begin{array}{ccc} 
& & \\
m^{2} & n^{2} & 2 m^{*} n \\
n^{2} & m^{2} & -2 m^{*} n \\
-m^{*} n & m^{*} n & m^{2}-n^{2}
\end{array}\right\}
$$


TRANSFORMED LAMINA COMPLIANCE MATRIX

$$
\left[S_{\mathrm{ijBAR}}\right]=\left[\mathrm{T}_{1}\right]\left[\mathrm{S}_{\mathrm{ij}}\right]\left[\mathrm{T}_{1}^{-1}\right]
$$

TRANSFORMED LAMINA STIFFNESS MATRIX

$$
\left[\mathrm{C}_{\mathrm{ijBAR}}\right]=\left[\mathrm{S}_{\mathrm{iBBAR}}\right]^{-1}
$$

\section{$A, B$ \& D MATRICES (LAMINATE VALUES)}

$$
\begin{aligned}
& {[\mathrm{A}]=\Sigma\left[\mathrm{C}_{\mathrm{ijBAA}}\right]^{*}\left(\mathrm{z}_{\mathrm{i}}-\mathrm{Z}_{\mathrm{i}-1}\right)} \\
& {[\mathrm{B}]=\Sigma\left[\mathrm{C}_{\mathrm{ijBAA}}\right]^{*}\left(\mathrm{z}_{\mathrm{i}}^{2}-\mathrm{z}_{\mathrm{i}-1}{ }^{2}\right)} \\
& {[\mathrm{D}]=\Sigma\left[\mathrm{C}_{\mathrm{ijBAR}}\right]^{*}\left(\mathrm{z}_{\mathrm{i}}^{3}-\mathrm{z}_{\mathrm{i}-1}{ }^{3}\right)}
\end{aligned}
$$

Where:

$z_{i}=$ the height with respect of the laminate center of layer $i$

$\mathrm{z}_{\mathrm{i}-1}=$ the height with respect of the laminate center of the previous layer

(Formulas from References 8, 13 \& 14; Composite Training and University of Akron Composite Classes)

Material Properties in the Structural Coordinate System for 7781

$$
\text { Glass/Epoxy }
$$

$\begin{aligned}-45^{\circ} & \mathrm{S}_{\mathrm{ijBAR}}=\left(\begin{array}{ccc}2.01 & -1.70 & -0.01 \\ -1.70 & 2.01 & -0.01 \\ -0.01 & -0.01 & 0.41\end{array}\right) & \mathrm{C}_{\mathrm{ijBAR}}=\left(\begin{array}{ccc}1.754 & 1.484 & 0.102 \\ 1.484 & 1.754 & 0.102 \\ 0.051 & 0.051 & 2.467\end{array}\right) \\ +45^{\circ} & \mathrm{S}_{\mathrm{ijBAR}}=\left(\begin{array}{ccc}2.01 & -1.70 & 0.01 \\ -1.70 & 2.01 & 0.01 \\ 0.01 & 0.01 & 0.41\end{array}\right) & \mathrm{C}_{\mathrm{ijBAR}}=\left(\begin{array}{ccc}1.754 & 1.484 & -0.102 \\ 1.484 & 1.754 & -0.102 \\ -0.051 & -0.051 & 2.467\end{array}\right) \\ +90^{\circ} & \mathrm{S}_{\mathrm{ijBAR}}=\left(\begin{array}{ccc}0.370 & -0.048 & 0.000 \\ -0.048 & 0.345 & 0.000 \\ 0.000 & 0.000 & 3.704\end{array}\right) & \mathrm{C}_{\mathrm{ijBAR}}=\left(\begin{array}{lll}2.750 & 0.385 & 0.000 \\ 0.385 & 2.954 & 0.000 \\ 0.000 & 0.000 & 0.270\end{array}\right)\end{aligned}$

Material Properties in the Structural Coordinate System for 15155 Quartz/Epoxy

$\begin{aligned}-45^{\circ} & \mathrm{S}_{\mathrm{iBAR}}=\left(\begin{array}{ccc}1.55 & -1.31 & -0.02 \\ -1.31 & 1.55 & -0.02 \\ -0.01 & -0.01 & 0.47\end{array}\right) & \mathrm{C}_{\mathrm{ijBAR}}=\left(\begin{array}{lll}2.308 & 1.958 & 0.169 \\ 1.958 & 2.308 & 0.169 \\ 0.084 & 0.084 & 2.141\end{array}\right) \\ +45^{\circ} & \mathrm{S}_{\mathrm{ijBAR}}=\left(\begin{array}{ccc}1.55 & -1.31 & 0.02 \\ -1.31 & 1.55 & 0.02 \\ 0.01 & 0.01 & 0.47\end{array}\right) & \mathrm{C}_{\mathrm{ijBAR}}=\left(\begin{array}{ccc}2.308 & 1.958 & -0.169 \\ 1.958 & 2.308 & -0.169 \\ -0.084 & -0.084 & 2.141\end{array}\right) \\ +90^{\circ} & \mathrm{S}_{\mathrm{ijBAR}}=\left(\begin{array}{ccc}0.370 & -0.117 & 0.000 \\ -0.117 & 0.333 & 0.000 \\ 0.000 & 0.000 & 2.857\end{array}\right) & \mathrm{C}_{\mathrm{ijBAR}}=\left(\begin{array}{lll}3.035 & 1.062 & 0.000 \\ 1.062 & 3.372 & 0.000 \\ 0.000 & 0.000 & 0.350\end{array}\right)\end{aligned}$


Material Constitutive Values

$\begin{array}{cccccc}\mathrm{A}_{11} & \mathrm{~A}_{12} & \mathrm{~A}_{22} & \mathrm{~A}_{66} & \mathrm{~A}_{16} & \mathrm{~A}_{26} \\ 0.3153 & 0.0809 & 0.3071 & 0.1104 & 0.0026 & 0.0026 \\ & & & & & \\ \mathrm{~B}_{11} & \mathrm{~B}_{12} & \mathrm{~B}_{22} & \mathrm{~B}_{66} & \mathrm{~B}_{16} & \mathrm{~B}_{26} \\ 0.001 & -0.001 & 0.001 & -0.001 & 0.000 & 0.000 \\ & & & & & \\ \mathrm{D}_{11} & \mathrm{D}_{12} & \mathrm{D}_{22} & \mathrm{D}_{66} & \mathrm{D}_{16} & \mathrm{D}_{26} \\ 0.000 & 0.000 & 0.000 & 0.000 & 0.000 & 0.000\end{array}$




\section{CHAPTER VI}

\section{RADOME TESTING}

\subsection{Shearography}

Given the main goal of this thesis, brief validation of the quality the test article was desired. Manufacturing defects could skew the results and effect the displacements, mode shapes and even possibly failure during the pressure testing. As a result of this need, Non-Destructive Investigation (NDI) was completed.

\subsubsection{Introduction}

There are many types of NDI currently used in the Aerospace Industry including, Ultra-Sonic Inspection and Shearography. Ultrasonic inspection is a form of NDI that can be applied to composites for locating internal discontinuities by the use of ultrasonic frequency reflection (reference \#3). A second form of NDI is Shearography, which the University of Akron has the facilities for.

Shearography is a form of NDI that can be applied to composites to determine internal flaws by the application of a pressure or change in temperature which causes a deformation recorded by a computer, camera and green laser field. Shearography uses Electronic Speckle Pattern Interferometer (ESPI), which allows one to measure the surface deformation of an object. The basic principle of ESPI is the continuous recording of a holographic speckle-pattern projected by a green laser on a photosensitive camera. This technique is used to observe the real-time deformation of the surface that is being investigated. ESPI produces results in the form of images 
which are scaled to a value inputted into the software, which provides quantitative deflection \& strain results (Reference 3. www.videsignline.com).

As an example, a composite helicopter blade can be inspected in production with vacuum excitation, while it can be rapidly inspected in the field with thermal excitation from a heat source, such as a heat gun or even a hairdryer. Typically light vacuum, thermal, acoustic or mechanical loading is used (Reference 1. trillion.com). Due to the scaling of deformation, a vacuum chamber is used for the investigation of the St.-Gobain $5135-200$

ESPI has been used in many fields, including the study and characterization of building materials, artwork conservation assessment, applications in the automotive industry, and in this application, researching manufacturing flaws. Most of the individuals present in the Polytec training seminar were engineers in the automotive industry performing vibration testing on vehicles in wind tunnels.

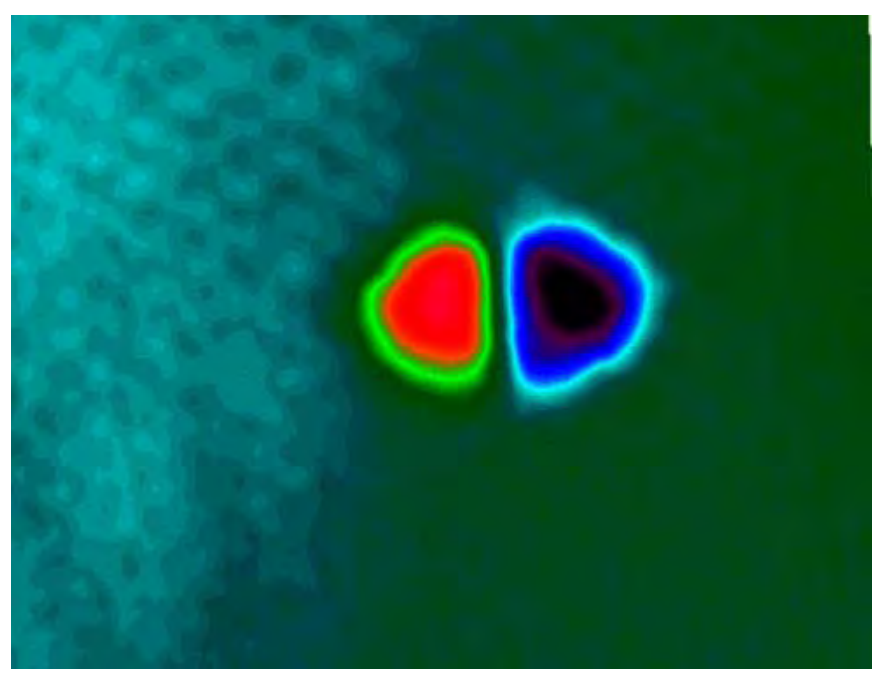

Figure 17) Example of Manufacturing Defect in Composite Structure (Reference 1. trillion.com) 


\subsubsection{Shearography Test Hardware}

The University of Akron has a Shearography testing system which was purchased from Trillion. The hardware consists of a camera which has the greenspeckle laser attached all connected to a computer which has the Trillion software installed. The following two figures depict the camera and computers used in the Shearography testing. As well as the vacuum chamber that encloses the radome and applies a pressure field to the radome sandwich structure.

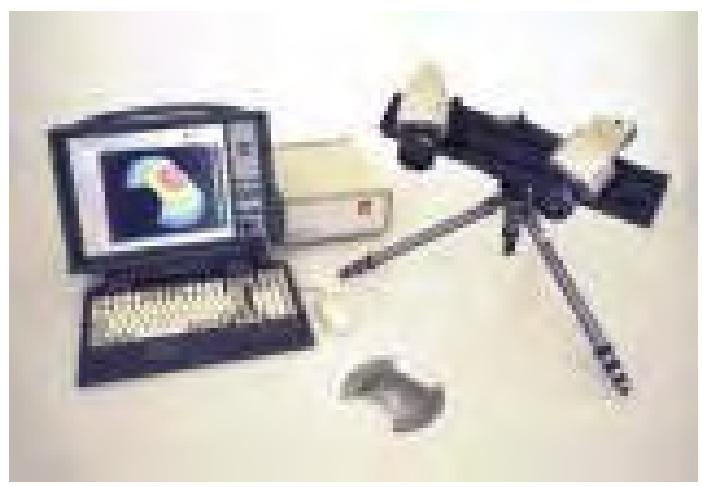

Figure 18) Example of Trillion Shearography Hardware (Reference 1. trillion.com) 


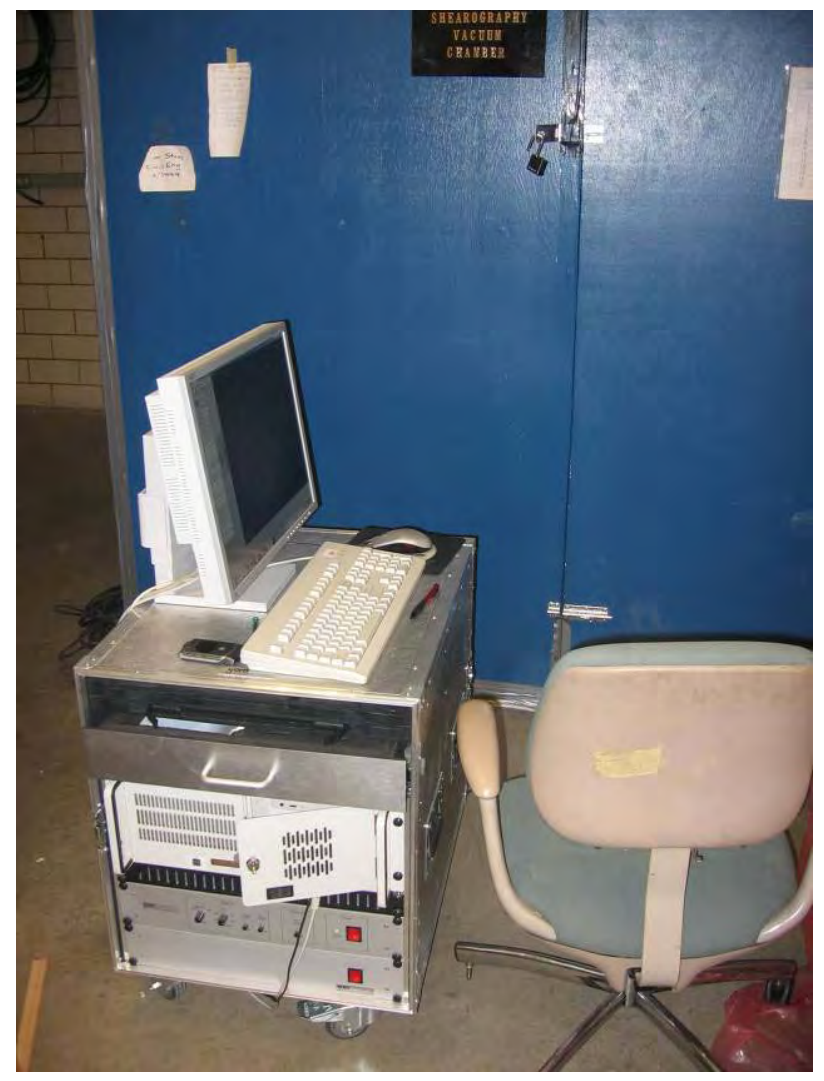

Figure 19) The University of Akron's Trillion Shearography Hardware

\subsubsection{Shearography Test Set Up}

Since the green speckle laser footprint is approximately 6 in $\times 6$ in (the camera being moved closer would increase the resolution) several vacuum and camera recording cycles were completed. To easily track the location of investigation, a grid was drawn on the radome. The stand which holds the camera and the green speckle laser orients the camera view parallel to horizontal. For this reason a test stand was fabricated to position the radome vertically for the camera system to view. The radome grid, the test stand and the entire test set up is depicted in the following figures. 


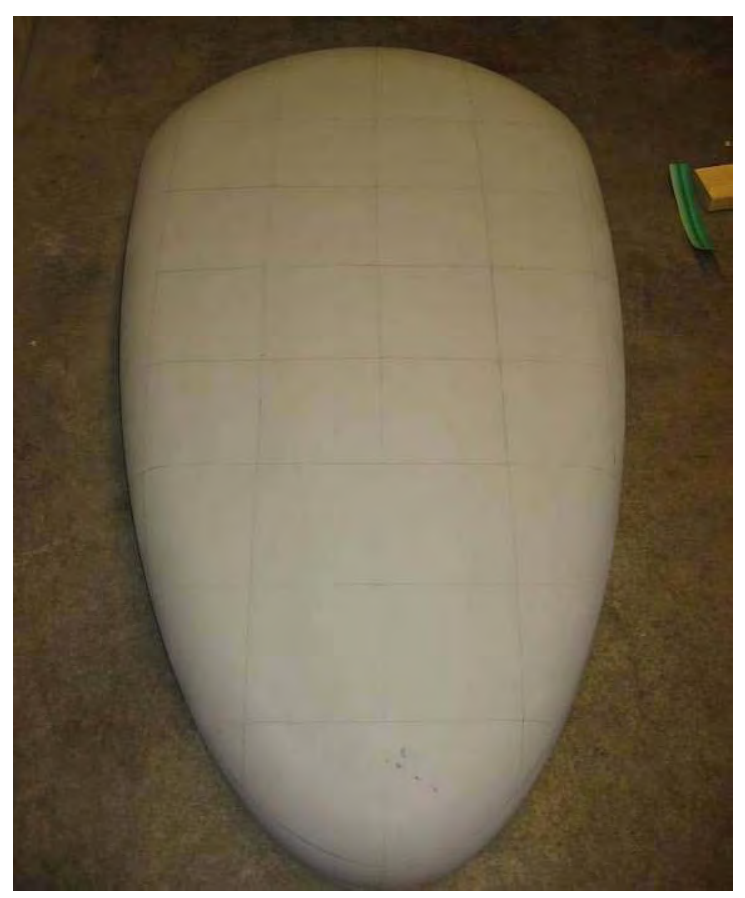

Figure 20) 5135-200 Radome - Shearography Investigation Grid

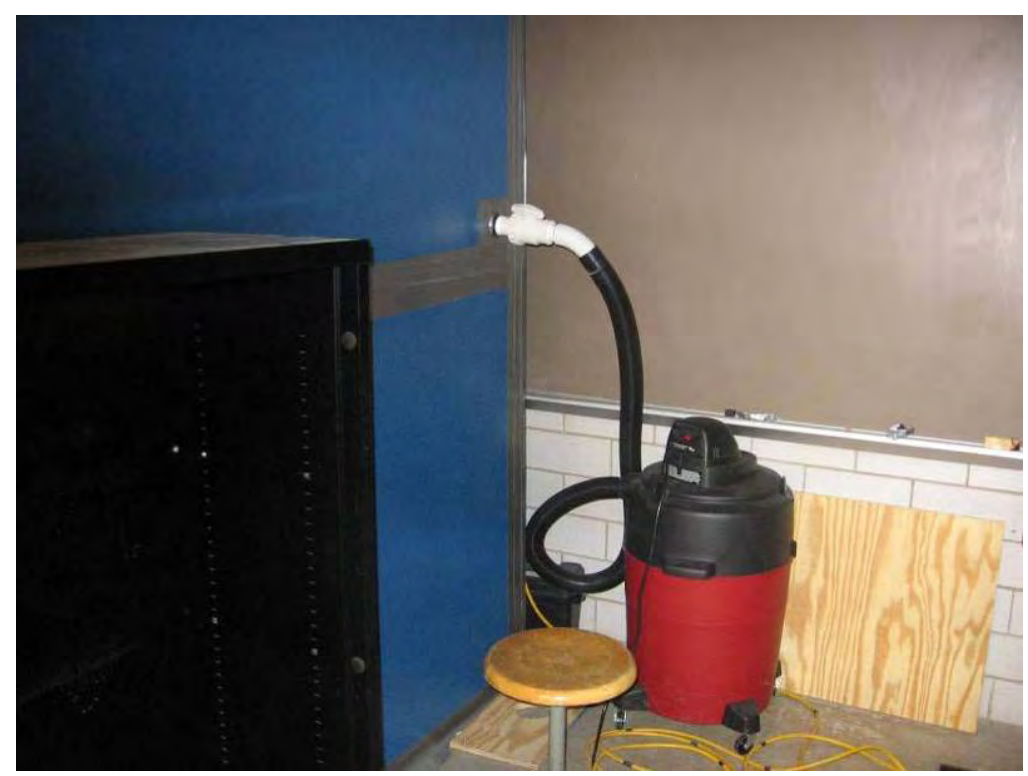

Figure 21) University of Akron's Vacuum Chamber 


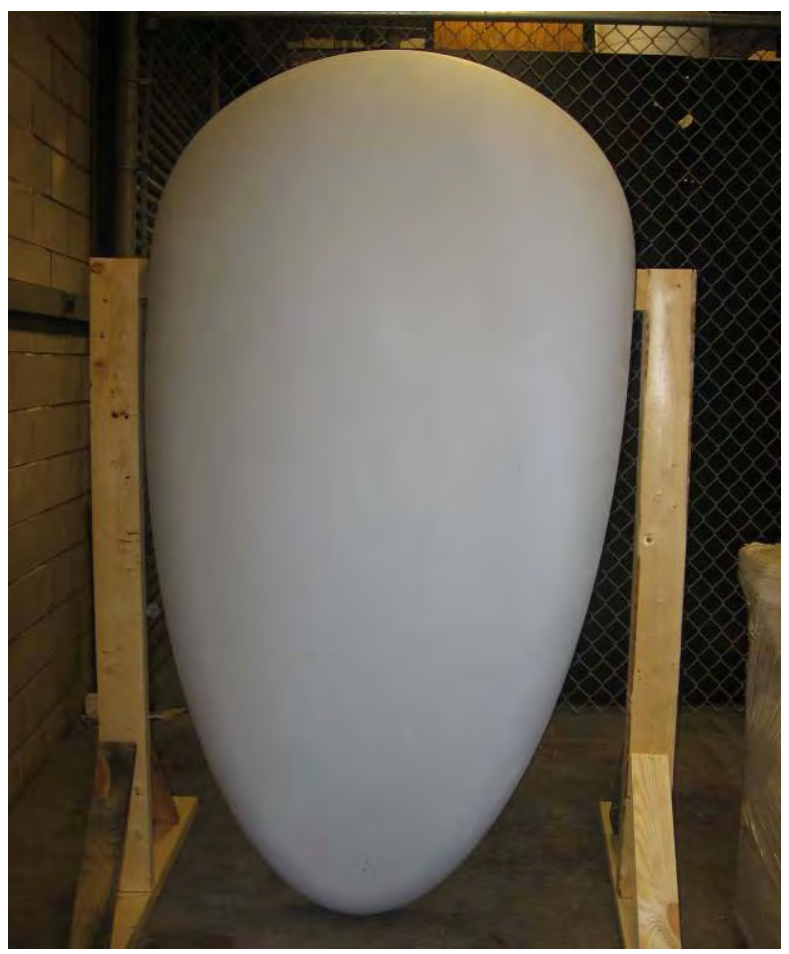

Figure 22) 5135-200 Radome Test Stand

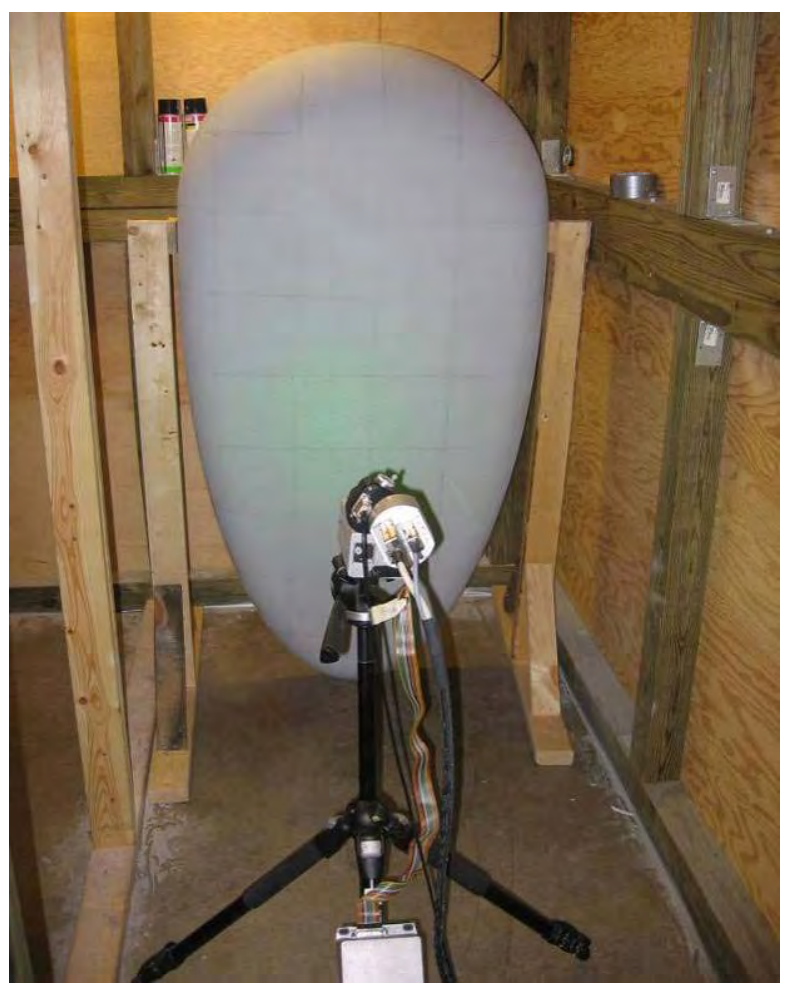

Figure 23) 5135-200 Radome Shearography Test Set-Up 


\subsubsection{Shearography Results}

In Shearography testing displacement irregularities for a structure under a certain force will draw attention to a possible manufacturing defect. Unfortunately, when there are no manufacturing defects present, the plots are not very interesting. For composites if the resolution is high enough, (ie the camera is close enough) the deflection of the laminate in the individual honeycomb cells is evident. In the case of the radome under test, there were no delamination or manufacturing defects found. All deflections seemed to be uniform throughout the sandwich structure. There were no lobed plots similar to Figure 17 which would lead one to believe a manufacturing defect is present. This testing was not a direct goal of the research, however after completion, it is determined that the radome should behave as predicted and that manufacturing defects are not evident. It would be very beneficial to research this area of testing more by creating test panels with known delamination(s) in both sandwich and solid laminate composite structures.

\subsection{Vibrometry}

A certain type of vibration that is encountered in aerospace application is the presence of vibrations in a random pattern. One problem with this occurrence is that since it is random it is not able to be predicted.

\subsubsection{Introduction}

On average for the typical type of aircraft that this radome is installed, the natural frequencies are wished to be above $75 \mathrm{~Hz}$, which will keep one of the modes of the fuselage from causing unwanted vibrations in the radome. For this reason in is desirable to determine the frequencies at which a structure is excited causing unwanted vibrations. Luckily testing methods and more recently computer analysis programs enable engineers to predict and design around certain frequencies which may cause excess 
vibration. Finite Element software allows the possibility to analyze both natural frequencies and a frequency response under different boundary conditions. For natural frequencies, Nastran will calculate eigenvectors or the normal mode/mode shape under the given boundary conditions, material properties and mass. The normal mode corresponds to the deflected shape patterns of the shape being analyzed. When a certain structure is being excited the deflected shape at a certain time is a combination of its normal modes. A simplified example of these modes can be seen in the following figure for a simply supported Beam

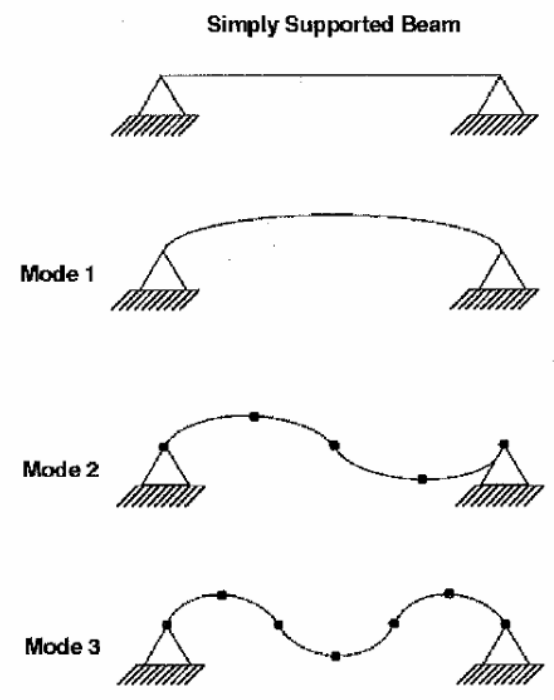

Figure 24) Simply Supported Beam Mode Shapes (Reference 10. Nastran Manuals) For the "Hands On" type of Engineer and for the validation modification of finite element models, Vibration testing can also be performed. This can be done by many methods the most common being setting up the test article on a large vibrating plate and measuring the acceleration at certain points with an accelerometer. While this is a very acceptable and widely used method the field of Vibration testing and measurement is pushing forward. An example of another test method uses a shaker which is attached to 
a structure at vibrates at a known frequency. The surface velocity can then be measured by a laser very similar to the laser used by police officers for traffic control. The University of Akron has a system created by Polytec which uses the technology of Laser Doppler Vibrometry (LDV). LDV is a non-contact vibration measurement that was used to determine the natural frequencies and mode shapes of the 5135-200 Saint Gobain Composite Radome Structure. LDV is based on the principle of the detection of the Doppler shift of light that is reflected from the test object. A measurement beam is focused on the radome and reflected back to the interferometer which measures the differing distance of the wavelengths.

An example of an interferometer as known as the Michelson Interferometer:

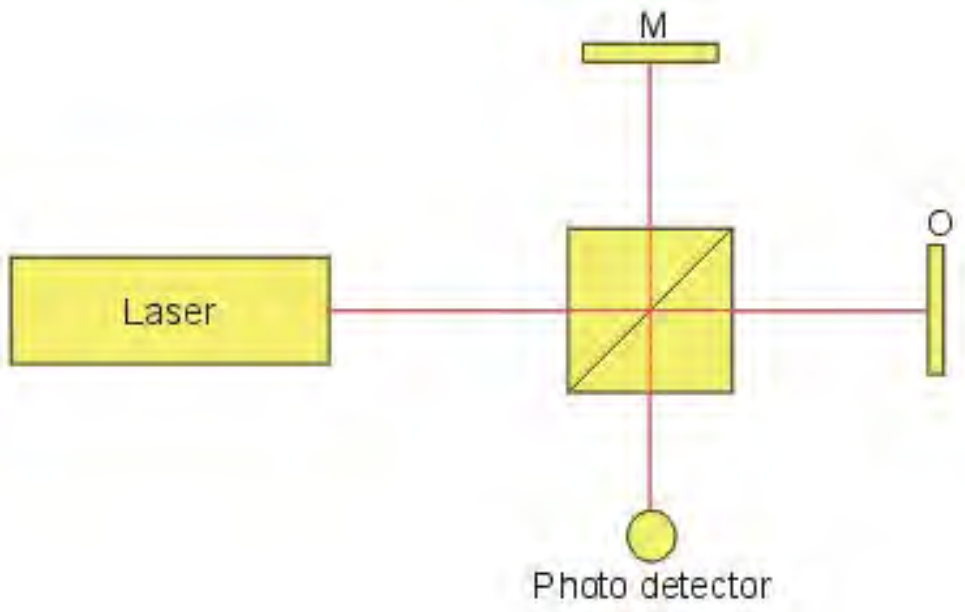

Figure 25) Michelson Interferometer (Reference 5. Polytec)

Shown in Figure 1, a laser beam is focused at an object $(O)$ and divided at a beam splitter into a measurement beam $(\mathrm{M})$ and a reference beam which propagates in the arms of the interferometer. The laser consists of an optical cavity which consists of the lasing material with a mirror at each end. The light which is repeatedly reflected between the two mirrors, which one is only partially reflecting, and a small laser 
beam is deflected that is focused through the laser hole. The two equations below define the Reference Phase and the Measurement Phase (Reference 5. Polytec):

$$
\begin{gathered}
\text { Reference: } \quad \Phi_{R}=2 k x_{R} \\
\text { Measurement: } \quad \Phi_{M}=2 k x_{M} \\
\text { Where } k=2 \pi / \lambda \\
\text { And } \Phi(t)=\Phi_{R}-\Phi_{M}
\end{gathered}
$$

The rate of change of phase $\Phi$ is proportional to the velocity $(V)$ of the surface. This leads to the well known formula for the Doppler frequency $f_{D}$ :

$$
f_{D}=2 \mathrm{~V} / \lambda
$$

The Doppler Frequency is used to calculate the velocity at the reference point. When the entire set of points defining the surface is scanned, the software can plot the modal frequencies and modal shapes by applying the applicable formulas. To reiterate, the laser hardware measures the phase shift which is entered into to the software automatically which calculates the velocity and displacement. Viewing the displacement response as a function of the excitation frequency, the modal shapes \& frequencies can be determined. 


\subsubsection{Hardware}

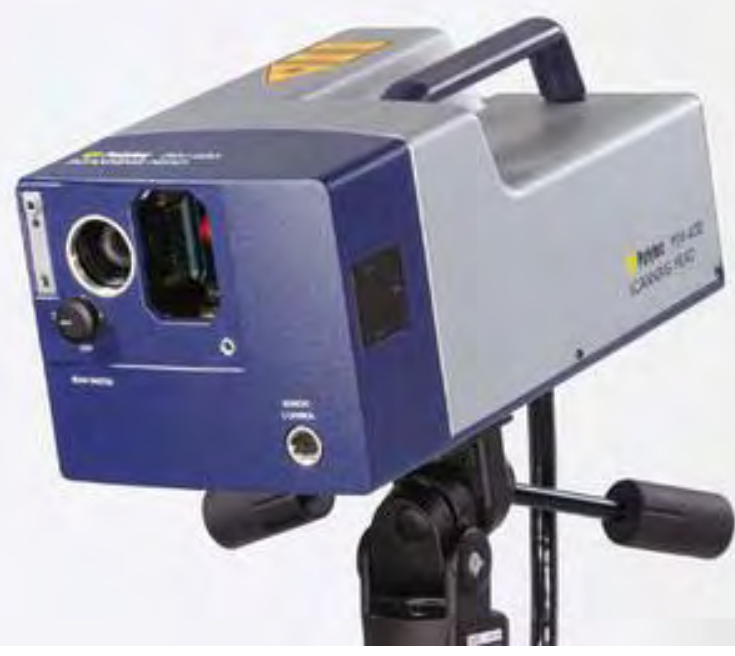

Figure 26) University Of Akron PSV-400 Camera

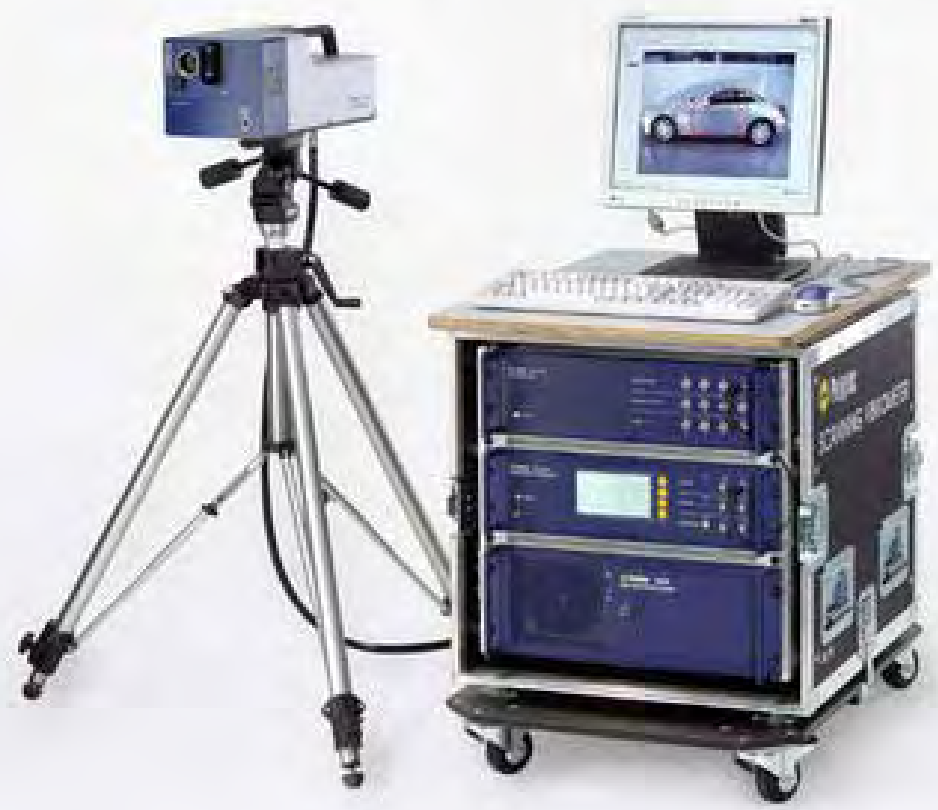

Figure 27) University Of Akron PSV-400 Laser Vibrometer System

\subsubsection{Test Set Up}

The vibration testing was completed using a few different boundary conditions and many varying excitation frequency sweeps. The first boundary condition was an 
attempt for free-free boundaries. As learned in the Polytec training course, free-free boundary conditions make it easier to excite more of the mode shapes than a fixed boundary condition. Also to more accurately portray the accurate boundary conditions as installed on the aircraft, the edges of the radome were fixed. The series of tests under the fixed boundary conditions required a higher power input to excite a less amount of natural mode shapes.

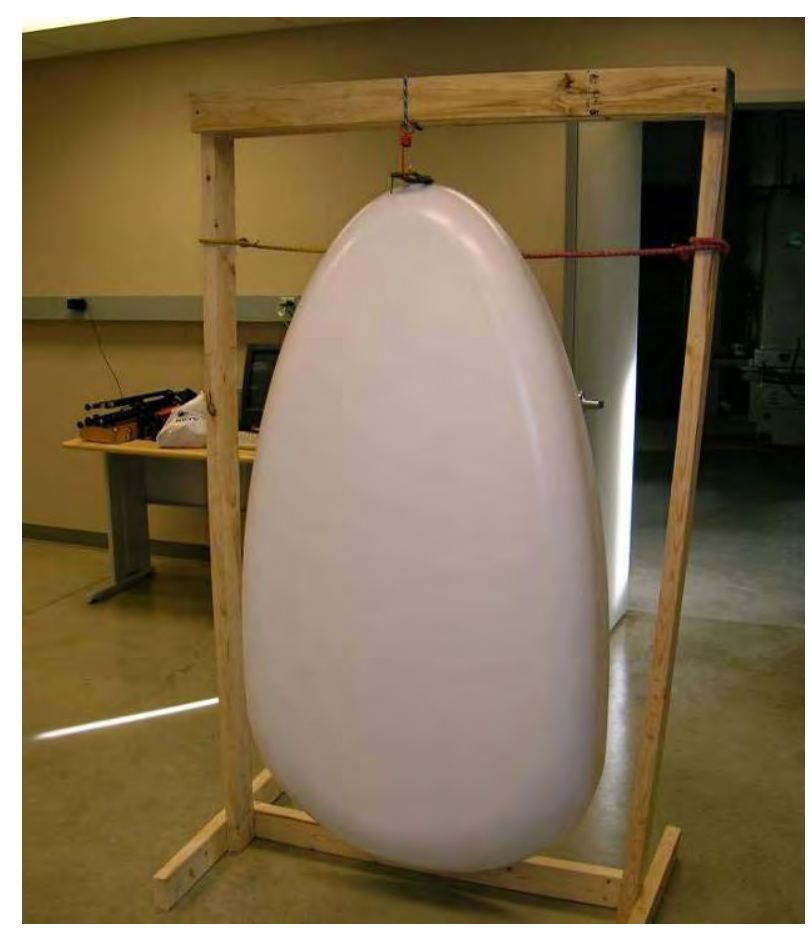

Figure 28) 5135-200 Vibrometry Radome Stand

The distance between the scanning laser head and the radome was varied to determine the sensitivity of the scanning distance for data validity. It was determined that the data is accurate and varies minimally for the distances that were tested. Notice that the radome is painted white for Vibrometry for optimal laser performance. 


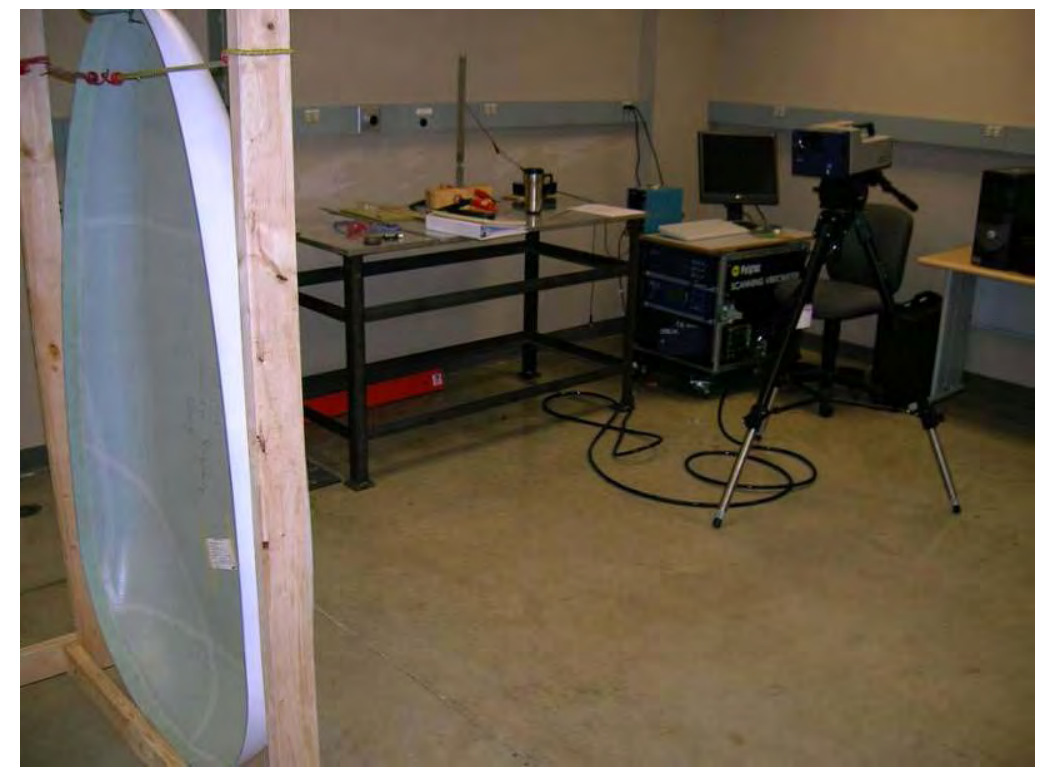

Figure 29) 5135-200 Vibrometry Test Set-Up

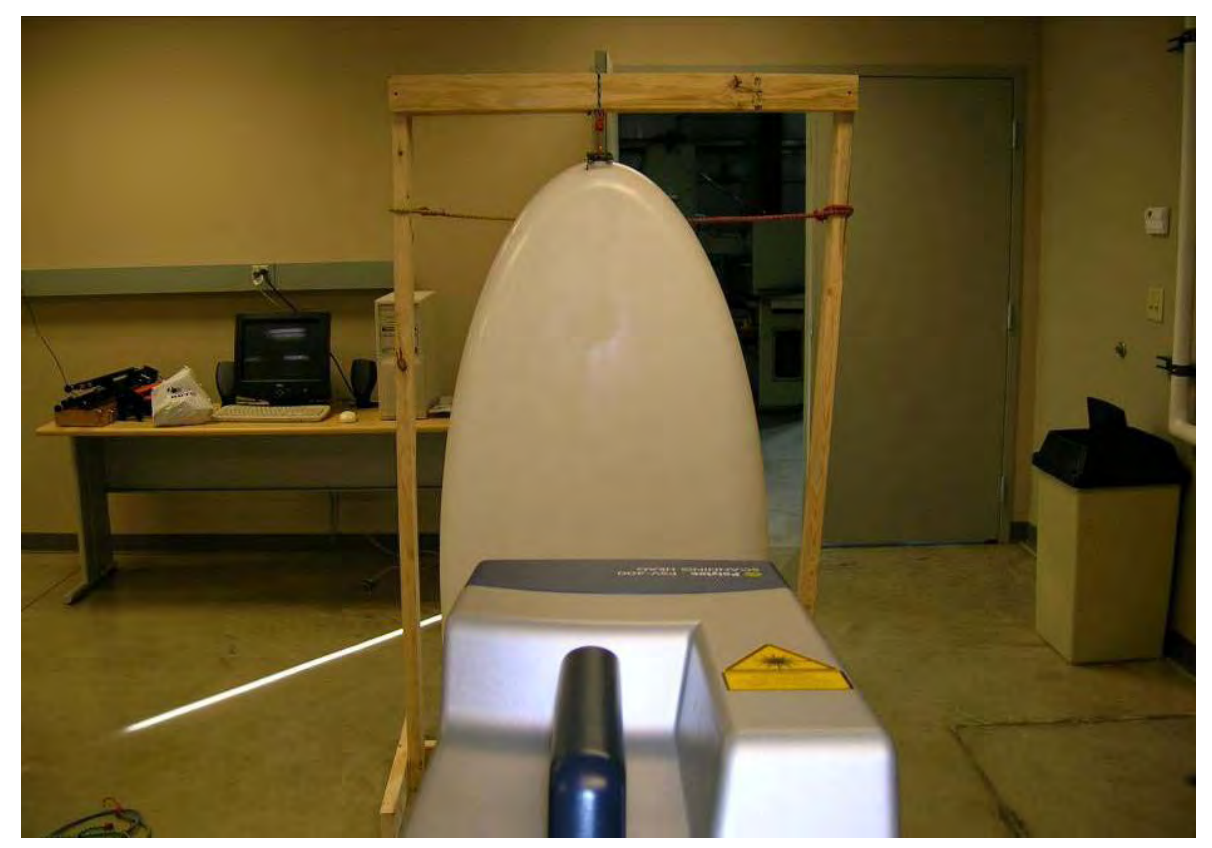

Figure 30) 5135-200 Vibrometry Test Set-Up 


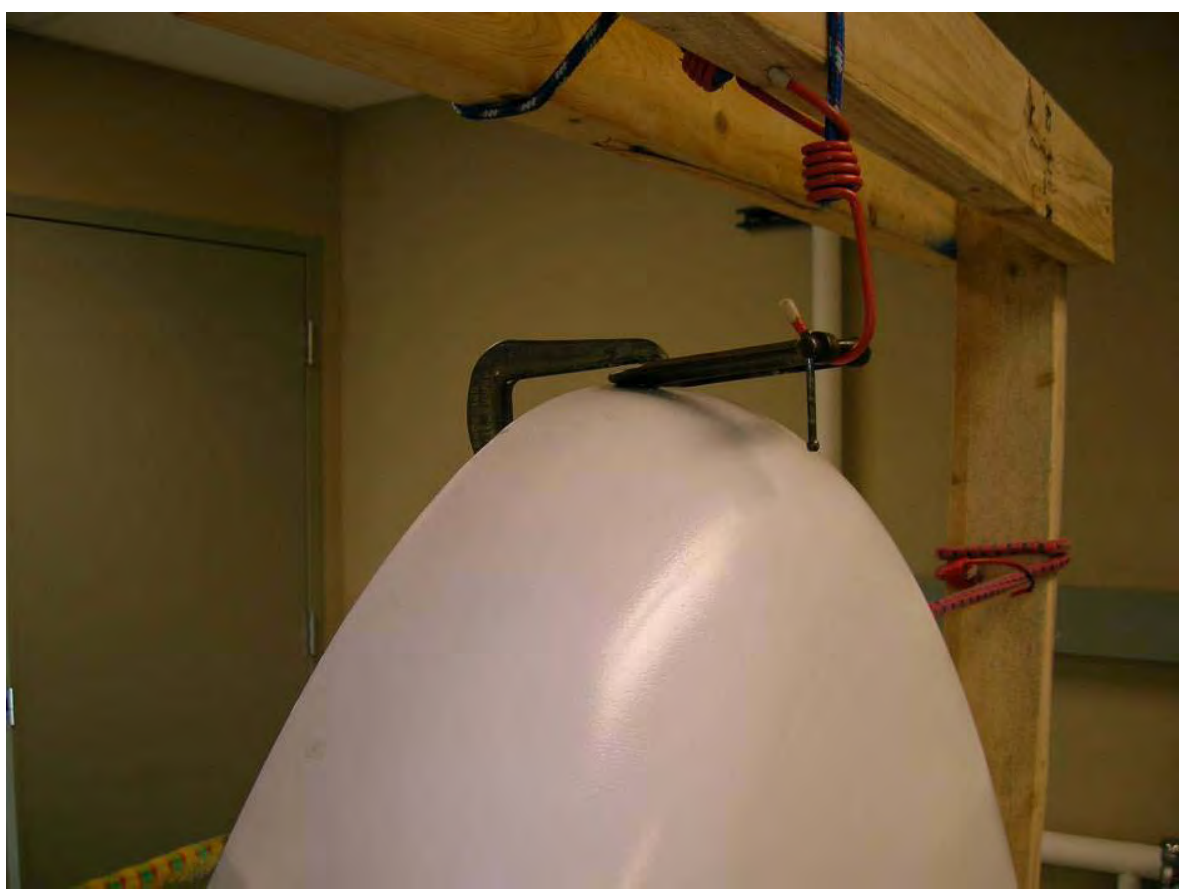

Figure 31) Radome/Clamp Test Set-Up Detail

The polytec vibrometry software allows the user to select from a series of different excitation sweeps such as sine sweeps, burst chirps, random chirps and white noise. Most of these methods produced acceptable results; however the white noise method of excitement seemed to provide the clearest results in terms of displacement vs. frequency.

\subsubsection{Software Set-Up}

After the radome, shaker and scanning laser are all in position. The grid needed to be drawn in the software to represent the scanning boundary. For this process, a set of predefined shape such as squares or circles can be used, however since the footprint of the radome is not a simple shape a closed poly-line was created. After the poly-line is closed a grid of blue points shows up, this is shown in the following figure. This is very similar to a finite element mesh and represents the points where the scanning laser head will measure surface velocities. The next figure shows the main Vibrometry screen where the focus is automatically optimized by using the focus-scan points command. 
This focusing optimizes the intensity of the laser for the points to produce the most accurate results. In this screen, one point can be selected and the distance from the head of the laser to the selected point can be entered.

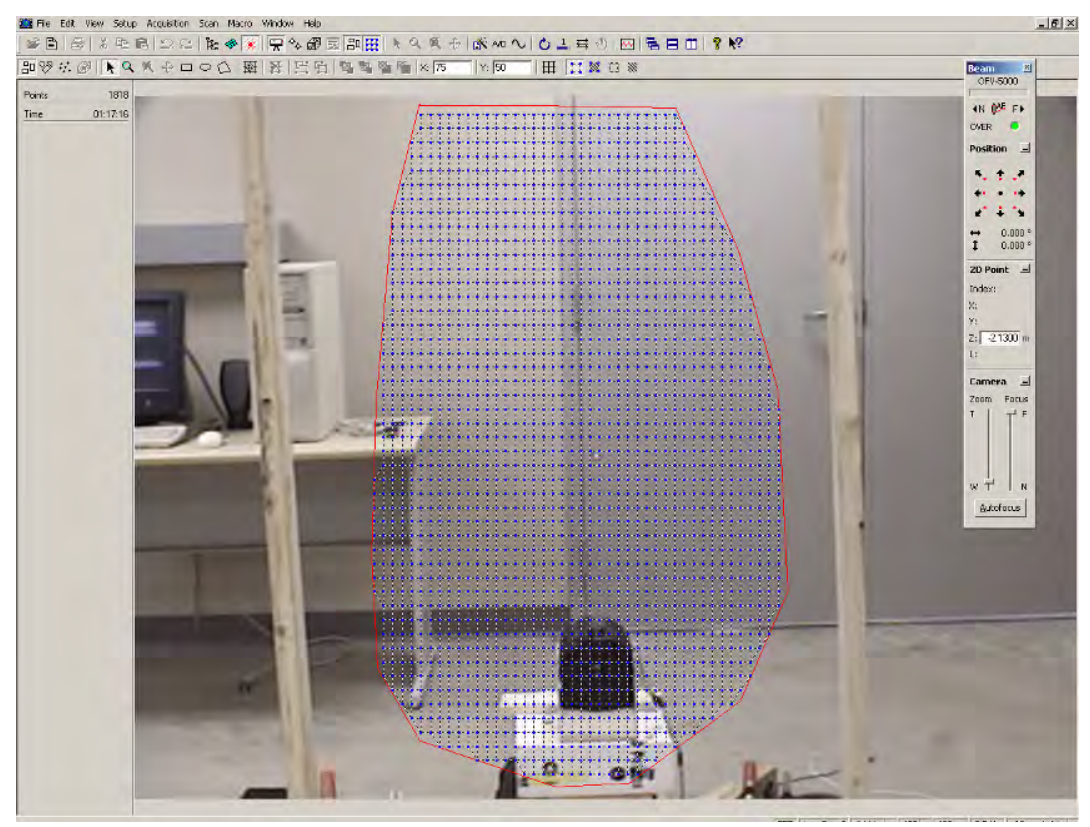

Figure 32) Grid Outline for Laser Scanning Points

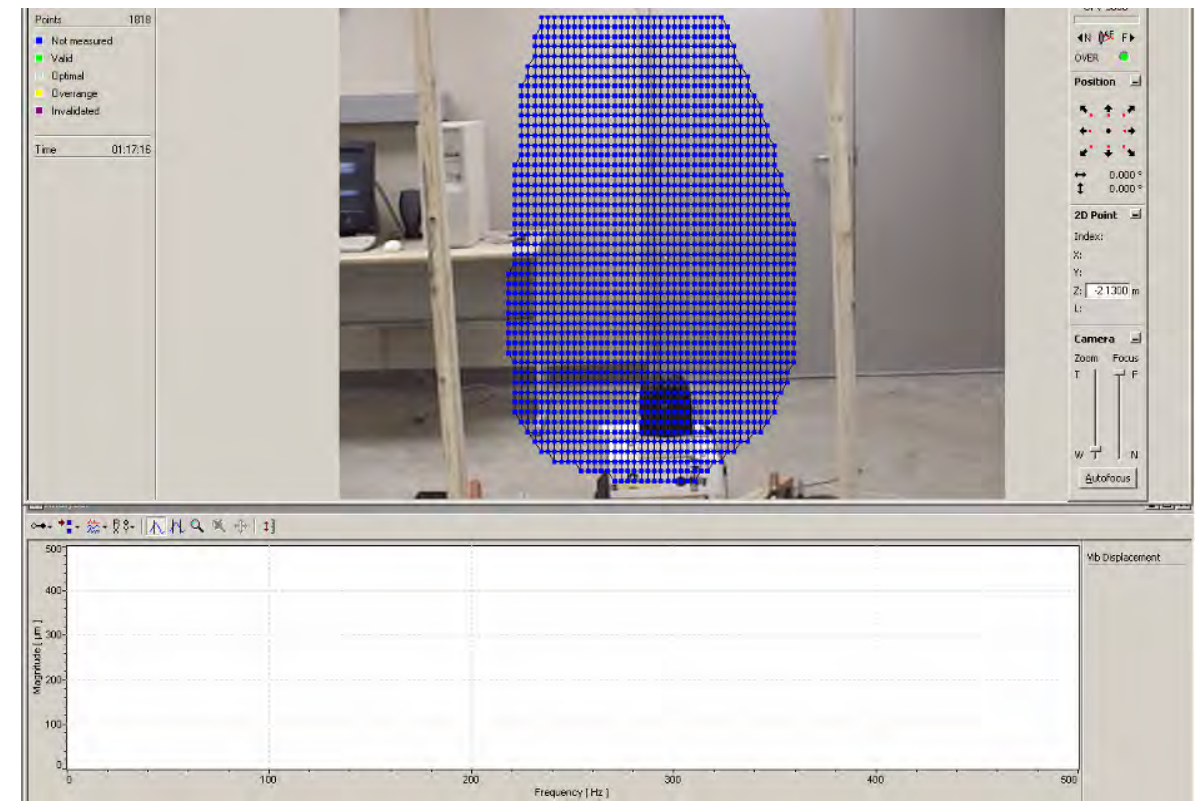

Figure 33) Main Vibrometry Screen 
After the grid has been created and the laser has been focused for the specific distance of the test article, the acquisition settings must be entered. For the radome vibrational testing the Fourier transform (FFT) Measurement mode was used for all runs and a complex averaging value of three was selected. This averaging setting was suggested at the Polytec training course for accurate measurements. When the scanning laser records a displacement at a certain frequency, it will actually take three measurements and average the result, thus improving the accuracy.

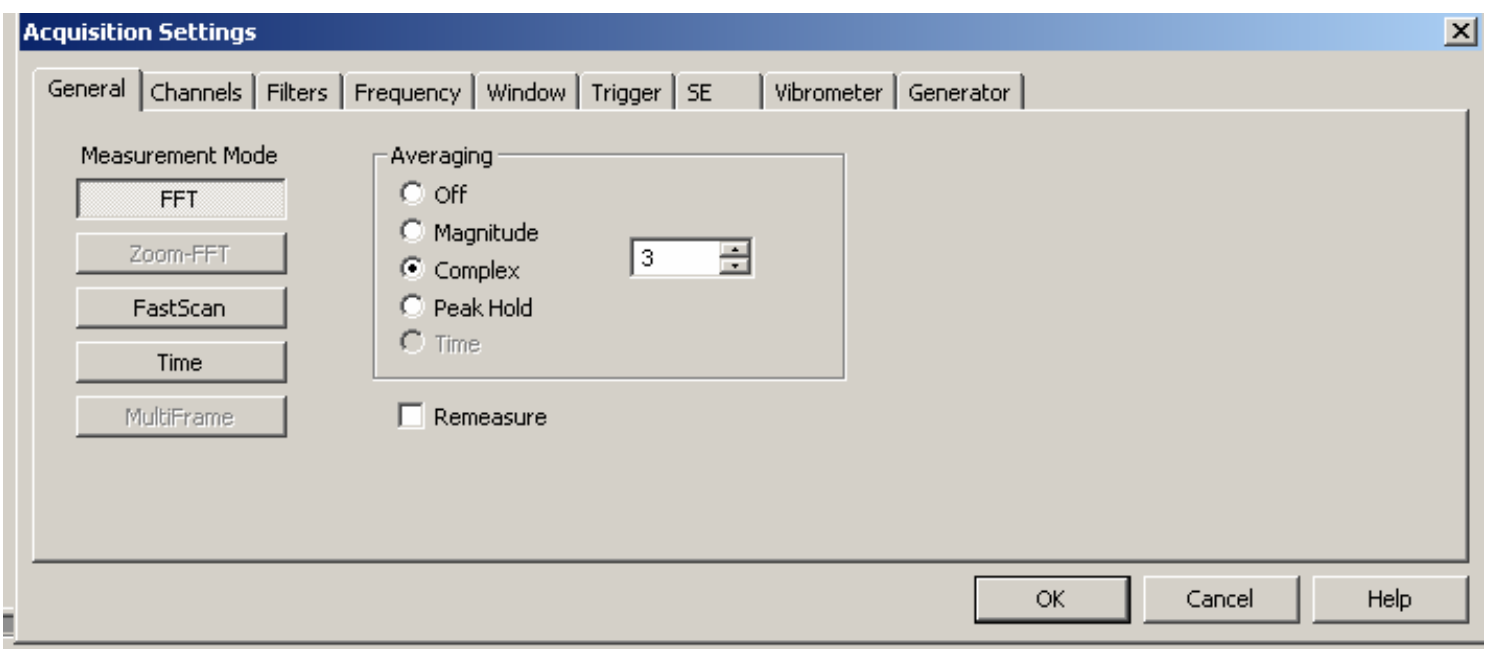

Figure 34) Acquisition Control Window - General Settings

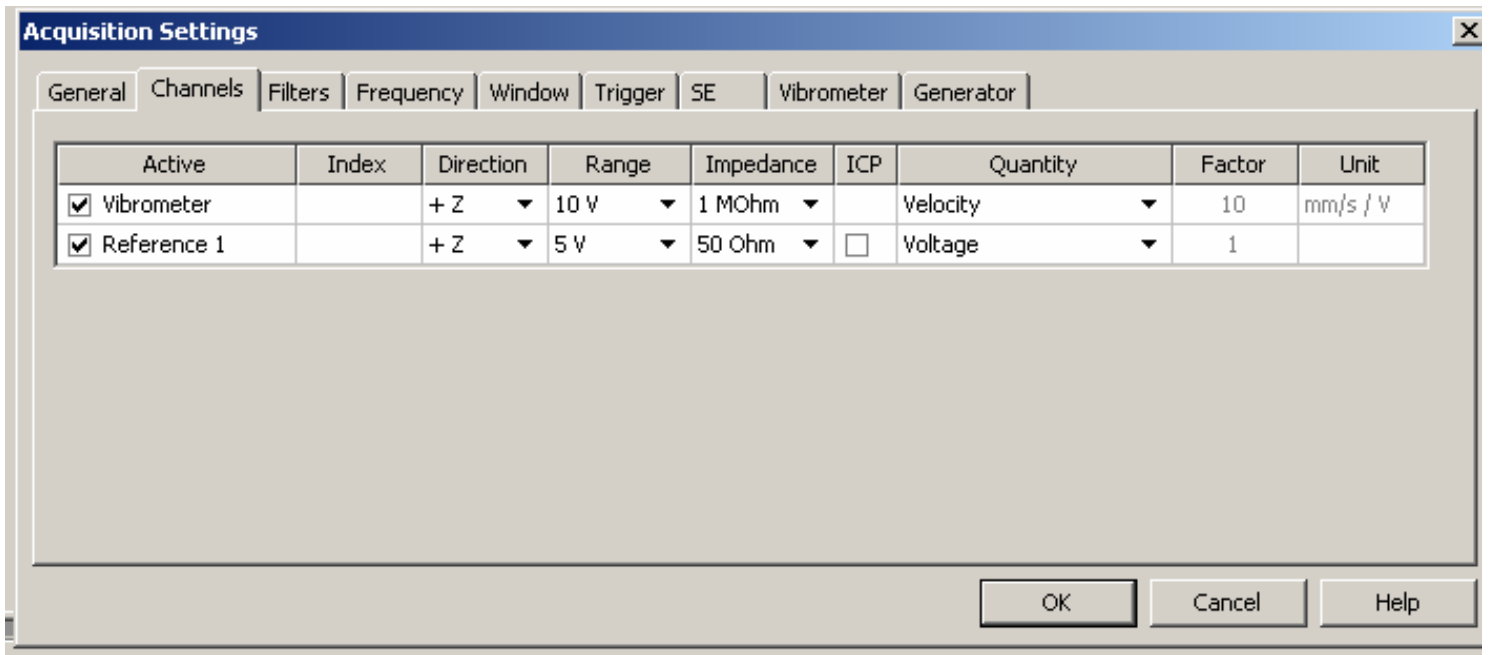

Figure 35) Acquisition Control Window - Acquisition Settings 
The figures above show the general settings and the channels or input for the software. The Vibrometer check box shown in the previous figure is the scanning Vibrometer with the settings and Reference 1 is the amplified which is directly connected to the shaker. The next set of input entered is the frequency settings where the bandwidth and FFT lines are entered, which basically sets the range and individual frequency steps used in the measurement. The higher the FFT line value the greater the resolution in terms of frequency however it is directly proportional to the run time.

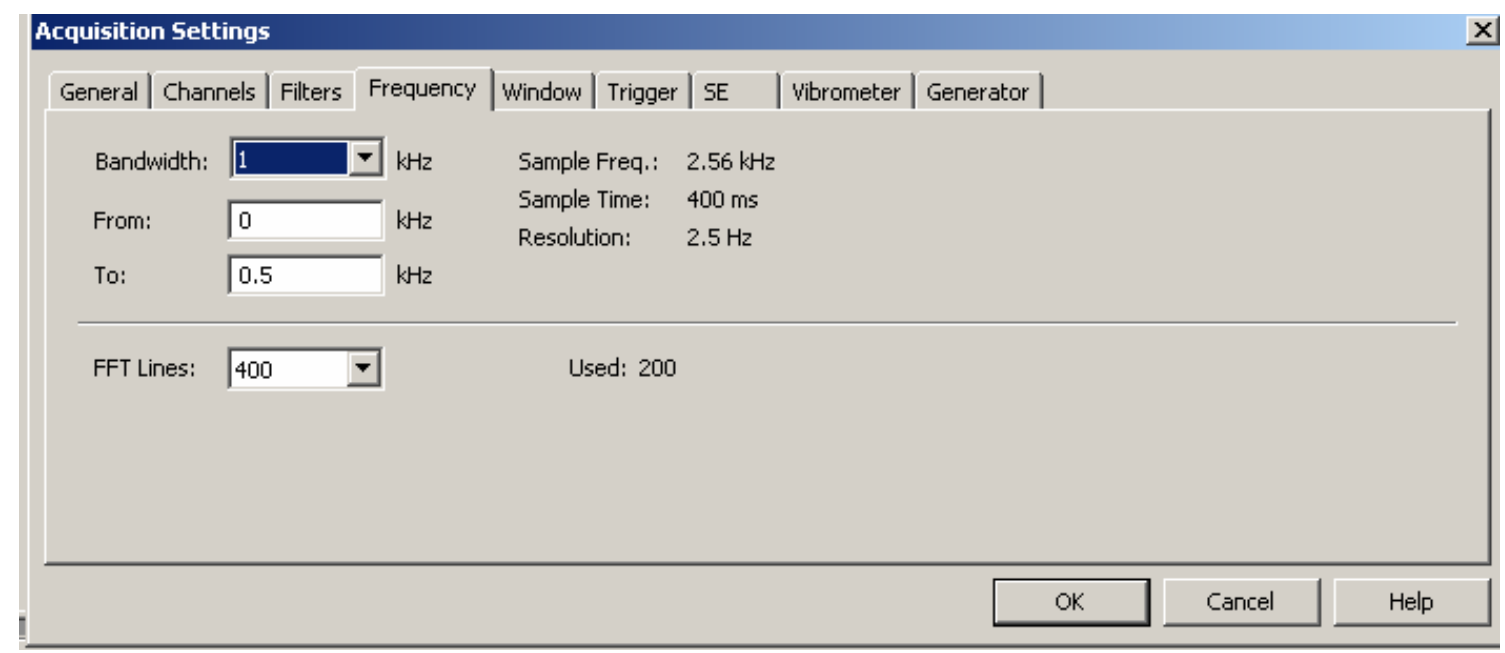

Figure 36) Acquisition Control Window - Frequency Settings

Several of the other tabs not explained were left as a default and are used for optimizing measurements and for other generator types which were not used. The last acquisition setting entered is the generator setting where the specific type of waveform is selected. The waveform options include Sine sweep, Periodic Chirp, Pseudo Random, Burst Chirp, Burst Random, White Noise, Square, Triangle and Ramp. 


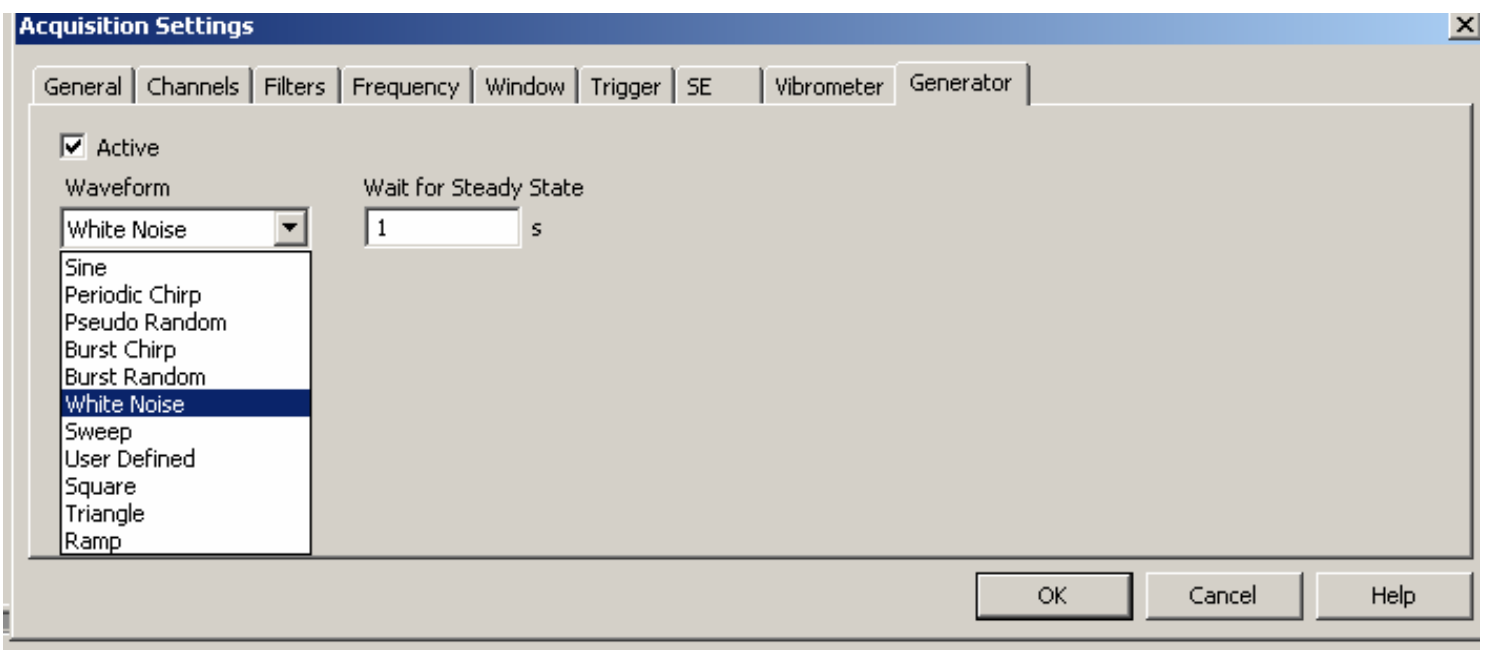

Figure 37) Acquisition Control Window - Generator Settings

\subsubsection{Vibration Testing Results}

The first boundary condition mentioned previously, was the radome being supported at one point at the bottom of the edgeband. The following figure shows the interactive result screen for the Polytec software. The graph at the bottom is set to show the displacement as a function of frequency. When a peak on the curve is selected the figure above shows the displacement range and the deflected radome contour and shape. There is also an option to animate the mode shape at the selected frequency. After the initial spike that appears in the lower frequencies, a small peak seems to appear at $80 \mathrm{~Hz}$, followed by a spike at approximately $125 \mathrm{~Hz}, 160 \mathrm{~Hz}, 220 \mathrm{~Hz}$ and 290 $\mathrm{Hz}$. The following figures show the deflected radome contour and the overall average deflection as a function of the excitation frequency. The first series of figures is for the test set up with one fixed point and the four fixed points follow. 


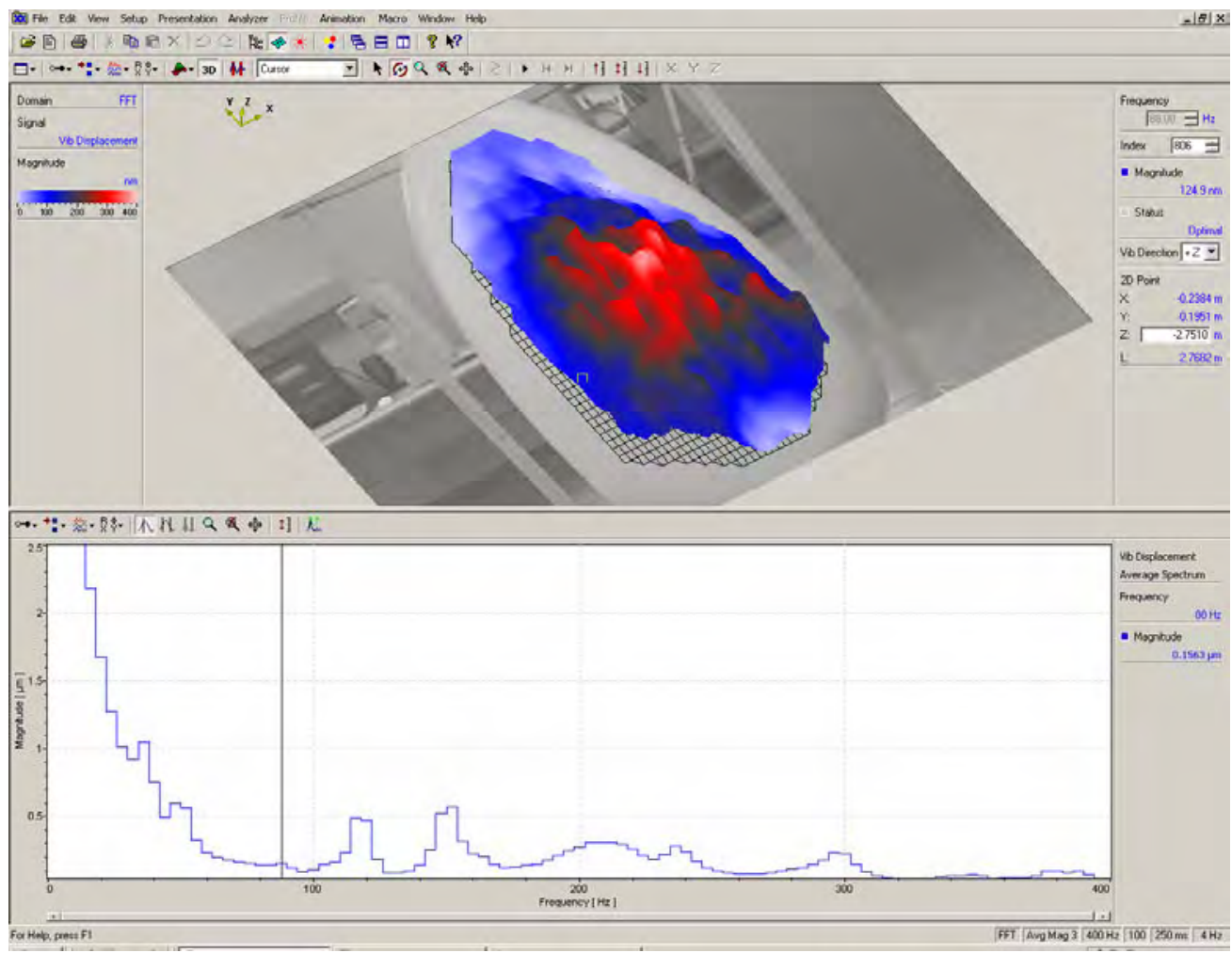

Figure 38) 1 Fixed Node $-88 \mathrm{~Hz}$

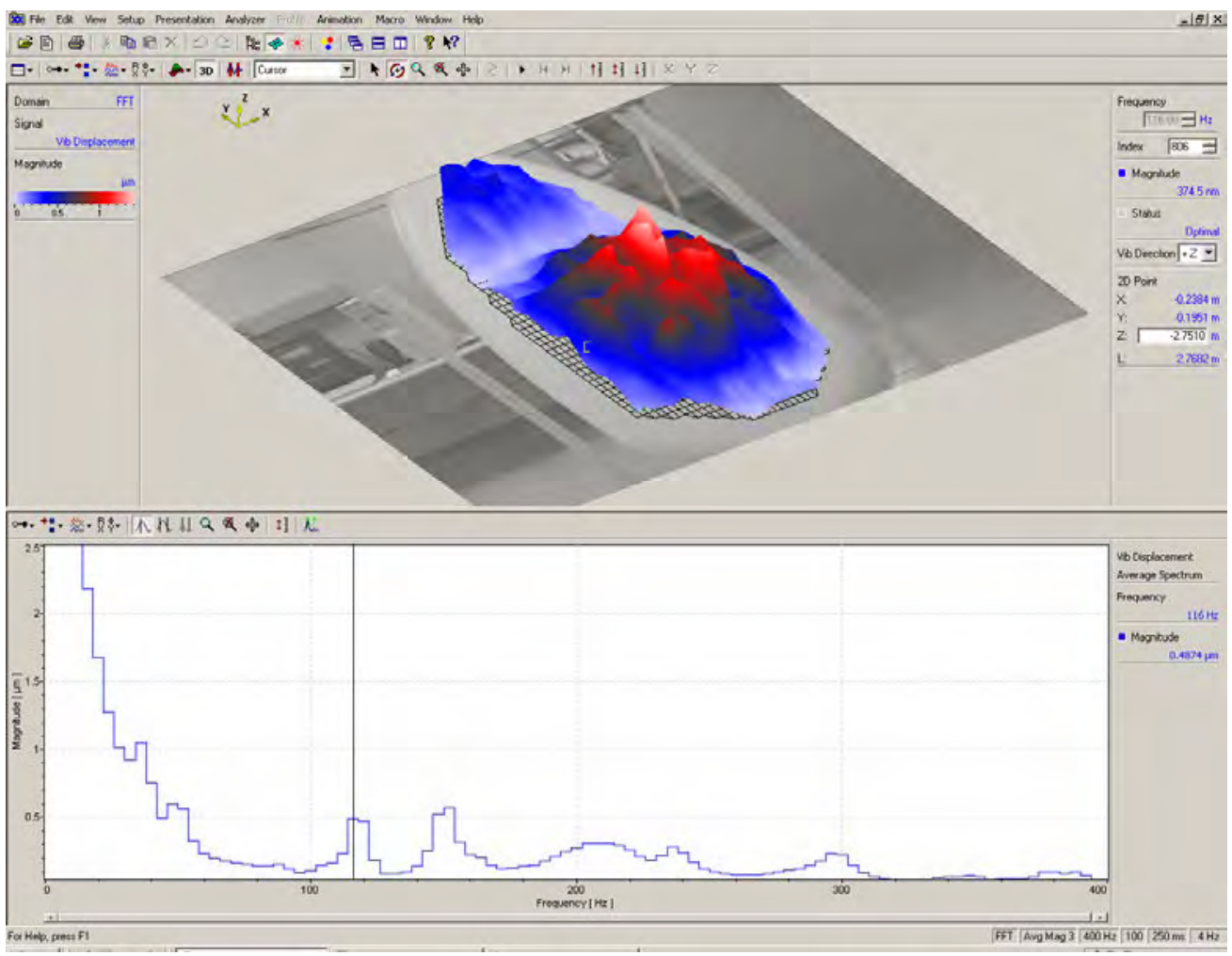

Figure 39) 1 Fixed Node $-116 \mathrm{~Hz}$ 


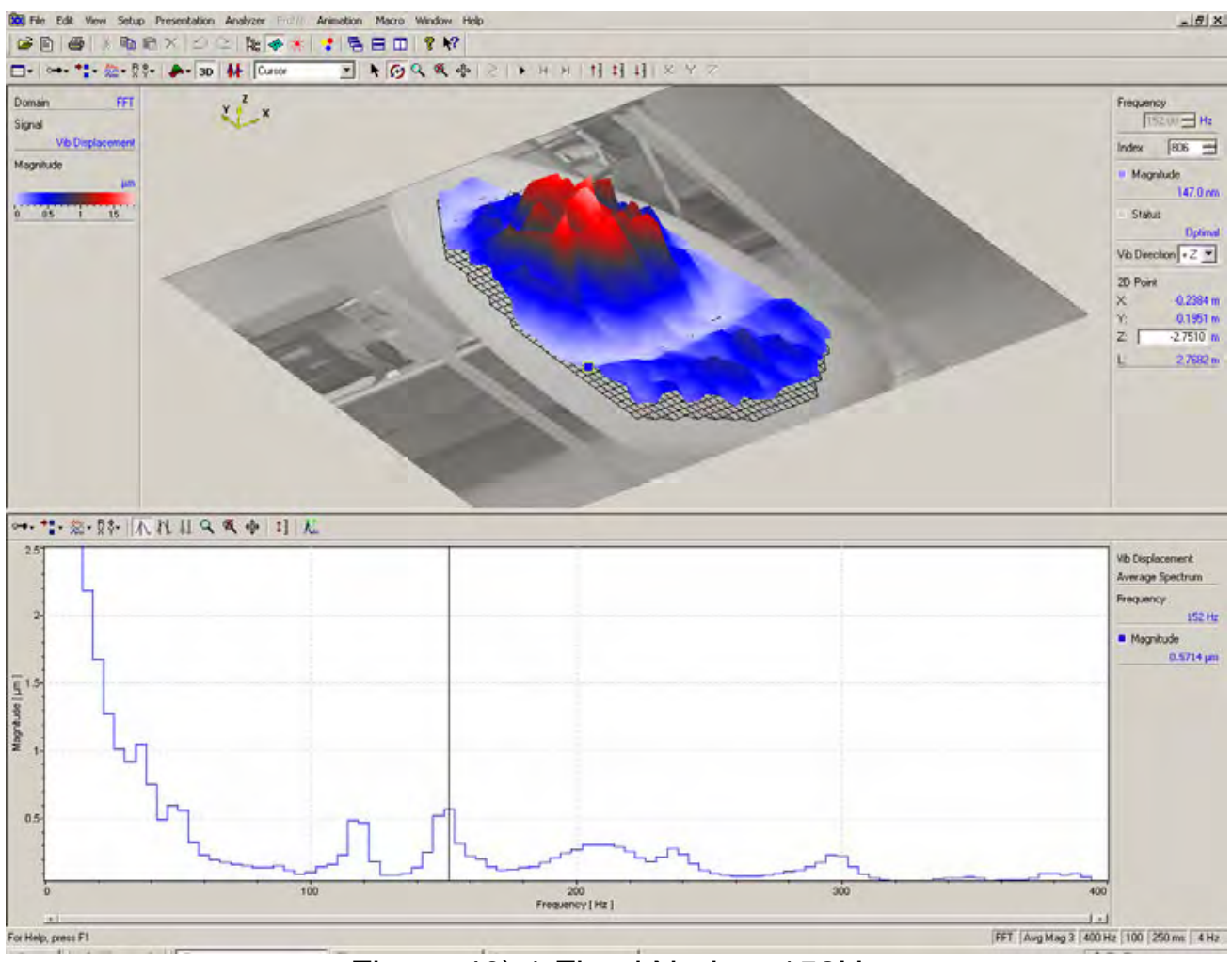

Figure 40) 1 Fixed Node $-152 \mathrm{~Hz}$

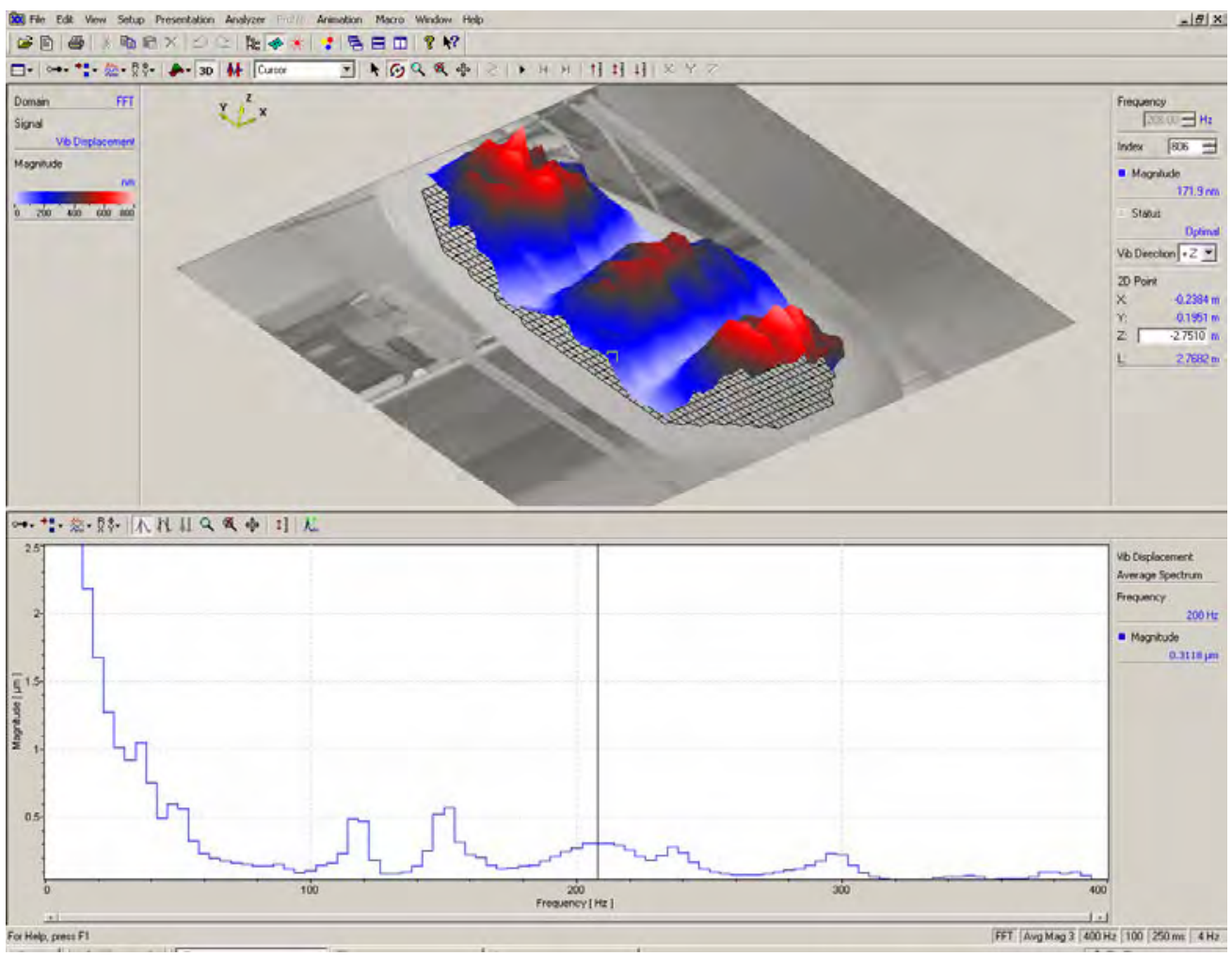

Figure 41) 1 Fixed Node $-208 \mathrm{~Hz}$ 


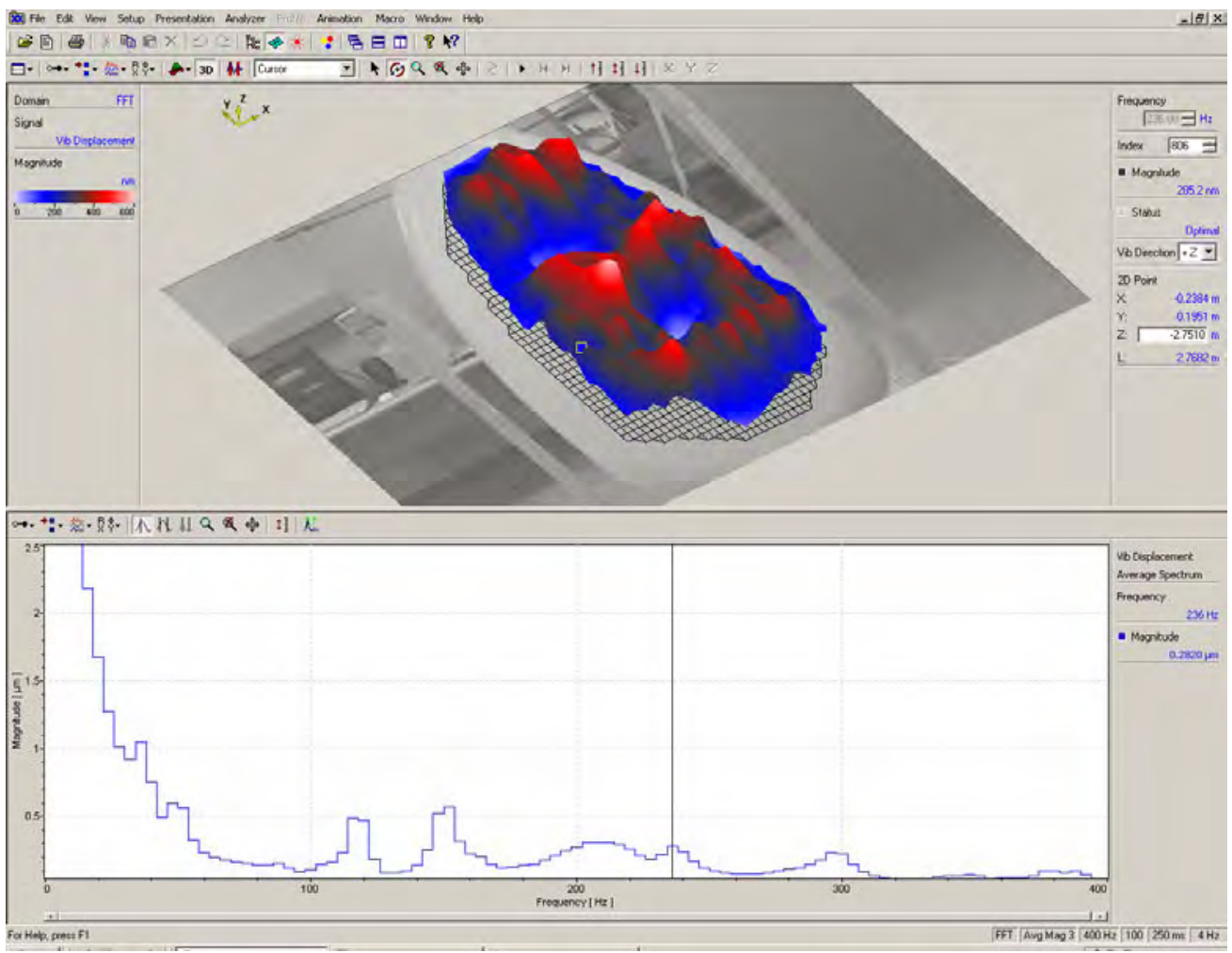

Figure 42) 1 Fixed Node - $236 \mathrm{~Hz}$

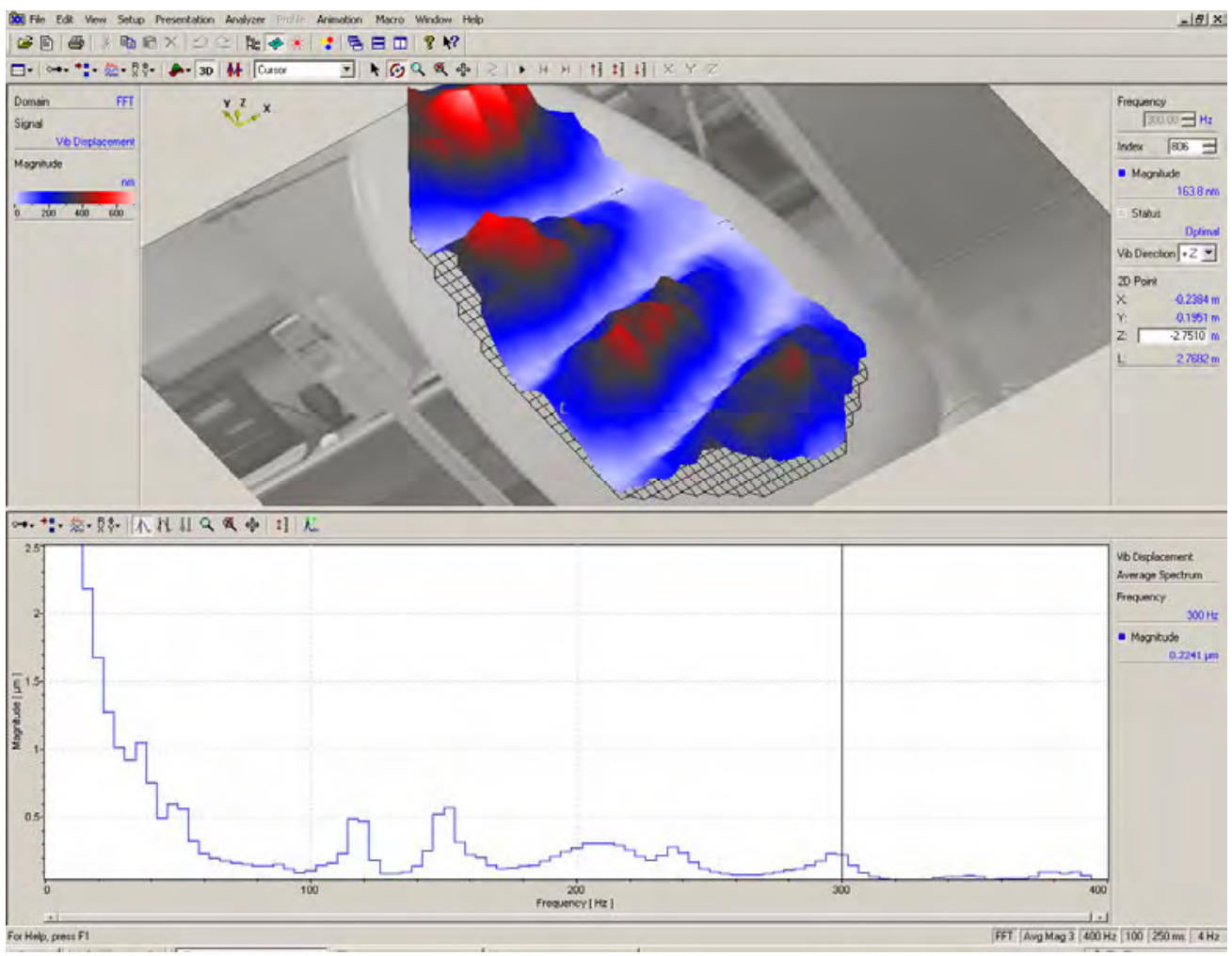

Figure 43) 1 Fixed Node $-300 \mathrm{~Hz}$ 


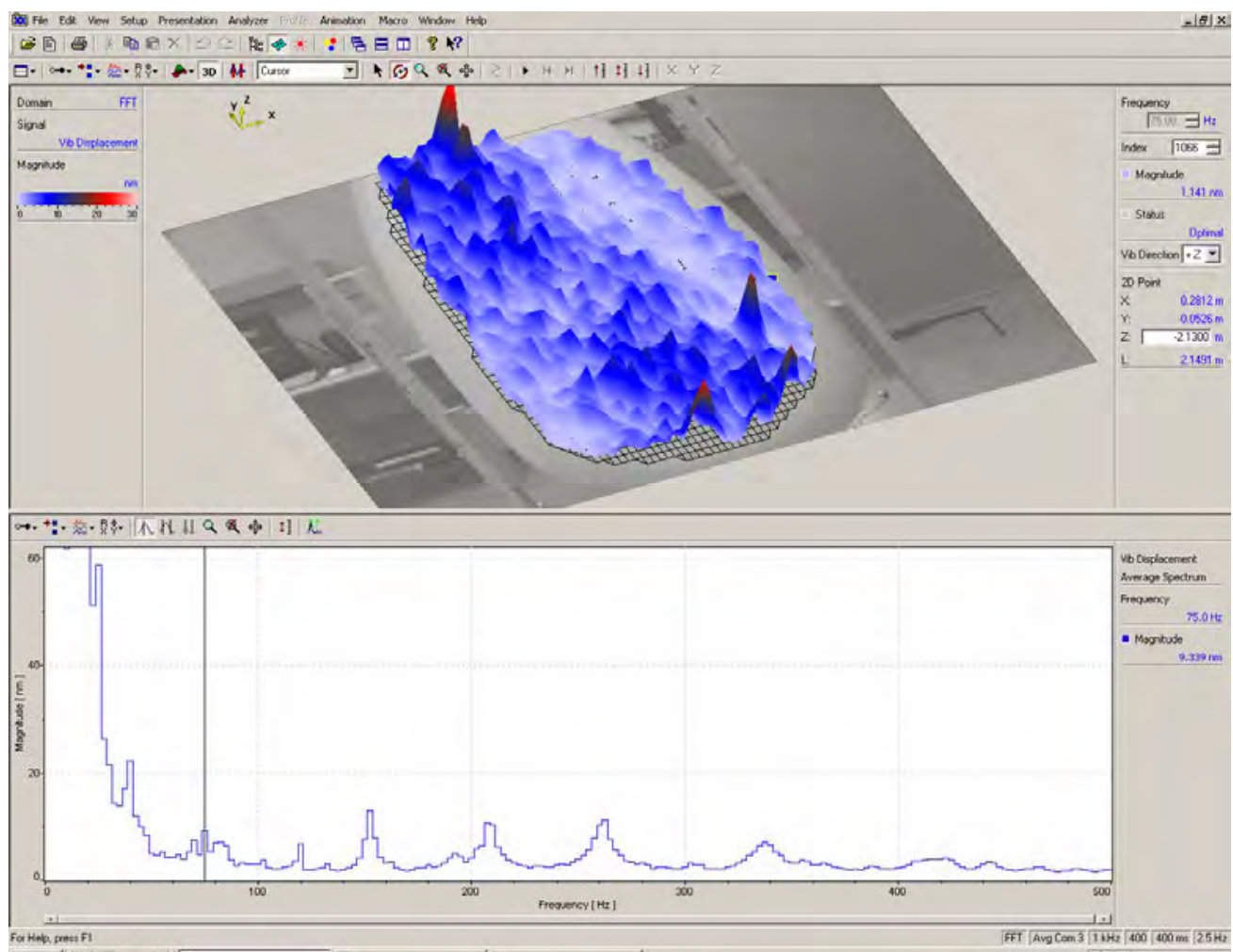

Figure 44) 4 Fixed Nodes - $75 \mathrm{~Hz}$

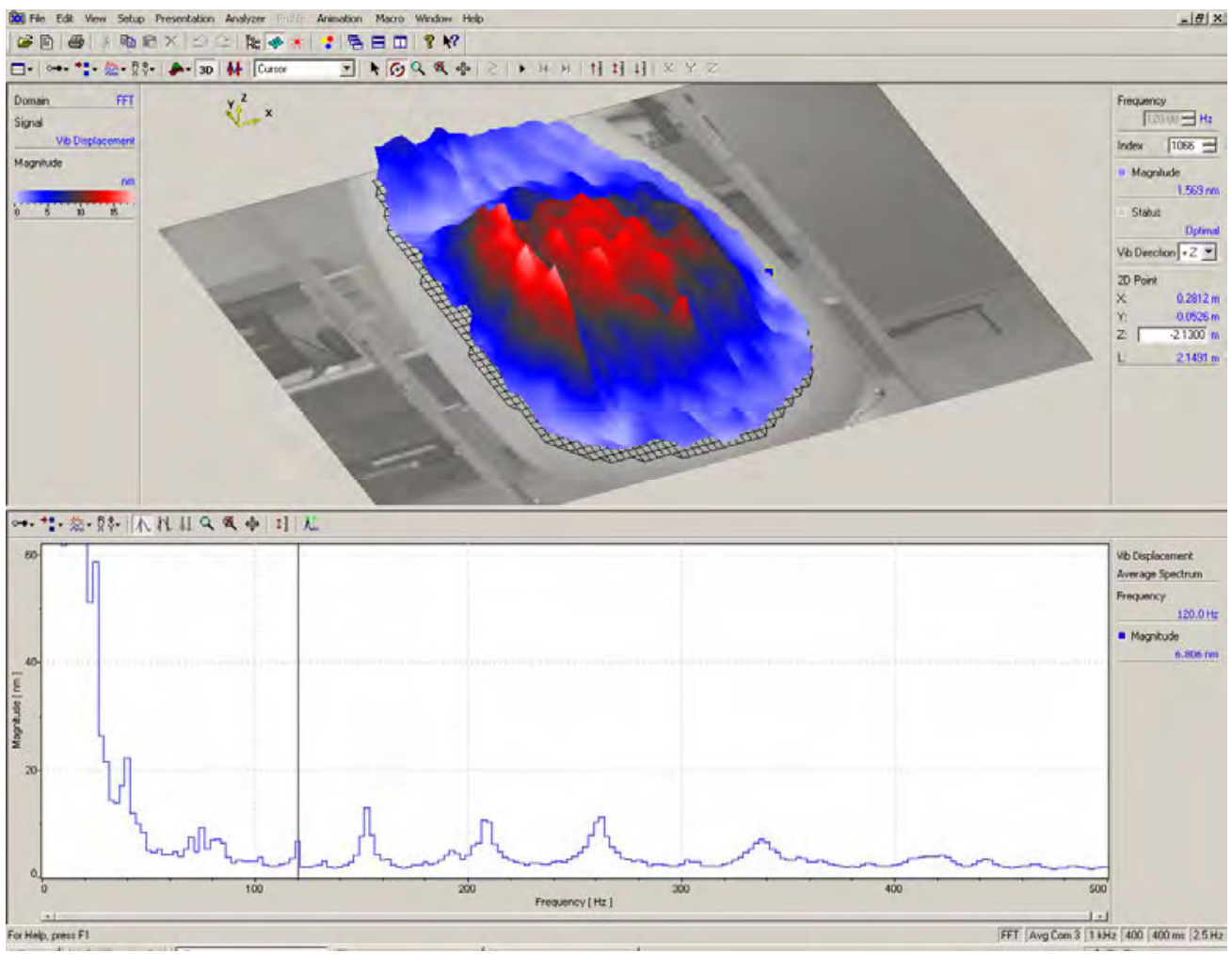

Figure 45) 4 Fixed Nodes $-120 \mathrm{~Hz}$ 


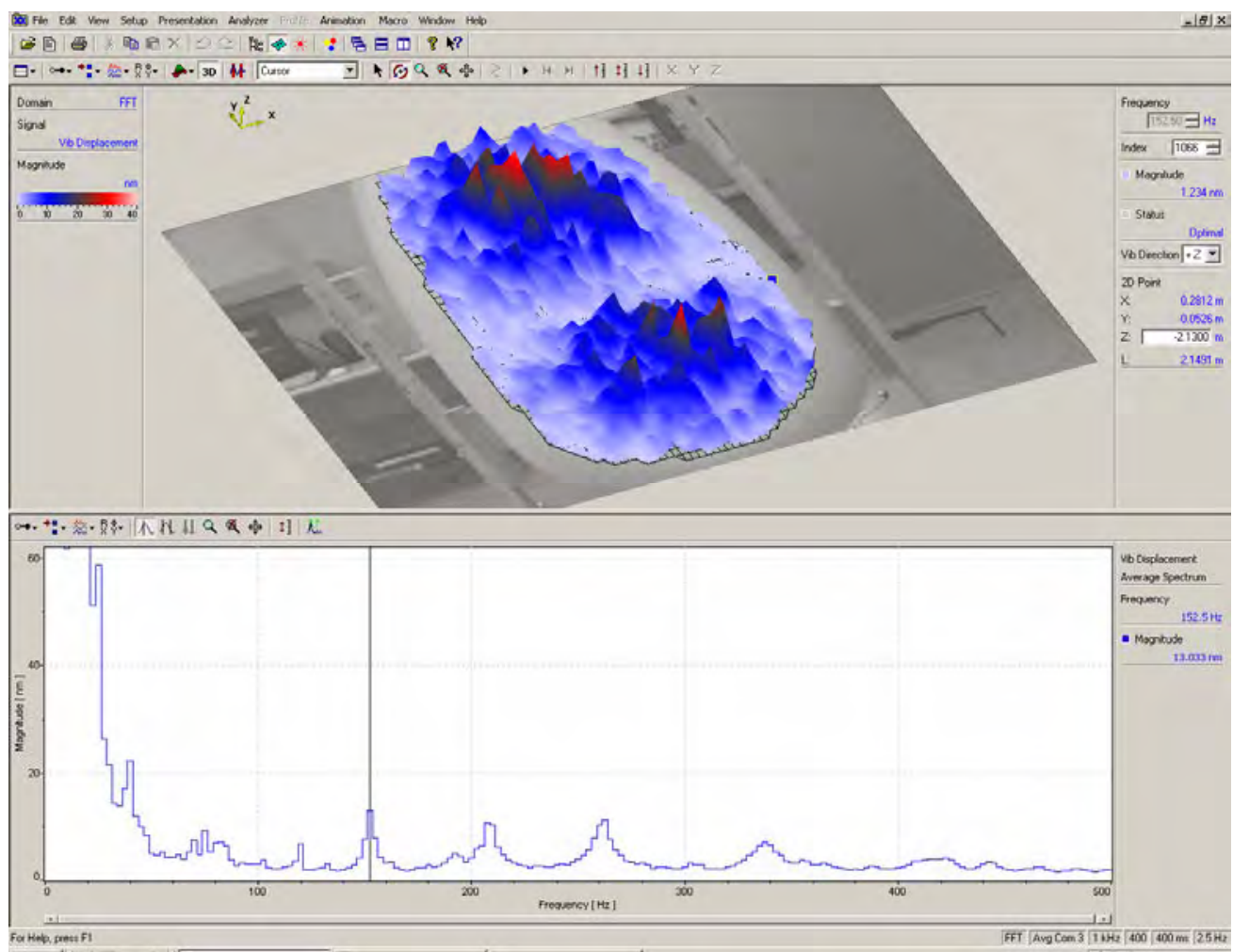

Figure 46) 4 Fixed Nodes $-152.5 \mathrm{~Hz}$

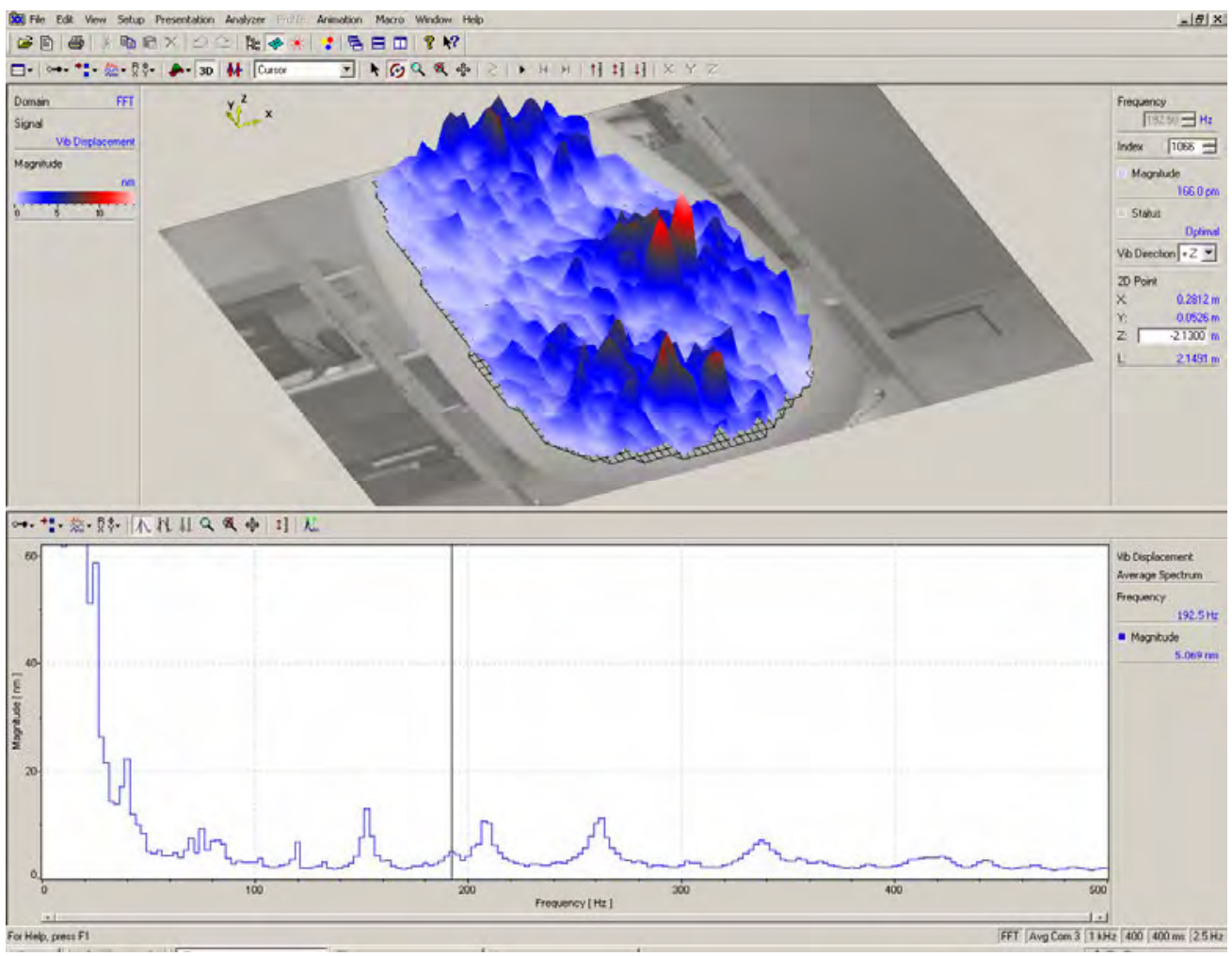

Figure 47) 4 Fixed Nodes $-192.5 \mathrm{~Hz}$ 


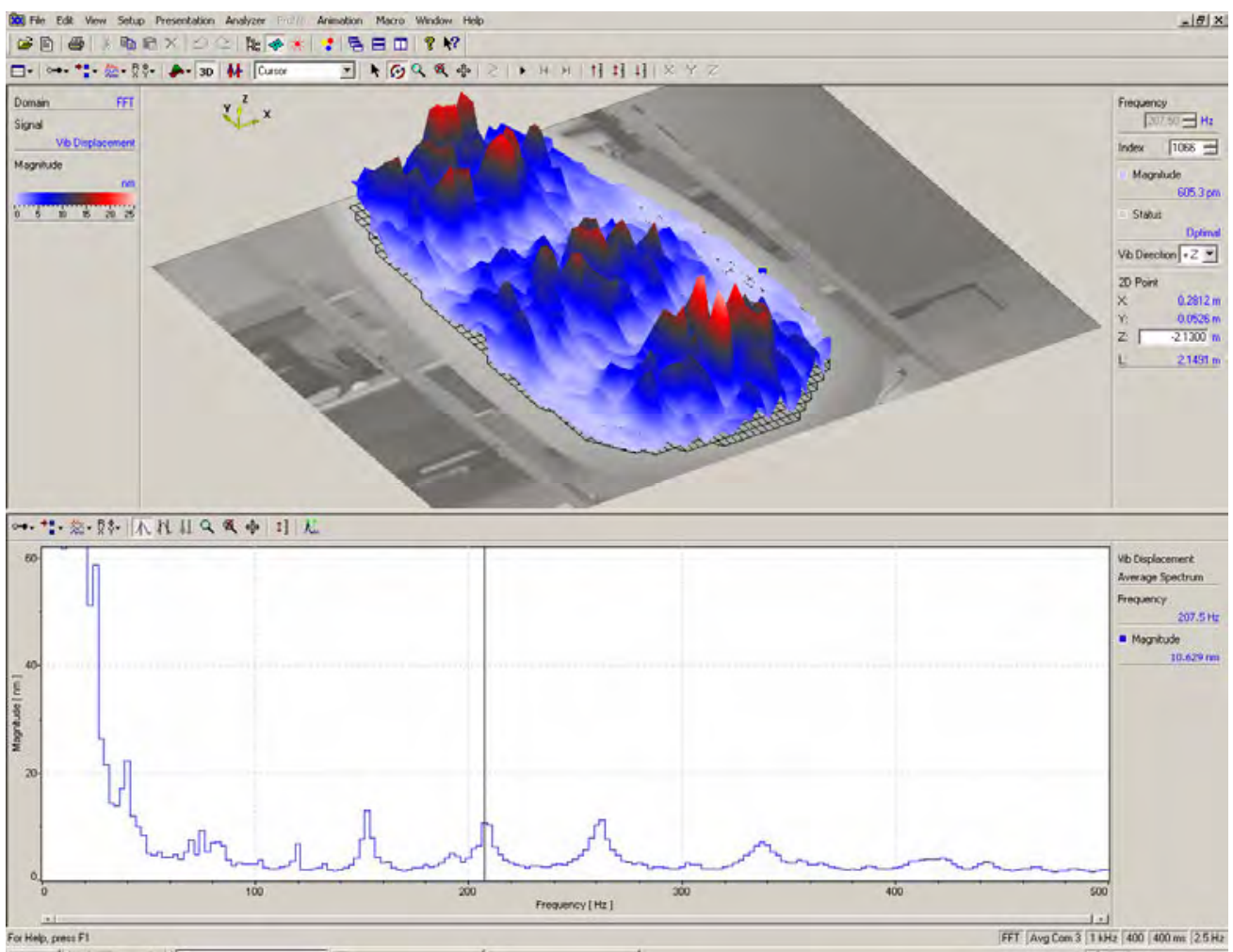

Figure 48) 4 Fixed Nodes $-207.5 \mathrm{~Hz}$

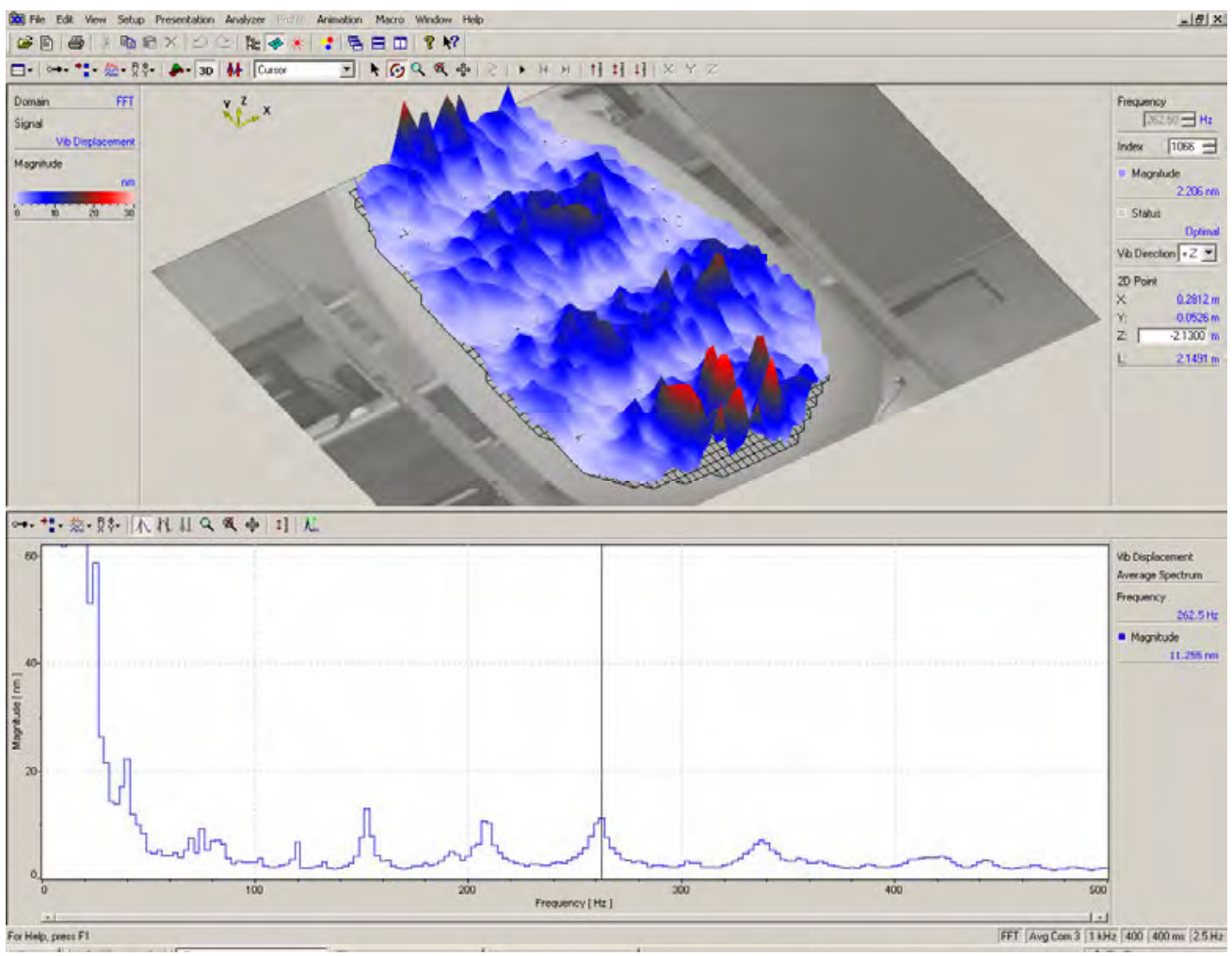

Figure 49) 4 Fixed Nodes $-262.5 \mathrm{~Hz}$ 


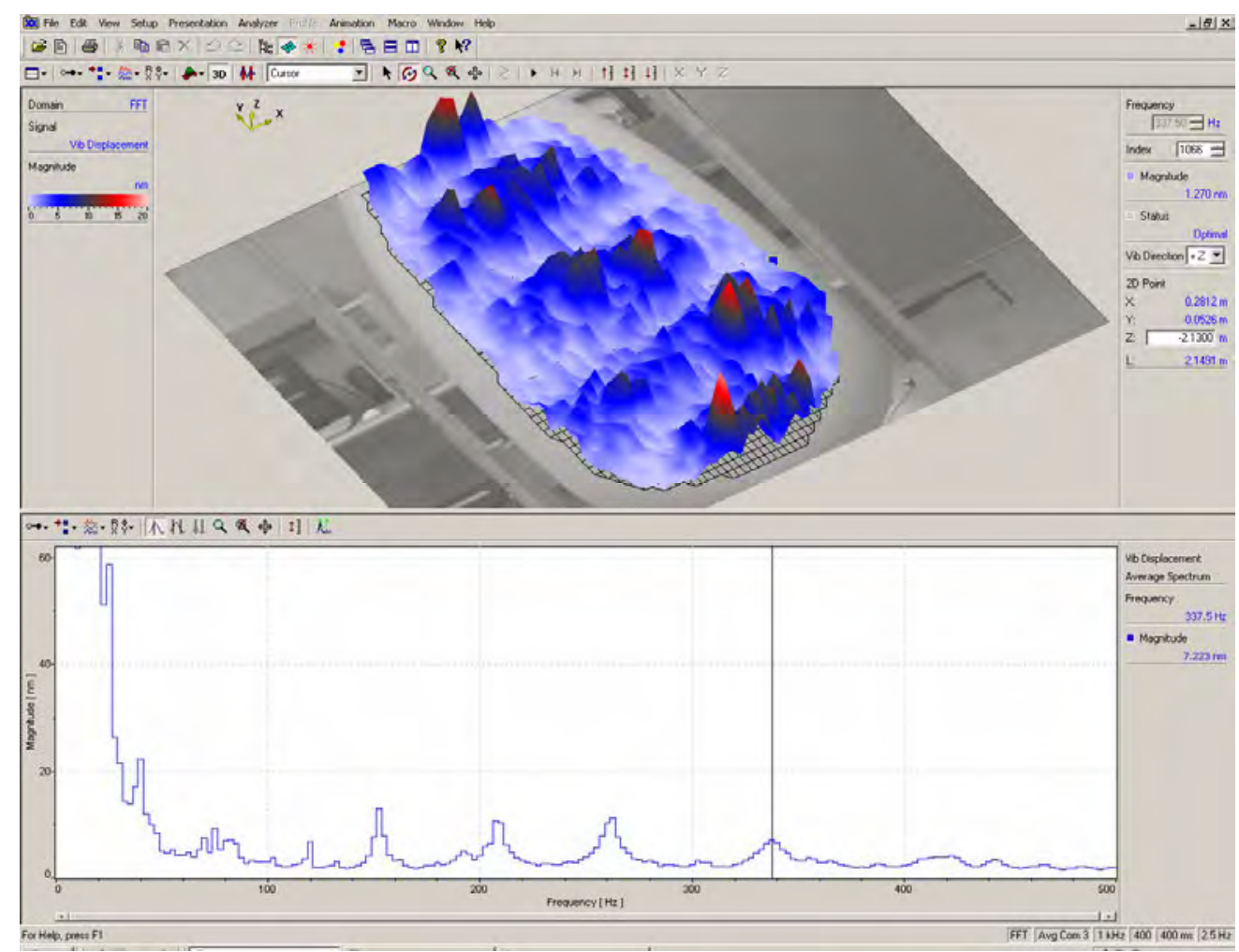

Figure 50) 4 Fixed Nodes $-337.5 \mathrm{~Hz}$

The data was then plotted into excel and then plotted together on the same graph to visualize the difference in the frequency response for 1 fixed point vs. a stiffer boundary condition of 4 fixed points.

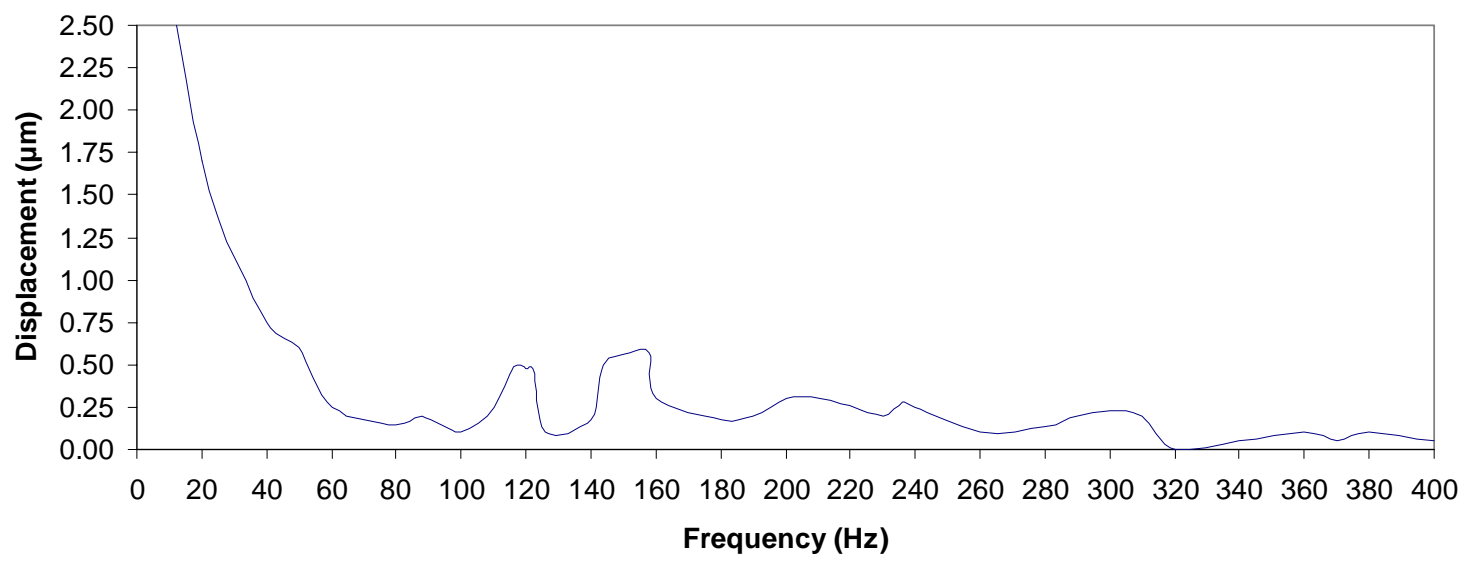

Figure 51) Frequency Response for 1 fixed point 


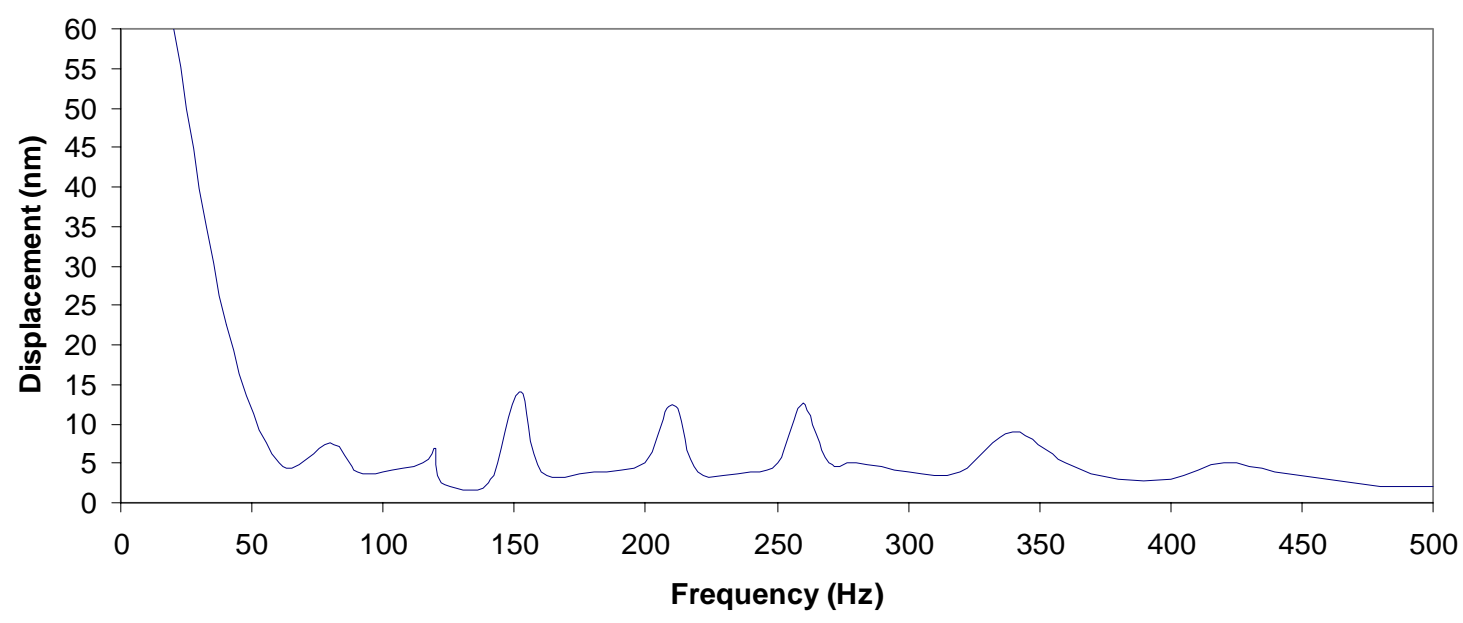

Figure 52) Frequency Response for 4 fixed points

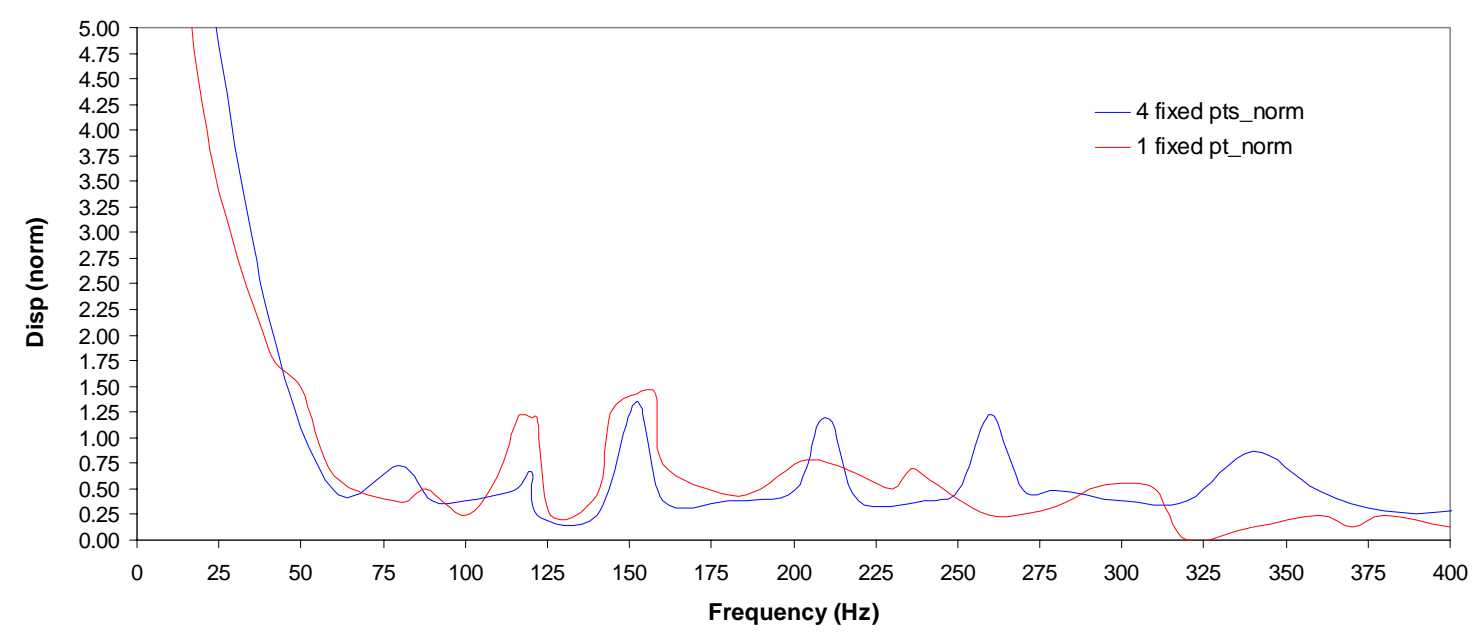

Figure 53) Frequency Response - Boundary Condition Comparison (Normalized)

The displacements were normalized for each boundary condition case by dividing each individual displacement by the average of the range. Normalizing keeps the shape of the curve but scales the displacements by the average, which can be used to compare two separate sets of data that have a different range of displacements. The figure above shows the normalized displacement for the two different boundary conditions; 1 fixed point and 4 fixed points. Some of the spikes appear at very close 
frequencies however other seemed to shift and become more defined at at the more fixed boundary condition. Notice in the previous figures that the range of displacements for the 1 fixed point boundary condition is in the micrometers where the 4 fixed point boundary condition has a displacement range in the nanometers. It is believed that the 4 fixed point boundary condition more closely represents the assembly of the radome to the aircraft.

\subsubsection{Finite Element Results \& Correlation to the Test Data}

For the comparison of the finite element results to the test data both the excitation frequencies from the frequency responses were compared, as well as the mode shapes. The maximum and minimum displacements for each frequency analyzed in the finite element model were recorded for what was approximately the scanning laser view window. For these results areas outside of the view of the scanning laser were not included in the displacement to more accurately compare to the test results. The following figure shows the curves for the test results and the finite element analysis results. Notice that the ranges of displacements are relatively close however the excitation frequencies are very close. The vertical lines represent a few of the modes that were outputted in the modal analysis. 


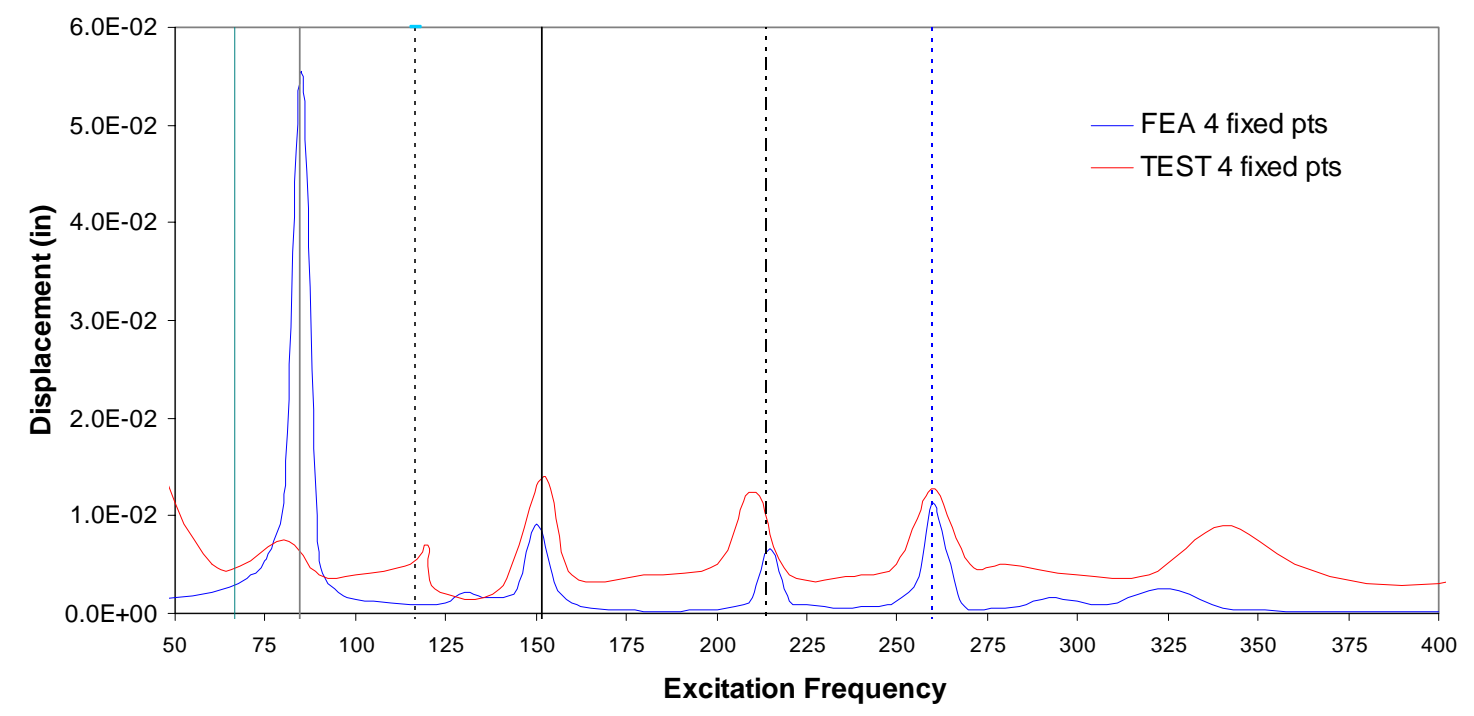

Figure 54) Frequency Response - Testing Vs. FEA

Notice that the finite element analysis show a natural mode at about $66.7 \mathrm{~Hz}$, but the displacement in the frequency response is much lower than the next natural frequency of $84.6 \mathrm{~Hz}$. The following figure shows the test deflected shape for $75 \mathrm{~Hz}$ (first mode in testing) and the first FEA first mode of $66.7 \mathrm{~Hz}$.
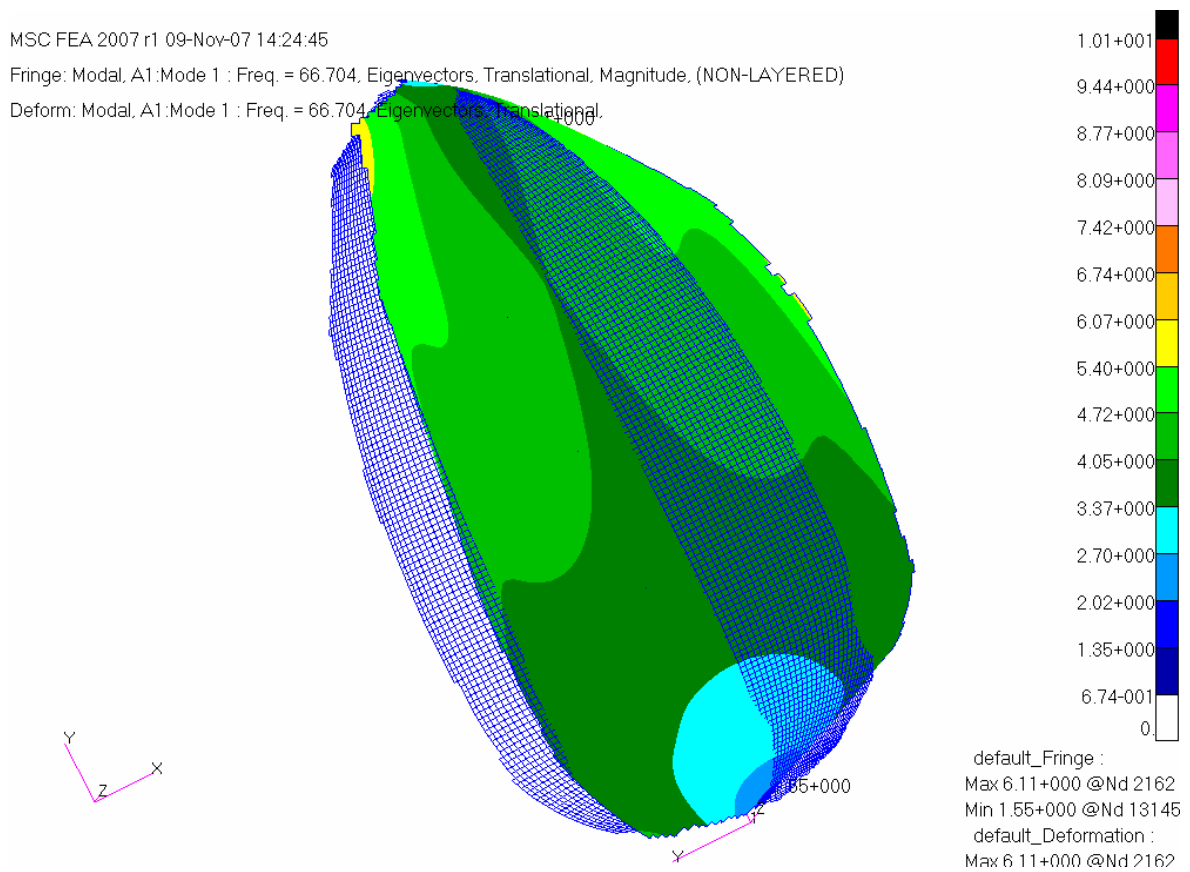

Figure 55) Finite Element Analysis $1^{\text {st }}$ Mode Shape $-66.704 \mathrm{~Hz}$ 


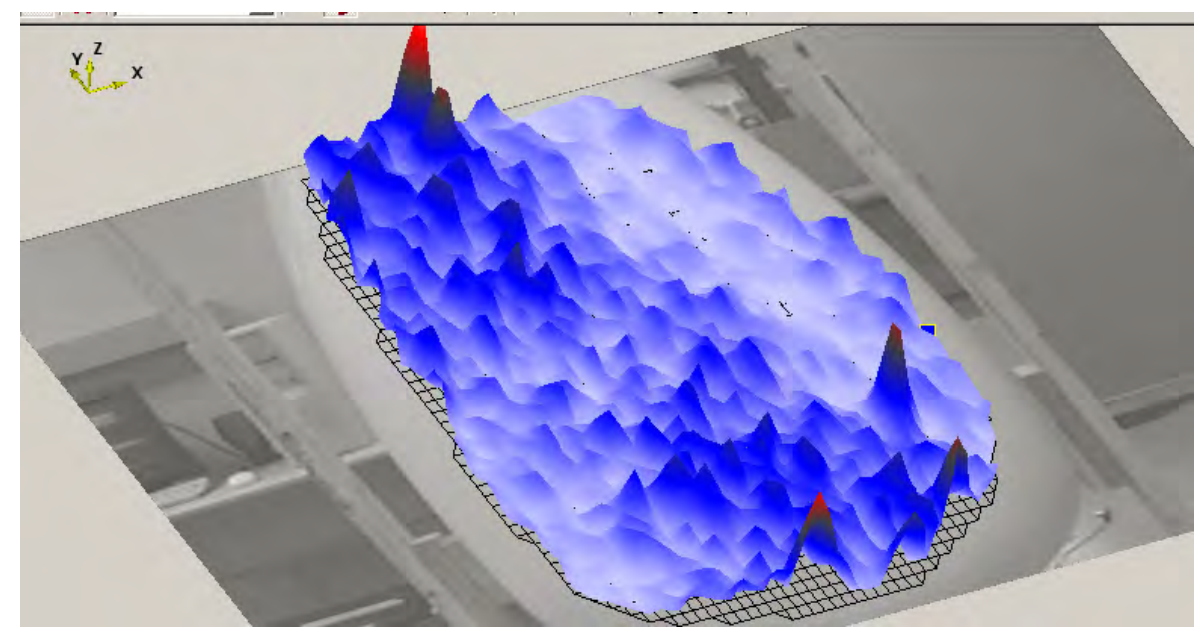

Figure 56) Test Results $1^{\text {st }}$ Mode Shape $-75 \mathrm{~Hz}$

Given the resolution of the scanning points, the figure appears to be choppy however; the trend of the left portion of the radome to be raised and the right portion of the radome to be deflected backward is noticed in both figures. Unfortunately the mode shapes of the other frequencies did not match very well. It seemed that the test data showed shapes that had more peaks and valleys more like the $3^{\text {rd }}$ and $4^{\text {th }}$ modes of a simple beam where the finite element model accurately predicted the frequency responses but shows shapes more close to the $2^{\text {nd }}$ mode of a simple beam. There were a few modal shapes from the finite element analysis that did show a higher order mode shape like the following figure. The FEA mode shape at $178 \mathrm{~Hz}$ seems to closely represent that seen in the test at $152 \mathrm{~Hz}$, which was one of the higher displacements resulting from the excitation frequency. 
Fringe: Modal. A1:Mode $8:$ Freq. $=178.38$, Eigenvectors, Translational, Magnitude, (NON-LAYERED)

Deform: Modal, A1: Mode $8:$ Freq. $=178.38$, Eigenvectors, Translational
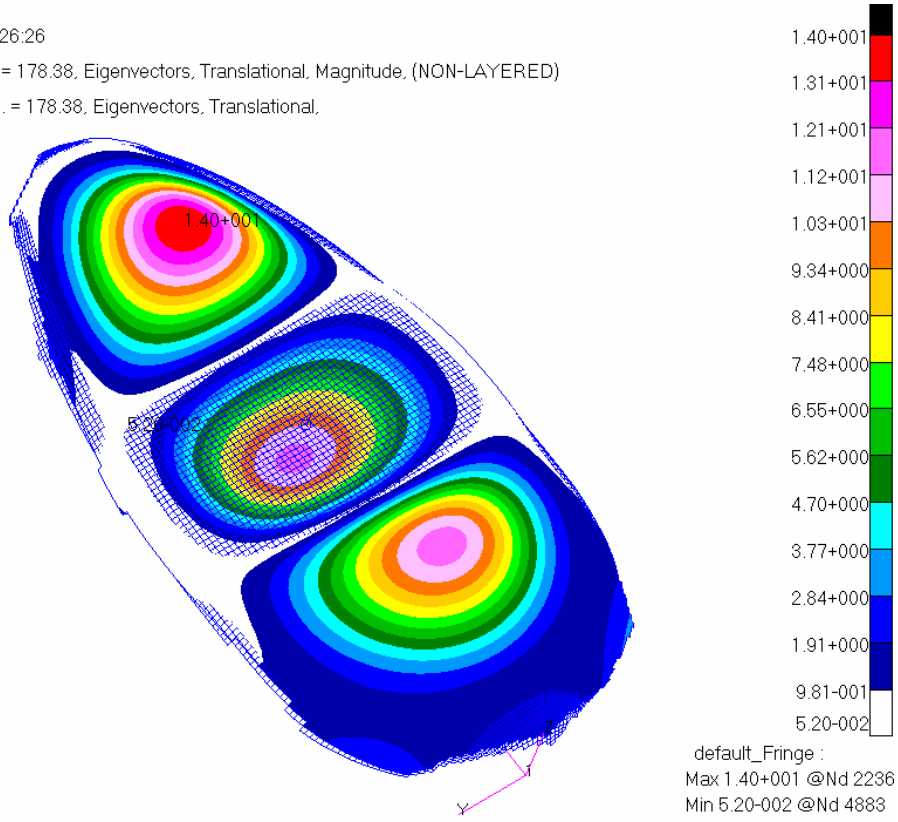

default_Fringe

$\operatorname{Max} 1.40+001 @ N d 2236$

Min 5.20-002@Nd 4883

default_Deformation :

Max140+001@Nd 2236

Figure 57) Finite Element Analysis Mode Shape at $178.38 \mathrm{~Hz}$

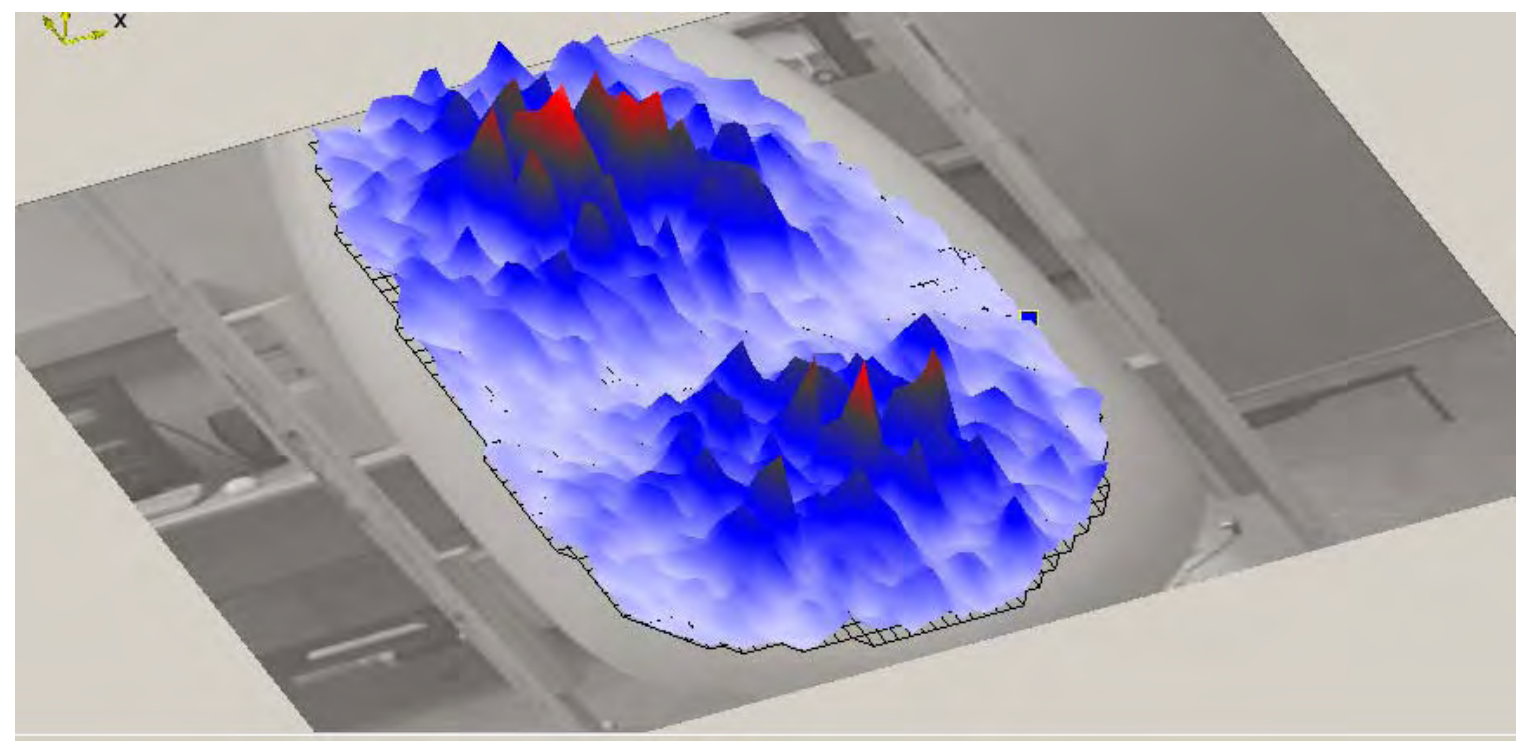

Figure 58) Test Results Mode Shape at $-152.5 \mathrm{~Hz}$

As a result of the FEA correlation and Vibrometry testing it was noticed that the finite element analysis model can accurately predict the excitation frequencies but seems to miss on the actually shape at the specific excitation frequency. 


\subsection{Pressure Testing}

To validate the calculated deflections in the finite element model, a pressure test on the composite radome structure was performed at the Saint-Gobain Facility in Ravenna, $\mathrm{OH}$.

\subsubsection{Setup}

A wooden structure in the exact shape of the radome footprint at the edgeband was constructed to restrict the radome from deflecting at the edgeband. Four holes were drilled, front, side and aft in the Radome edgeband and a 0.25 " diameter standard screw was used just to restrict the radome from slipping off of the wood bulk head.

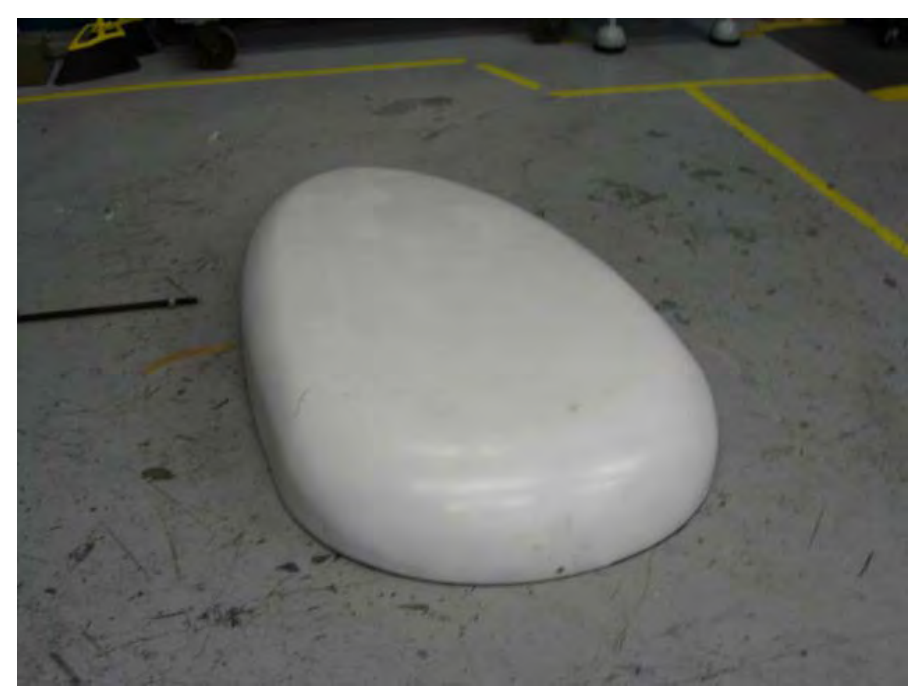

Figure 59) Radome Installed on Wood Bulkhead 


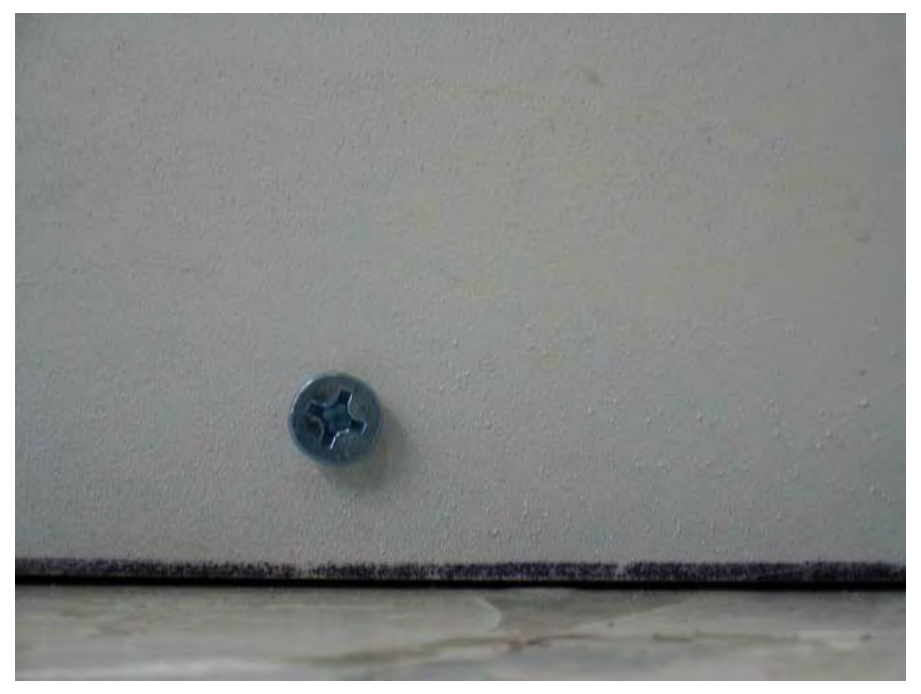

Figure 60) Standard Screw Installed on Wood Bulkhead

As shown in the following figure, cloth breather was then placed around the edge of the radome to allow for the vacuum pressure to be more uniform.

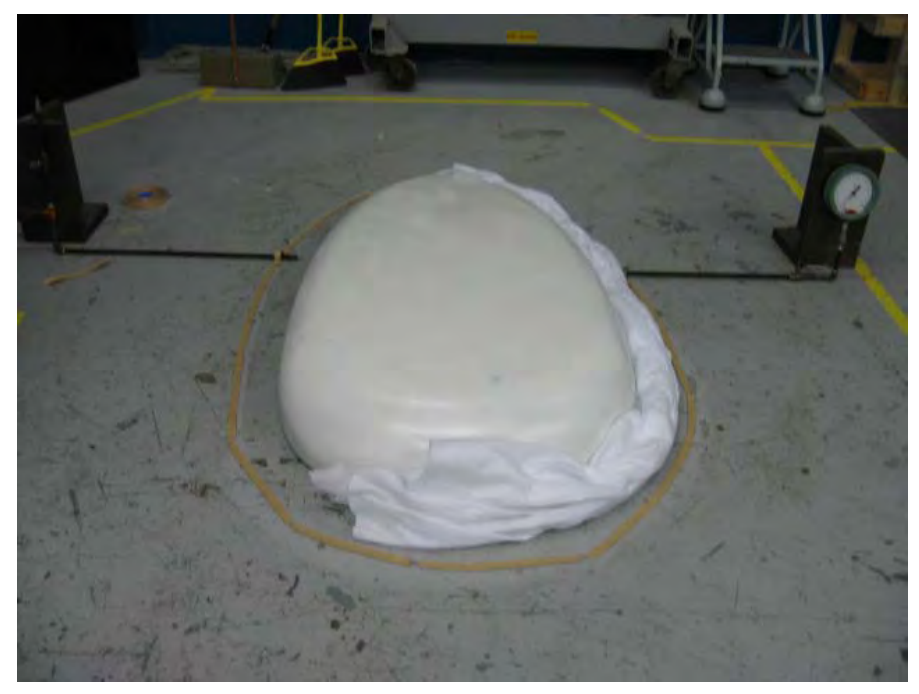

Figure 61) Radome with Cloth Breather for Uniform Vacuum

Double sided thick rubber adhesive tape was attached to a large plastic vacuum bag and placed over top of the radome. The vacuum line and vacuum gage (in $\mathrm{Hg}$ ) was then placed inside of the bag under the rubber adhesive tape. 


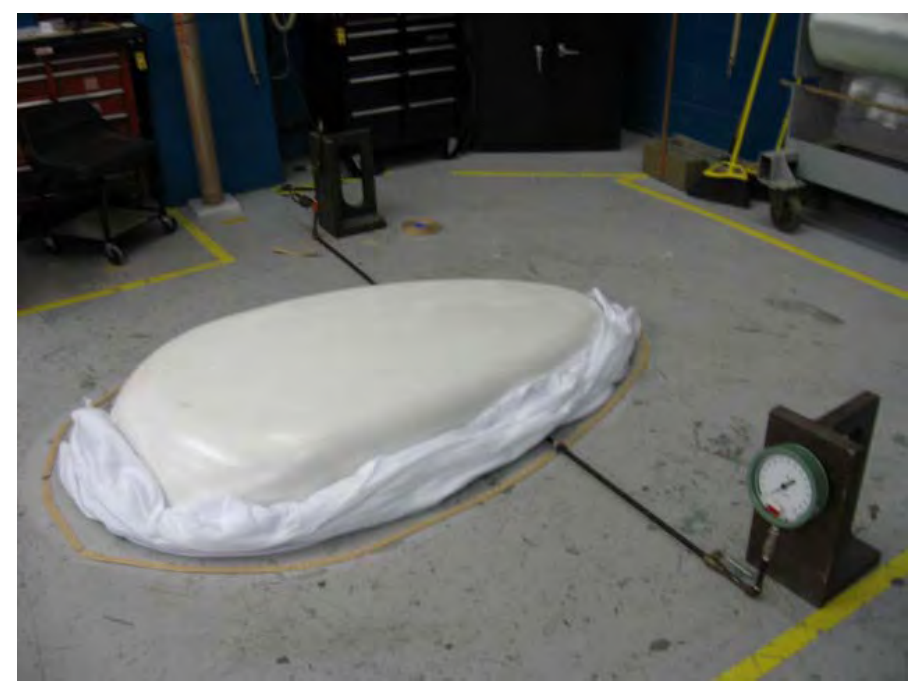

Figure 62) Vacuum Line \& Vacuum Gage

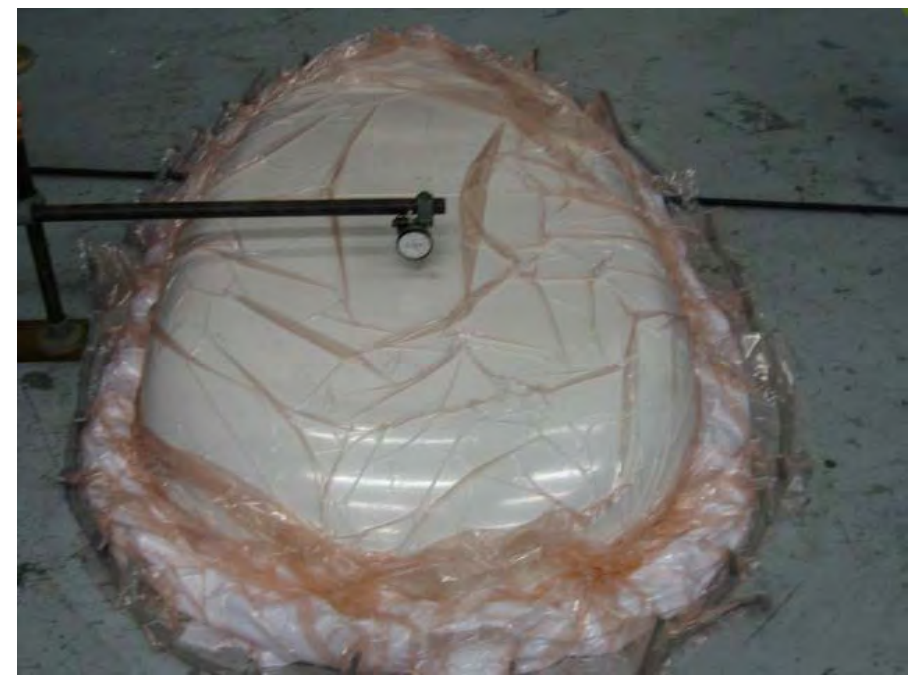

Figure 63) Pressure Test Set Up

A dial indicator was setup and set to zero at the point being measured. A series of pressures and displacements were recorded for three points, 24 in, 36 in and 48 in back along the surface of the radome. 


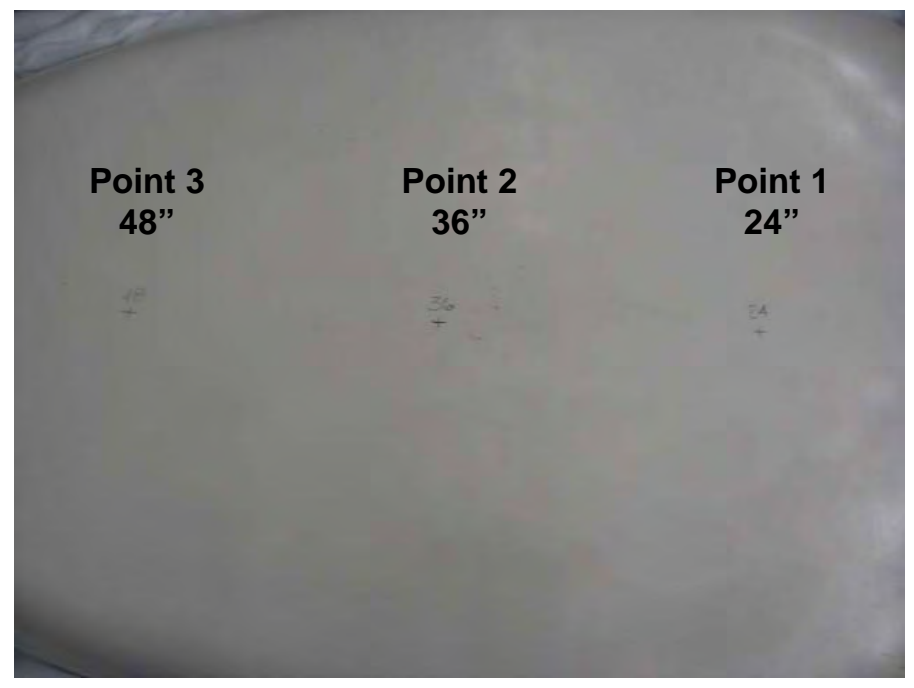

Figure 64) Three Test Inspection Points

\subsubsection{Pressure Test Results}

Data was taken at varying pressures up to the resulting maximum deflection allowed by the dial indicator (1.0"). Since a vacuum is equivalent to a pressure pushing down on the radome all of the deflections were inward. At the higher end the deflection was clearly visible to the eye. The radome was able to go up to a maximum of 8 in of $\mathrm{Hg}$ (@4.0 in of $\mathrm{lb} / \mathrm{in}^{2}$ ) resulting in a 1.0" deflection. Given the approximate surface area of the radome of $2537 \mathrm{in}^{2}$, and the resulting $4.0 \mathrm{lb} / \mathrm{in}^{2}$, there was a total of over $10,000 \mathrm{lbs}$ of force being applied to the radome. Each point was tested two times to achieve a reasonable amount of data and to check the accuracy of the measurements. The radome did not fail however there was an audible creaking heard caused by the fasteners in the wood and the added force of the edgeband on the wood bulkhead. The deflection appeared to be uniform across the radome as expected. The following figure shows the plot of the recorded data with a polynomial curve fit and their corresponding equation and $R^{2}$ value. The data was more scattered at point number two which had the largest deflection. I believe this is a result of the speed of deflection as a function of pressure at this point. It became difficult to accurately record the data quickly as the 
deflection spiked near $3.0 \mathrm{lb} / \mathrm{in}^{2}$. A polynomial curve fit was applied to the data which yielded an average $R^{2}$ value of 0.962 . The polynomial curves will be used later in this report to compare to the test results for clarity purposes.

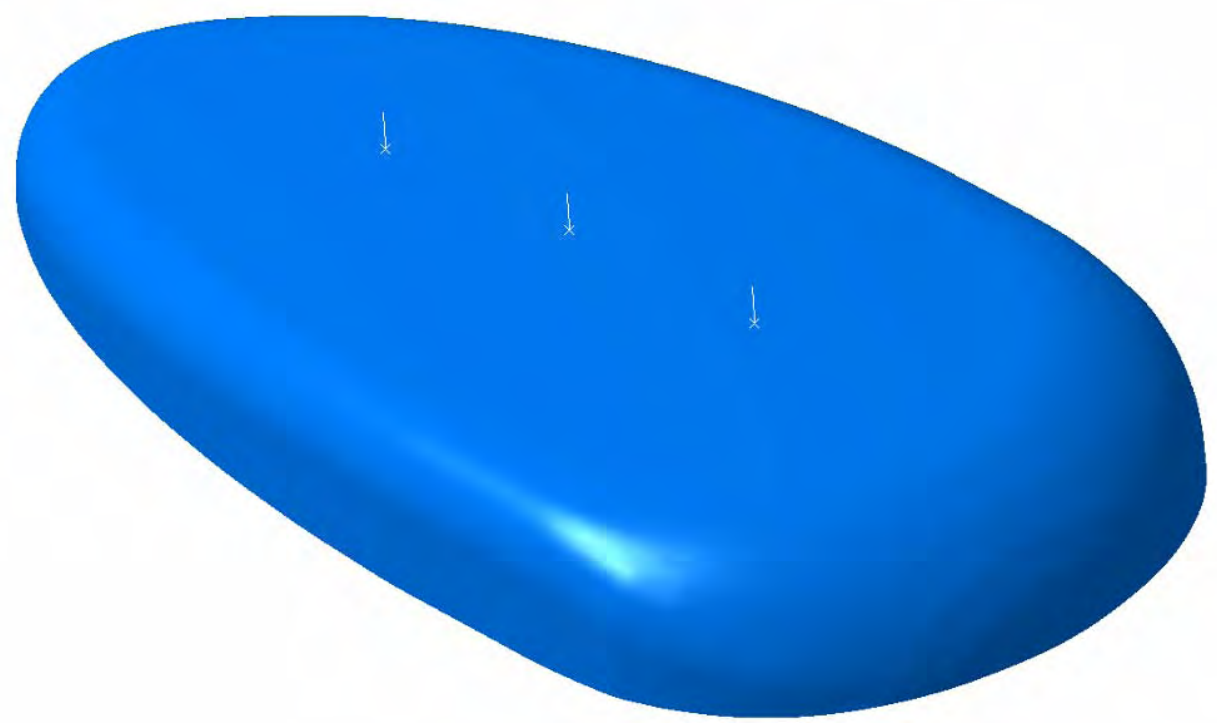

Figure 65) Three Test Inspection Points in CATIA File for FEA 


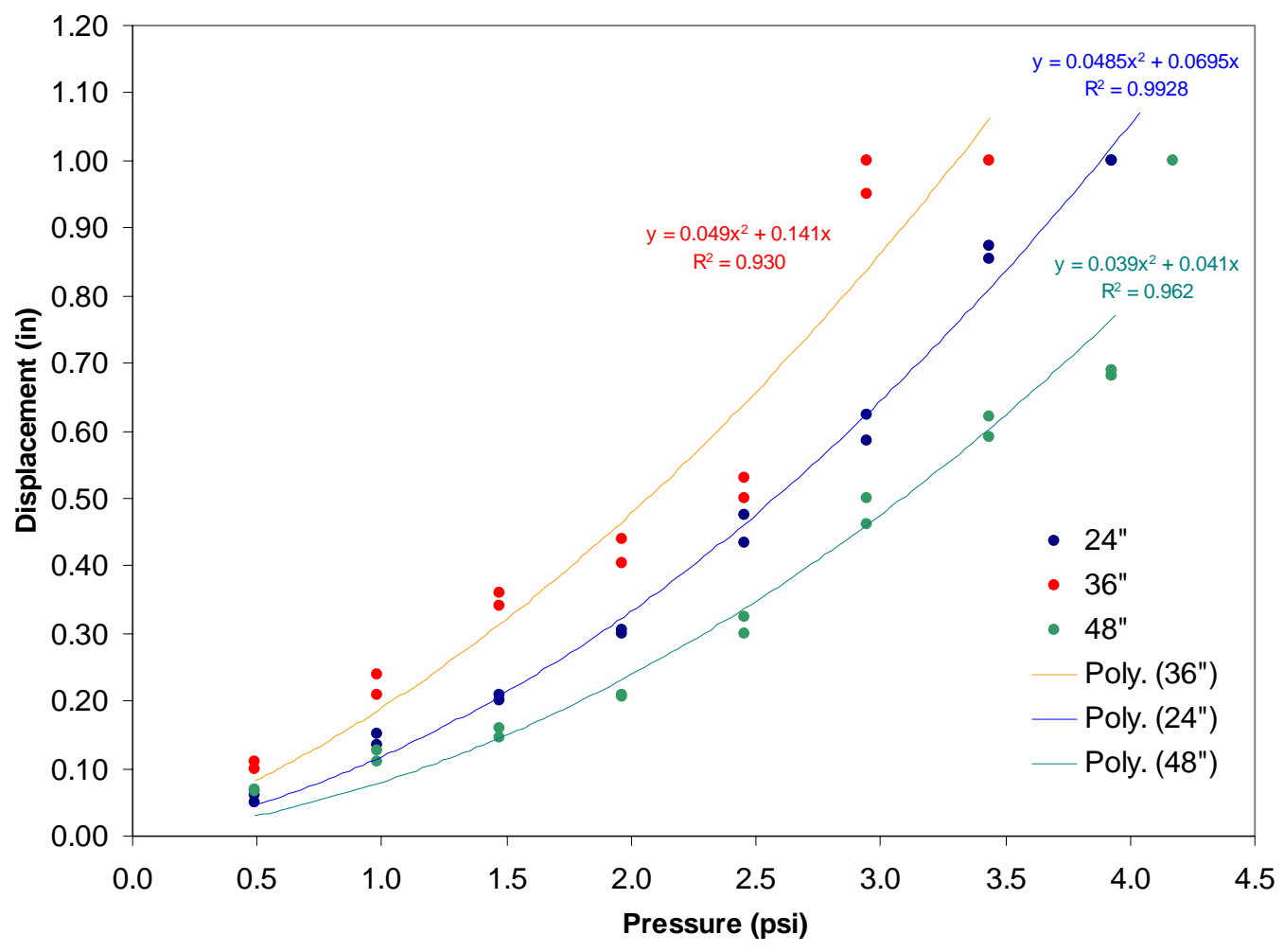

Figure 66) Three Test Inspection Points Deflection Results vs. Pressure

\subsubsection{Finite Element Results \& Correlation to the Test Data}

The finite element analysis performed on the radome under the pressure loading range of $0.0-0.45 \mathrm{lb} / \mathrm{in}^{2}$ was done using a linear solver. What this means is that the material properties, specifically modulus of elasticity is linear under a given stress and strain as high as the loading condition goes. It is important to understand this when performing finite element analyses. As the deflections (i.e. strain) reach a certain point a linear model becomes insufficient providing non-conservative results. Shown in the figure below is a linear curve fit for the pressure load on the radome finite element results. Note the perfect linearity of the deflections as a function of pressure. The shape of this radome is nearly flat in a few portions yielding relatively high displacements at the pressures analyzed. A displacement of 0.765 in is seen at $4.0 \mathrm{lb} / \mathrm{in}^{2}$. 


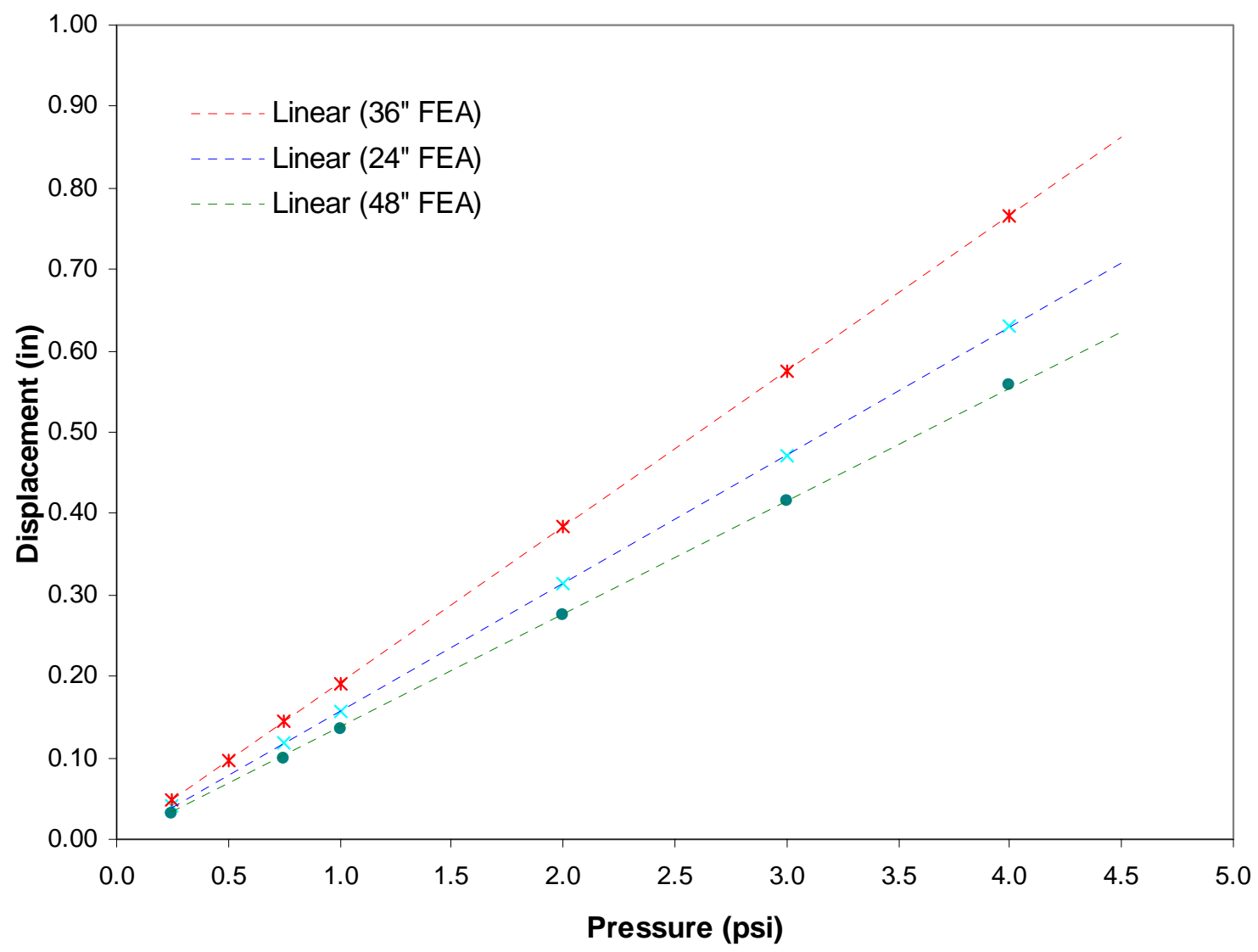

Figure 67) Three FEA Points Deflection Results vs. Pressure

For all of the pressure loading conditions point \#2, which is 36.0 in back along the centerline of the surface, has the largest displacements. Shown in the following figures are the displacement profiles for the applied pressures on the radome. 
MSC.FEA 2005 r2 31-Oct-07 10:53:39

Fringe: 0.25psi, A1:Static Subcase, Displacements, Translational, Magnitude, (NON-LAYERED)

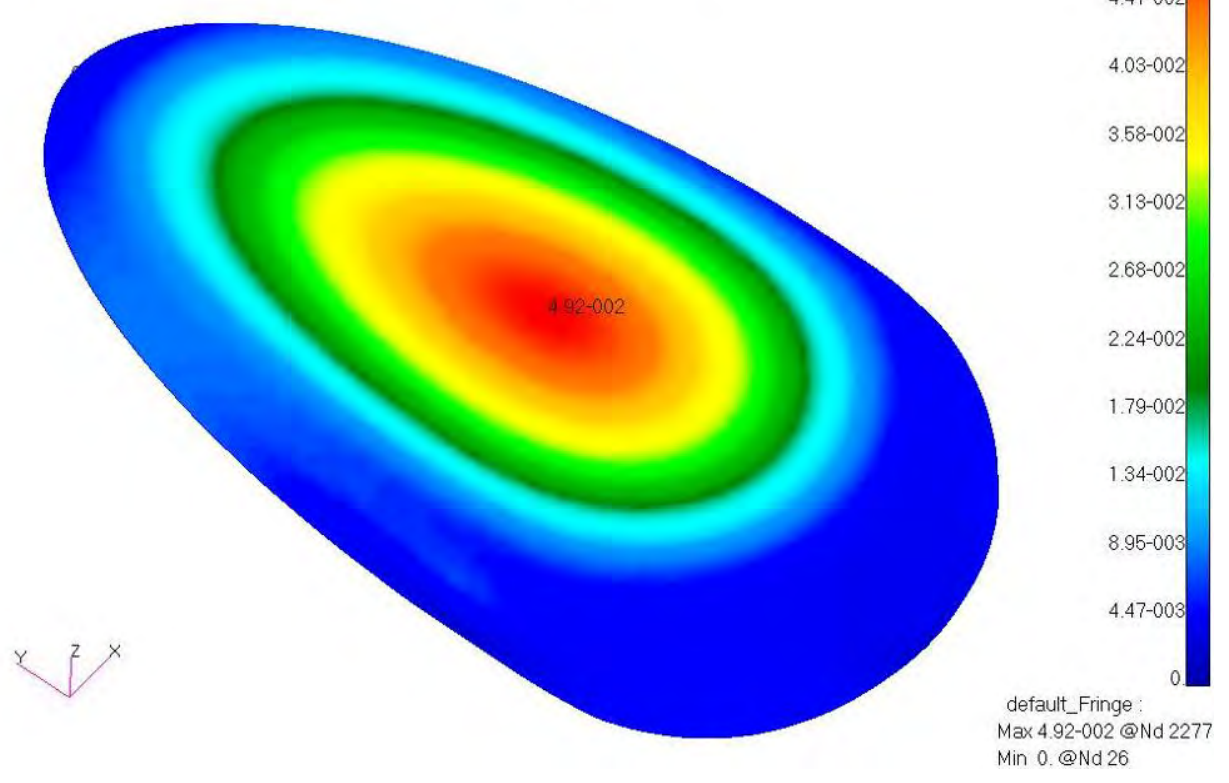

Figure 68) Radome Displacement for $0.25 \mathrm{psi}$

MSC.FEA 2005 r2 31-Oct-07 10:54:25

Fringe: $0.75 \mathrm{psi}$, A1:Static Subcase, Displacements, Translational, Magnitude, (NON-LAYERED)

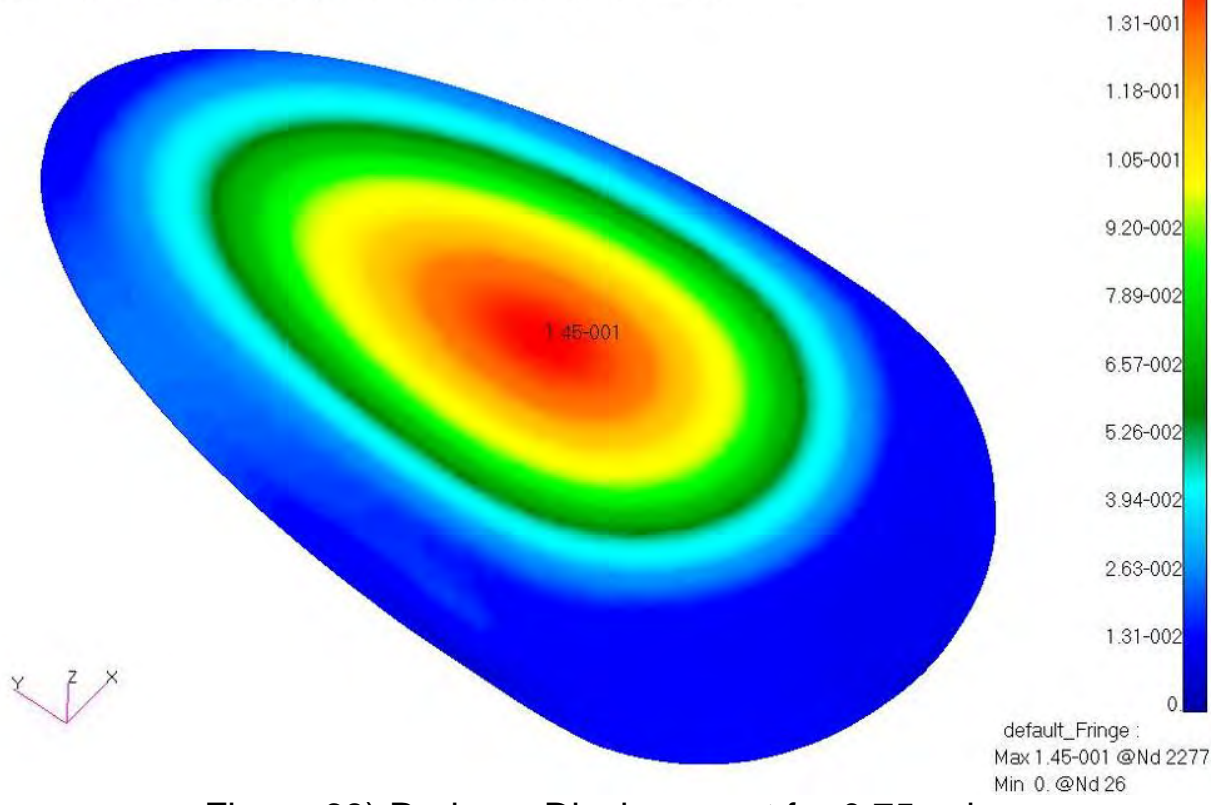

Figure 69) Radome Displacement for 0.75 psi 
MSC.FEA 2005 r2 31-Oct-07 10:54:34

Fringe: 1.0psi, A1:Static Subcase, Displacements, Translational, Magnitude, (NON-LAYERED)

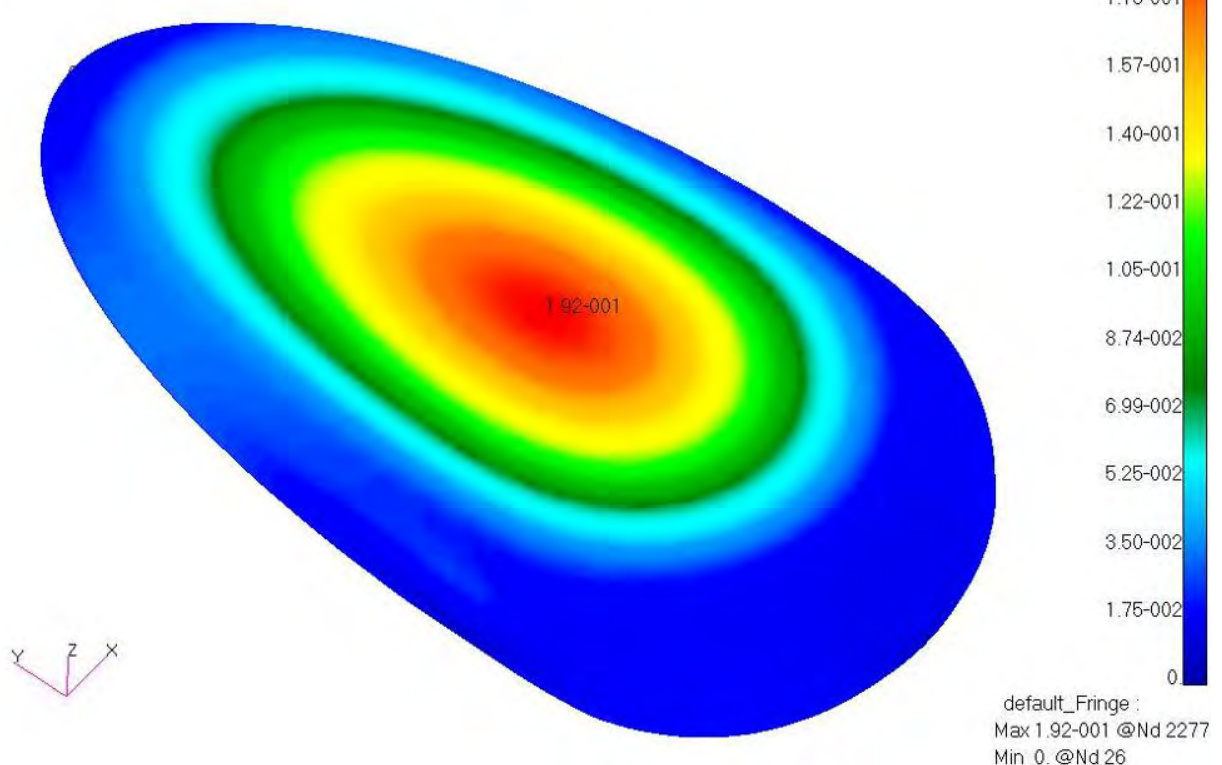

Figure 70) Radome Displacement for 1.0 psi

MSC.FEA 2005 r2 31-Oct-0 07 10:54:44

Fringe: 2.0psi, A1:Static Subcase, Displacements, Translational, Magnitude. (NON-LAYERED)

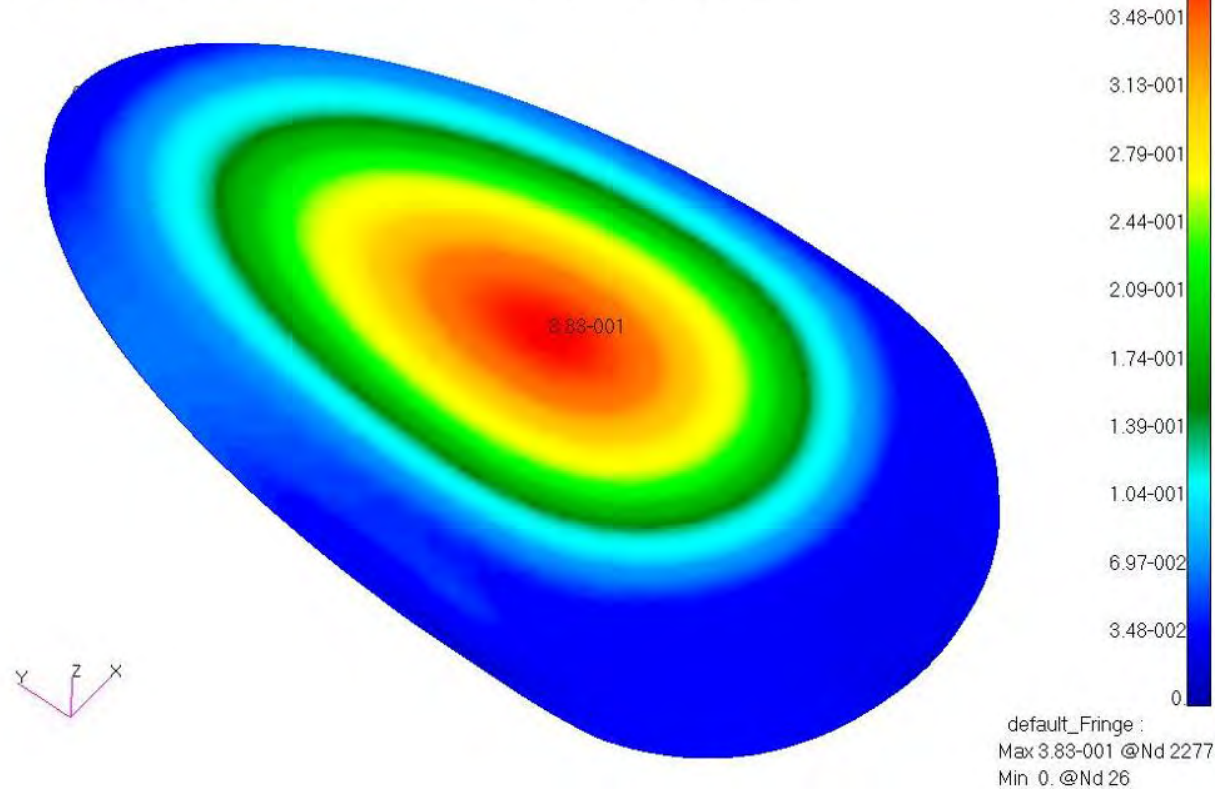

Figure 71) Radome Displacement for 2.0 psi 
MSC.FEA 2005 r2 31-Oct-07 10:54:57

Fringe: 3.0psi, A1:Static Subcase, Displacements, Translational, Magnitude, (NON-LAYERED)

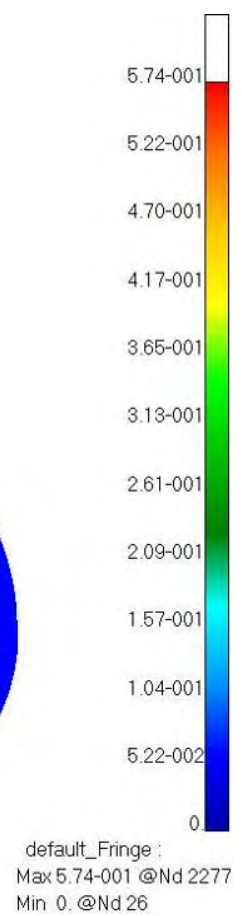

Figure 72) Radome Displacement for 3.0 psi

MSC.FEA 2005 r2 31-Oct-07 10:55:07

Fringe: 4.0psi, A1:Static Subcase, Displacements, Translational, Magnitude, (NON-LAYERED)

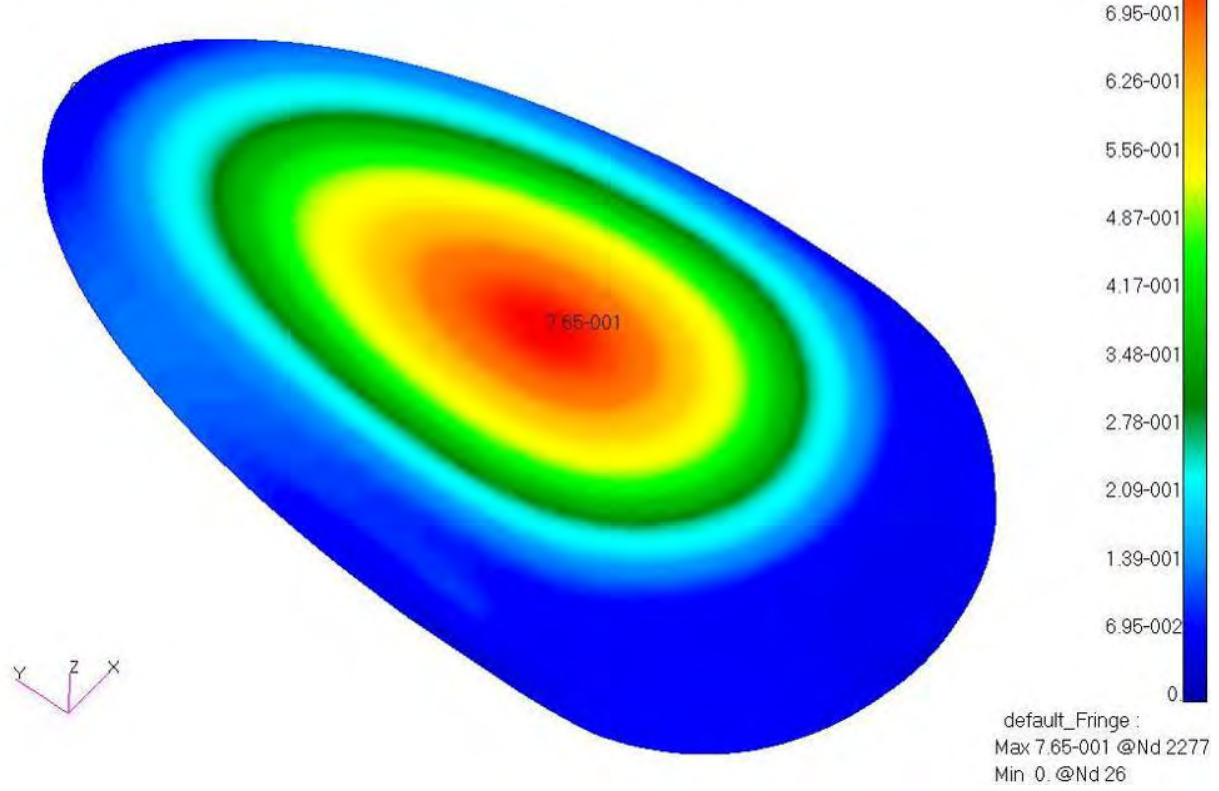

Figure 73) Radome Displacement for $4.0 \mathrm{psi}$ 


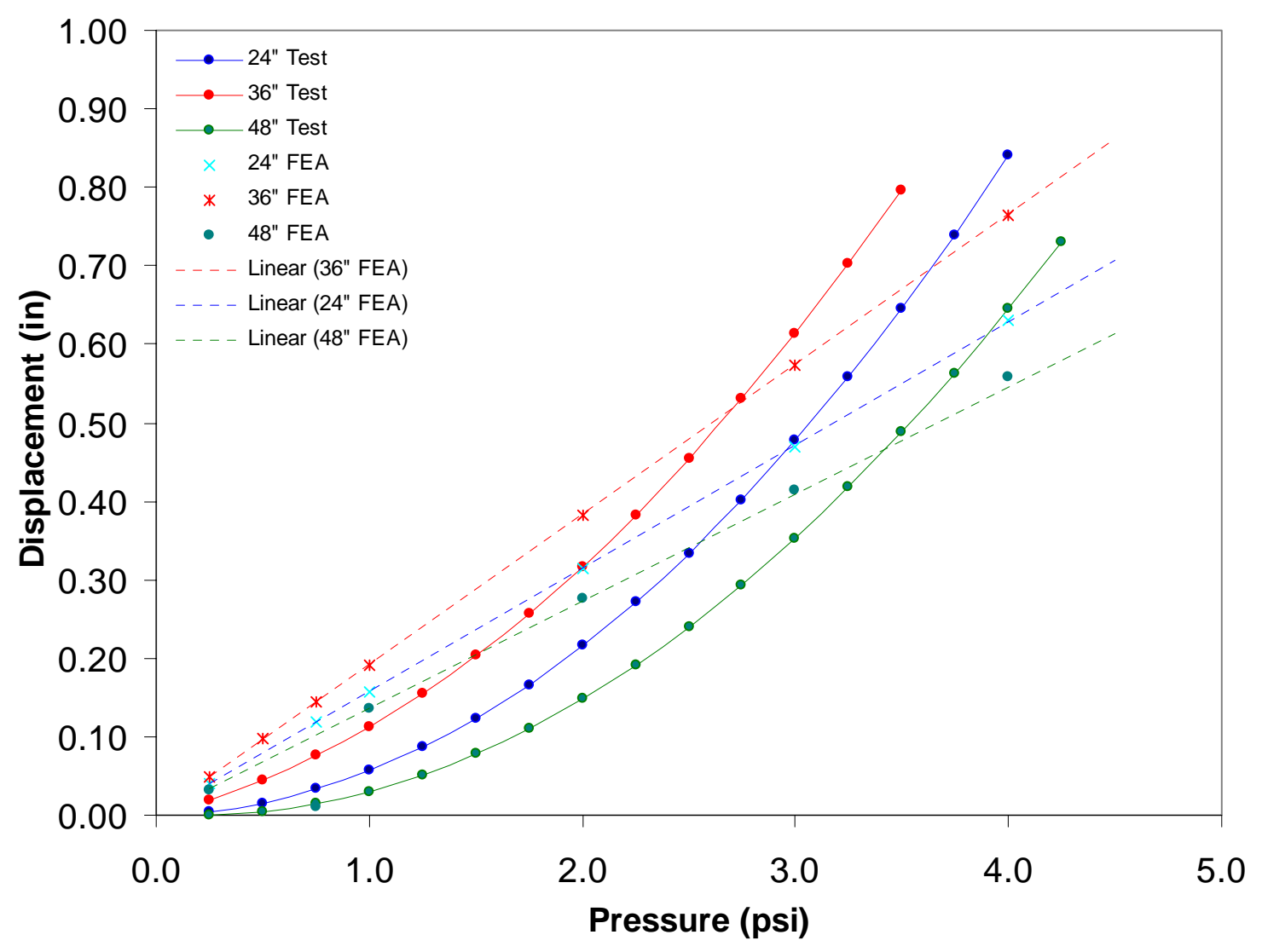

Figure 74) FEA \& Test Data Correlation

Shown in the figure above is the correlation of the pressure testing data to the finite element model displacements. The trend line for the finite element model displacements is linear which is expected given the linear calculations performed by the software. Notice that in the real pressure test the displacement is not linear with respect to the varying pressure loads. This is an important trend to realize and a critical limitation/feature of the finite element analysis programs for shells. As the displacement becomes larger the results become less accurate under a linear analysis. In the case of this specific radome, it appears that around displacements of 0.70 in, the curves start to separate. If displacements larger than 0.70 in were seen, a non-linear model would be preferred and more accurate. 


\section{CHAPTER VII}

\section{SUMMARY}

Shearography was completed on the 5135-200 Saint-Gobain Dorsal Radome which is installed on aircraft such as Airbus A320 (A319, A320, \& A321) series, Boeing 737 and 777 . It was determined that there were no manufacturing defects such as delaminations where the laminate is disbanded from the honeycomb core. Such defects would have possibly distorted the frequency response and possibly cause early failure during pressure testing.

Laser Vibrometry was performed where a series of frequencies were applied to the radome and the displacement was measured predicting the excitation frequencies. A finite element model for the radome calculated very close excitation frequencies. However, the modal shapes displayed at the excitation frequencies in testing did not correlate well with the finite element model. After learning that a fixed boundary fixture should be approximately 10 times the weight of the test article, it is suspected that some possible fixture response may be evident. The test fixture that was used was approximately 2 times greater in weight than the test article. Future frequency response testing on a heavier fixture is desired to validate data and learn more about the shapes in regarding to the FEA correlation. However, it is believed that the shape and the location of the excitation frequencies would not change drastically, but a heavier fixture may affect the magnitude of the deflections. 
A final test was performed on the radome where a series of vacuum pressures were applied to the radome causing an inward deflection. These deflections were measured by a dial indicator and recorded as a function of the vacuum pressure. The same pressure range and boundary conditions were applied to the finite element model which conservatively predicted the displacements up to a certain point. At approximately 0.75 in of displacement the test data showed the finite element model to be nonconservative. For this reason a non-linear model would be desired to more accurately predict the radome behavior. It is believed that the materials at this point are still in the linear elastic region, however given the shape of the radome, geometric non-linearity appears to be present.

Future desired testing would first include creating a series of test panels with known defects of different sizes and types. This could help learn more about the set up and accuracy of the shearography testing system for finding manufacturing defects. For the frequency response correlation, the excitation frequencies seemed to be accurately predicted in the FEA however, a further in depth research about the finite element program parameters regarding the amount of energy applied to the system may results in a display of the correct modal shapes. Also, a heavier test fixture may isolate the radome better for more accurate results. And finally to accurately predict large displacements and ultimately predict failure, a non-linear FEA model could be analyzed to better correspond with the pressure test data. Furthermore, other Industry finite element analysis knowledge could be used from a company such as Goodyear which may encounter similar geometric non-linear models for their tires. 


\section{BIBLIOGRAPHY}

1.) http://www.trillion.com, January 2007

2.) http://www.frontier.com, August 2006

3.) http://www.videsignline.com/showArticle.jhtml?articlelD=192200500, January 2007

4.) Merriam Webster On-Line Dictionary, http://www.m-w.com/dictionary, January 2007

5.) Polytec Website \& Training, www.polytec.com, October 2006

6.) Palan, Vikrant, Phd., Polytec Engineer (Resource for Polytec Questions)

7.) "Theory of Vibration with Applications", Thompson, William, T., Prentice Hall, Englewood Cliffs, N.J. 1972

8.) Abaris Composite Laminate Design \& Analysis Training, Reno Nevada, November 2006.

9.) Engineered Materials Handbook, Composites, ASM international, copyright 1987,

10.) MSC Nastran Quick Reference Guide \& Manuals, Volume I., Copyright 2004.

11.) "Hexweb Attributes and Properties," Hexcel Composites Company, January 2007.

12.) Saint-Gobain Flight Structures, Ravenna, $\mathrm{OH}$.

13.) Binienda, Wieslaw Dr., University of Akron Civil Engineering Department Chair

14.) Goldberg, Robert Dr., University of Akron Professor 